\title{
APPICATION OF REMOTE SENSING TECHNIQUES AT DIFFERENT SCALES OF OBSERVATION ON WETLAND EVAPOTRANSPIRATION
}

\section{By}

CHUNG-HSIN JUAN

\begin{abstract}
A DISSERTATION PRESENTED TO THE GRADUATE SCHOOL OF THE UNIVERSITY OF FLORIDA IN PARTIAL FULFILLMENT OF THE REQUIREMENTS FOR THE DEGREE OF DOCTOR OF PHILOSOPHY
\end{abstract}

UNIVERSITY OF FLORIDA 
Dedicated to my parents

Chun-Chang and Hua-Yin 


\section{ACKNOWLEDGMENTS}

First, I would like to express my deepest gratitude to my former advisor, the late Dr. Sun-Fu Shih, and current advisor Jonathan D. Jordan for their guidance, support, and patience. Dr. Shih passed away suddenly on June 16,2000, which was a tragic loss for his loving family and his students. I feel mournful that Dr. Shih couldn't share my joy at the culmination of my Ph.D. study journey.

I also greatly appreciate Dr. Allen Overman, Dr. Byron Ruth, Dr. Mark T. Brown, and Dr. Bon Dewitt for serving on my graduate committee, providing knowledge and precious suggestions.

Many people helped and contributed to this Ph.D. research. I am thankful to everyone at the Center for Remote Sensing who ever worked with me. The lab manager, Orlando Lanni, was generous with his time and experience; former graduate students, Chih-Hung Tan, Lei-Wen Chen, and current graduate student, John Craig, offered great assistance in many field trips. Current graduate students, Assefa Melessa, Kai-Jen Tien, and Keng-Liang Huang, encouraged and inspired me in research. I would also like to thank the St. John's River Water Management District for installation of the lysimeter system, collecting some data, and partially sponsoring the research, especially the great assistance from Dr. Maria Mao and Ken Snyder. I also want to express my great appreciation to the Institute of Technology Development, Stennis Space Center, NASA for providing access to the hyperspectral imager. 
Moreover, I would like to acknowledge a very important person during these years of graduate study in United States, my best friend in Gainesville, Phillip M. Whisler. We share the sincerest friendship with all my joys and sorrows. With his friendship I was able to get through many frustrating moments. He also helped me with editing and proofreading this dissertation.

Finally, I express my deepest gratitude to my parents for their many years of love, support, and encouragement. 


\section{TABLE OF CONTENTS}

page

ACKNOWLEDGMENTS ..................................................................................... iii

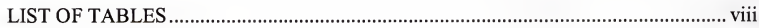

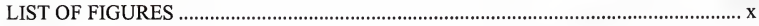

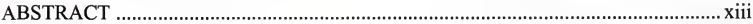

\section{CHAPTERS}

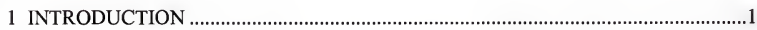

1.1 Importance of Wetland Evapotranspiration ........................................................ 1

1.2 Applicability of Conventional ET Methods to Wetland ET ................................. 1

1.3 Limited Field Study for Wetland ET ................................................................. 2

1.4 Conventional Remote Sensing Application on ET Estimation ................................ 3

1.5 Important Vegetation Parameters for ET Estimation.......................................... 4

1.5 Problems in Wetland Vegetation Mapping....................................................... 7

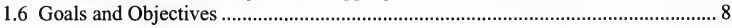

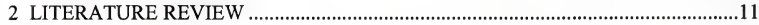

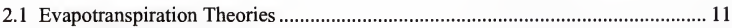

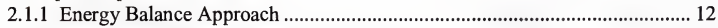

2.1.2 Aerodynamic Vapor Transport Approach ................................................ 14

2.1.4 Penman-Monteith Equation and Vegetation Influence on ET ........................18

2.1.5 Water Budget and Lysimeter ................................................................. 21

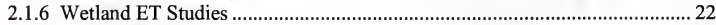

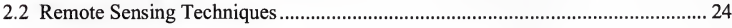

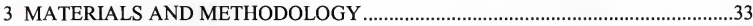

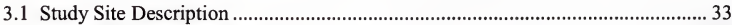

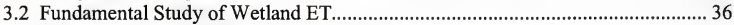

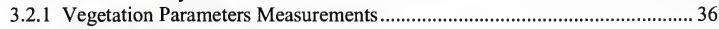

3.2.2 Estimation of Canopy Resistance .......................................................... 42

3.2.2.1 Revised procedure of measuring stomatal resistance ............................ 43

3.2.2.2 Revised procedure of measuring LAI ............................................. 43 
3.2.4 Methods for Evapotranspiration Estimation ................................................... 43

3.2.4.1 Modified FAO Penman method............................................................... 44

3.2.4.2 Priestley-Taylor method......................................................................... 46

3.2.4.3 Penman-Monteith combination method.................................................. 47

3.3 Spectroradiometry on the Responses of Vegetation Parameters ............................ 48

3.3.1 Monitoring of Spectral Responses .................................................................... 48

3.3.2 Spectral Analysis of Stomatal Resistance ........................................................ 51

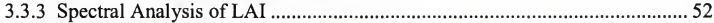

3.4 Aerial Hyperspectral Imaging ............................................................................... 53

3.4.1 Preparations Before Aerial Imaging ............................................................ 55

3.4.1.1 Preparation of geolocation targets ........................................................ 55

3.4.1.2 Preparation of calibration panels ........................................................... 56

3.4.2 Setup for Aerial Hyperspectral Imaging ........................................................ 57

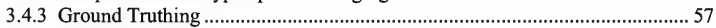

3.4.4 Hyperspectral Image Processing and Calibration .......................................... 60

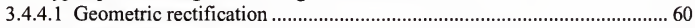

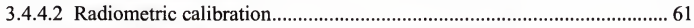

3.4.5 Vegetation Mapping Using Aerial Hyperspectral Image.................................. 63

3.4.5.1 Test of contingency for the selection of decision rules............................ 64

3.4.5.2 Test of separability for the selection of the most effective wavebands ... 64

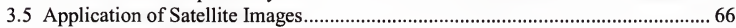

3.5.1 Spectral Calibration of ETM+ Images .............................................................. 67

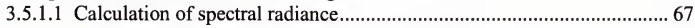

3.5.1.2 Calculation of at-satellite planetary reflectance....................................... 68

3.5.1.3 Calculation of at-satellite temperature .................................................... 69

3.5.2 Vegetation Mapping Using ETM+ Images....................................................... 70

3.5.2.1 Spectral analysis of different vegetation types on the ETM+ image ........ 70

3.5.2.2 Knowledge based classification................................................................... 71

3.6 Accuracy Assessment of Vegetation Maps............................................................ 72

3.7 Estimation of ET over the Fort Drum Marsh............................................................ 74

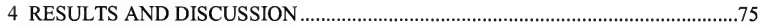

4.1 Fundamental Study of Wetland ET................................................................... 75

4.1.1 Conditions of the Lysimeters ...................................................................... 75

4.1.2 Vegetation Parameter Measurements ............................................................ 76

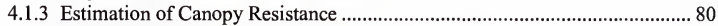

4.1.4 Methods for Evapotranspiration Estimation ..................................................... 86

4.1.4.1 Correlations between weather parameters and ET.................................... 89

4.1.4.2 Evaluation of the ET Methods for sawgrass ............................................ 90

4.1.4.3 Evaluation of the ET methods for cattail .................................................. 94

4.1.4.4 Overall evaluation of different ET methods ............................................ 98

4.1.4.4 Verification of different ET methods..................................................... 102

4.2 Spectral Radiometric Analysis............................................................................. 103

4.2.1 Spectral Response of Different Vegetation Types......................................... 103

4.2.2 Spectral Responses of Different Stomatal Resistance ................................... 110

4.2.3 Spectral Responses of Different LAI Values............................................... 116 


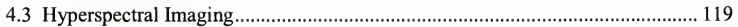

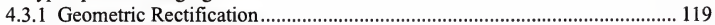

4.3.2 Radiometric Calibration................................................................................. 119

4.3.3 Vegetation Mapping Using the Aerial Hyperspectral Image........................ 125

4.4 Application of Satellite Images....................................................................... 131

4.5 Accuracy Assessment of Vegetation Maps............................................................ 136

4.6 Estimation of ET over the Fort Drum Marsh...................................................... 139

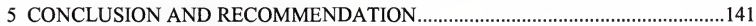

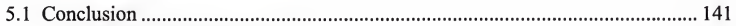

5.2 Recommendation for Future Research............................................................... 143

APPENDICES

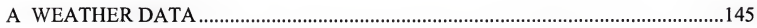

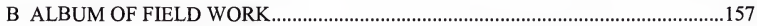

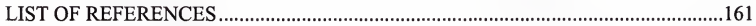

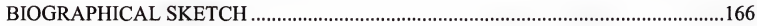




\section{LIST OF TABLES}

Table

Page

3.1 Spectral regions of different wavebands in the Landsat-7 ETM+ scanner.......51

3.2 Typical error matrix display for accuracy assessment..................................73

4.1 Vegetation parameters for sawgrass in seven field trips................................77

4.2 Vegetation parameters for cattail in seven field trips. ..................................78

4.3 Correlation coefficients of weather parameters and ET values .......................89

4.4 Correlation coefficients between the weather parameters. ..............................89

4.5 Annual mean ET and RMSE of different estimation methods for sawgrass in 1997.

4.6 Annual mean ET and RMSE of different estimation methods for cattail

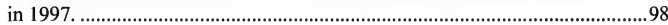

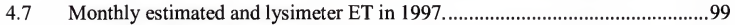

4.8 Annual mean ET and RMSE of different ET methods in 1999....................102

4.9 Computed NDVI of sawgrass and cattail from spectral measurements in each field trip

4.10 Different vegetation indices at different stomatal resistance values (sawgrass).

4.11 Different vegetation indices at different stomatal resistance values

(cattail).

4.12 Vegetation indices of sawgrass at different LAI values. .............................116

4.13 Vegetation indices of cattail at different LAI values...................................116

4.14 Knowledge rules for classification of wetland vegetation using the ETM+ images 
4.15 Matrix of accuracy of the classification using the hyperspectral image..........137

4.16 Matrix of accuracy of the classification using the ETM+ images ...................138 


\section{LIST OF FIGURES}

Figure

$1.1 \quad$ Illustration of the scaling-up concept.............................................................

2.1 Resistance model within canopy (adapted from Monteith \& Unsworth, 1990).

2.2 Typical spectral reflectance curves for vegetation, soil, and water (adapted from Lillesand \& Kiefer, 1994)

2.3 Reflected spectra for different combination of chlorophyll, anthocyanin. (adapted from Swain \& Davis, 1978).

2.4 Average course of reflectance, absorption, and transmittance of a green healthy plant leaf (adapted from de Boer, 1993)

2.5 Spectral reflectance curves of four agricultural crops (adapted from de Boer, 1993)

2.6 Changes in the spectral reflectance of oak leaves during the growing season (adapted from de Boer, 1993).

3.1 Location of the experimental site. (adapted from Mao \& Berman, 1999)........34

3.2 Location of lysimeters and Fort Drum marsh (Mao \& Berman, 1999) .............37

3.3 Desired aerial hyperspectral imaging area (the yellow square).........................54

$3.4 \quad$ Spectral reflectance of the calibration panels. .......................................................58

3.5 Possible classes in the aerial hyperspectral imaging area according to the 1999 aerial image of the same fly over path.

3.6 Atmospheric absorption effects especially at some particular wavelengths (adapted from Erdas, 1995)

4.1 Stomatal resistance of sawgrass versus height................................................81

4.2 Stomatal resistance of cattail versus height. .....................................................82 
4.3 Measured and estimated LAI of sawgrass versus height...................................83

4.4 Measured and estimated LAI of cattail versus height.........................................84

4.5 Computed ET of sawgrass versus different canopy resistance. The $\mathrm{x}$-axis was located at the actual lysimeter ET.

4.6 Computed ET of cattail versus different canopy resistance. The x-axis was located at the actual lysimeter ET.

4.7 Estimated ET using Penman equation versus lysimeter ET for sawgrass in 1997.

4.8 Estimated ET using Priestley-Taylor equation versus lysimeter ET for sawgrass in 1997.

4.9 Estimated ET using Penman-Monteith equation versus lysimeter ET for sawgrass in 1997.

4.10 Estimated ET using Penman equation versus lysimeter ET for cattail in 1997.

4.11 Estimated ET using Penman equation versus lysimeter ET for cattail in 1997. 96

4.12 Estimated ET using Penman-Monteith equation versus lysimeter ET for cattail in 1997.

4.13 Reflectance curves of cattail and sawgrass measured on 19 October 1996......104

4.14 Reflectance curves of cattail and sawgrass measured on 23 December 1996...105

4.15 Reflectance curves of cattail and sawgrass measured on 28 March 1997.........106

4.17 Reflectance curves of cattail and sawgrass measured on 11 August 1997........108

4.19 Spectral reflected radiance of cattail at the different values of stomatal resistance.

4.20 Spectral reflectance of cattail at the different values of stomatal resistance. .112

4.21 Spectral reflected radiance of sawgrass at the different values of stomatal resistance.

4.22 Spectral reflectance of sawgrass at the different values of stomatal resistance

4.23 Spectral reflectance of sawgrass at different LAI values 
4.24 Spectral reflectance of cattail at different LAI values ..................................118

4.25 Hyperspectral image with the observed flight direction change.....................121

4.26 Aerial hyperspectral image after piecewise polynomial rectification procedure

4.27 Spectral reflectance of different wetland vegetation species measured by a hand-held spectroradiometer.

4.28 Spectral reflectance of different wetland vegetation species from the spectrally calibrated hyperspectral image

4.29 Vegetation map of Ft. Drum marsh generated from the aerial hyperspectral image.

4.30 Vegetation map of the Fort Drum marsh generated from the hyperspectral image using $506.8 \mathrm{~nm}, 672.3 \mathrm{~nm}$, and $813.0 \mathrm{~nm}$ wavebands.

4.31 Vegetation map of the Fort Drum marsh generated from the hyperspectral image using $515.0 \mathrm{~nm}, 672.3 \mathrm{~nm}, 721.9 \mathrm{~nm}, 837.8 \mathrm{~nm}$ wavebands.

4.32 Vegetation map of the Fort Drum marsh generated from the hyperspectral image using $515.0 \mathrm{~nm}, 672.3 \mathrm{~nm}, 697.1 \mathrm{~nm}, 746.8 \mathrm{~nm}, 862.6 \mathrm{~nm}$ wavebands.

4.33 Spectral reflectance of different vegetation types extracted from Feb 05, $2000 \mathrm{ETM}+$ image

4.34 Spectral reflectance of different vegetation types extracted from May 11, $2000 \mathrm{ETM}+$ image

4.35 Vegetation map of Fort Drum marsh generated from the ETM+ images of Feb 5, 2000 and May 11, 2000.

4.36 Estimated ET distribution in the Fort Drum marsh on May 11, 2000. The whiter color represents higher ET value.

B.1 Cattail lysimeter in the Fort Drum marsh..................................................157

B.2 Weather station in the Fort Drum marsh.........................................................158

B.3. Geolocation target sitting on the water and vegetation surface.......................159

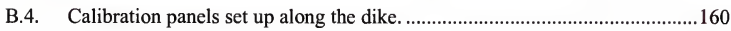




\section{Abstract of Dissertation Presented to the Graduate School of the University of Florida in Partial Fulfillment of the Requirements for the Degree of Doctor of Philosophy \\ APPLICATION OF REMOTE SENSING TECHNIQUES AT DIFFERENT SCALES OF OBSERVATION ON WETLAND EVAPOTRANSPIRATION}

By

Chung-hsin Juan

May 2001

Chairman: Jonathan D. Jordan

Major Department: Agricultural and Biological Engineering

The establishment and maintenance of the structure and functions in wetland ecosystems is greatly influenced by hydrologic conditions. Evapotranspiration (ET) is the major output component in the hydrologic water budget. Therefore, in order to provide efficient information for water resources management and the conservation of wetland ecosystems, research on ET is urgently needed. Moreover, to overcome the variable spatial vegetation distribution and the temporal change of wetlands, appropriate remote sensing techniques are also greatly needed.

The goal of this research was to study fundamental wetland ET and then with the aid of remote sensing techniques from the micro scale to the macro scale to develop useful wetland ET estimation methods. The study site was located in the Ft. Drum Marsh, Upper St. John's River Basin in Indian River County, Florida. The site is a freshwater marsh with southern cattail (Typha domingensis Pers.) and sawgrass (Cladium 
jamaicense $\mathrm{Crantz}$ ) as the dominant vegetation species. There were four stages of the study: 1) a fundamental ET study with a lysimeter system, 2) ground measurements and analyses of spectral responses of wetland vegetation using a field spectroradiometer , 3) wetland vegetation mapping using aerial hyperspectral images, and 4) application of satellite images to delineate wetland vegetation and estimate marsh-wide ET.

The results of the fundamental ET study showed the various important vegetation parameters of sawgrass and cattail. A more appropriate estimation method of canopy resistance for sawgrass and cattail was proposed. Among the various ET estimation methods, the Priestley-Taylor method was found to be most applicable. The ground spectral response measurements of sawgrass and cattail demonstrated a distinguishable difference in red wavebands and normalized difference vegetation index (NDVI), which indicated the spectral separability of the two wetland species. Leaf area index and stomatal resistance displayed a high correlation to spectral reflectance. Aerial hyperspectral imaging proved very successful in the identification of wetland vegetation species. Among all 64 wavebands, the separability tests revealed that the wavebands in the blue-green, red edge, and near-infrared spectral regions are the most important contributors for the identification of wetland vegetation species. The satellite image was applied to map wetland vegetation using the knowledge based classification method. Integrating the results from the four stages of study, the marsh-wide ET was estimated. The results of this research can have extensive application to wetland ET, wetland delineation, and remote sensing techniques. 


\section{CHAPTER 1 \\ INTRODUCTION}

\subsection{Importance of Wetland Evapotranspiration}

Evapotranspiration (ET), which is the conversion of water to vapor and the transport of that vapor away from the earth's surface into the atmosphere, accounts for a large portion of the hydrological water budget. Around $73 \%$ of Florida precipitation is returned to the atmosphere through ET (Fernald and Patton, 1984). Wetland systems are the transition zones between upland systems and aquatic systems. The hydrology of wetlands has an extremely great influence on the establishment and maintenance of the structure and functions in wetland ecosystems. Even a slight change in hydrology may cause a change in the wetland ecosystem or even the degradation of the wetlands. Therefore, in order to provide efficient information for water resources management and the conservation of wetland ecosystems, research on the major hydrologic parameter, ET, is urgently needed.

\subsection{Applicability of Conventional ET Methods to Wetland ET}

Among the conventional methods for the calculation of reference crop ET, the most common methods include the pan evaporation (Doorenbos \& Pruitt, 1977; Smith, 1992), Blaney-Criddle (Blaney \& Criddle), Priestley-Taylor (Jensen et al., 1990), and Penman-Monteith (Monteith, 1990) techniques. These are the common methods for crop 
ET estimation. Except for the Penman-Monteith method, they were developed empirically. ET estimate is formulated by the pan evaporation from a reference evaporation pan, from the temperature by the Blaney-Criddle method, from radiation by the Priestley-Taylor method, and from the Shih method (Shih, 1981) by both temperature and solar radiation. The Penman-Monteith method differs from the other empirical methods in that it was derived physically by utilizing micrometeorology methods. Thus, when the ET function of certain vegetation types are considered, the Penman-Monteith method is usually adopted to characterize a detailed ET process.

\subsection{Limited Field Study for Wetland ET}

Even though voluminous research has contributed to crop ET estimation, the applicability of the parameters concluded from crop ET research to the parameters for wetland ET may need further verification. Because wetland vegetation between terrestrial and open-water aquatic ecosystems is transitional, the characteristics of ET in wetlands should be different from those in the terrestrial systems and especially different from agricultural systems. Although, in recent decades, the importance of wetland ET has been gradually gaining recognition, the quantity of wetland ET research has been comparatively sparse. In addition, lack of consensus between researchers has lead to considerable debate regarding ET estimation (Abtew \& Obeysekera, 1995). Anderson and Idso (1987) suggested that the ratio of wetland plant ET to open water evaporation was linearly related to the ratio of vegetation area to open surface area. Allen et al. (1994) found the ratio of cattail ET to potential ET to be 1.15 and their earlier research (Allen et al., 1992) showed the ratios of cattail (Typha spp.) ET and bulrush (Scirpus spp.) ET to 
potential was 1.6 and 1.8, respectively. Bernatowicz et al. (1976) demonstrated the ratios of cattail ET of two different species (Typha angustifolia and Typha latifolia L.) to potential ET were 3.2 and 3.4, respectively. Having reviewed the experimental data from 25 sources, Allen et al. (1997) concluded that the wide range in ratios of wetland ET to potential ET ( 0.5 to 5.3$)$ resulted from the "clothesline effect" or "oasis effect" caused by improper experimental design and then suggested that well-watered, fully vegetated surfaces in similar climatic conditions should have similar ET rates. Several different reasons could explain the divergent opinions on wetland ET proposed by these researchers, such as the different wetland types, different wetland vegetation species, the misconducts of wetland ET mechanisms, or even improper experiment design. Thus, in order to estimate wetland ET with as little bias as possible, a fundamental study with a properly-designed lysimeter system is necessary to clarify the characteristics of wetland ET and to ensure reliable data collection.

\subsection{Conventional Remote Sensing Application on ET Estimation}

Generally, these previously depicted ET estimation methods are based either on the concept of energy balance or empirical formulas. Regardless of which ET method is used for estimating regional ET, a sound network of weather stations or observation stations is necessary in order to collect climatic data in cooperation with vegetation distribution information. Unfortunately, both weather station and vegetation distribution information for most Florida wetlands regions is not available at fine detail. Thus, using the sparse existing information available, it is difficult to estimate a region's wetland ET condition. The development of an alternative, therefore, is urgently needed. Moreover, 
the accuracy and applicability limited by the spatial and temporal variability in hydrological modeling is of great concern. Measuring the characteristics of an area rather than a point, remote sensing is a unique tool that enables hydrologists to visualize the hydrological processes over different spatial locations and time periods (Engman \& Gurney, 1991). Raymond and Owen-Joyce (1985) analyzed Landsat images to identify the landuse types of Palo Verde Valley, California and then estimated the total ET by combining the ET values of the different landuse types. Heimburg (1982) used the thermal band of satellite images to estimate regional ET. ET is a hydrologic phenomenon involving several climatic and land-surface parameters which usually change with time and space. Therefore, utilization of remote sensing techniques for collection of the needed spatial and temporal information has proven valuable.

\subsection{Important Vegetation Parameters for ET Estimation}

In recent years, several ET studies have been done through the application of remote sensing. Caselles et al. (1998) utilized the combination of Landsat TM and NOAA-AVHRR images to estimate the actual ET in Spain using a semi-empirical temperature equation. Choudhury (1997) using satellite and assimilated data estimated the global pattern of potential ET utilizing the Penman-Monteith equation. Those studies determined the vegetation parameters in the equations, either by some assumptions or by the semi-empirical estimations. Therefore, their remote sensing applications to ET estimations could not fully demonstrate the differences of regional ET values where the different vegetations were mixed. Thus, when using a remote sensing application, the exploration of the deterministic relations between spectral reflectance and vegetation 
parameters is necessary for the accurate estimation of regional ET. Therefore, in order to accurately determine vegetation parameters from spectral reflectance, a technique of ground-based remote sensing measurements associated with measurements of vegetation parameters is essential for the development of ET remote sensing methods on a micro scale and application of these methods on medium and regional scale. Three important vegetation parameters (that is, vegetation species, leaf area index, and stomatal resistance) affecting ET estimation methodology can be grouped into two categories. The first category is the vegetation parameters which are the empirical coefficients calculated from the regression of experimental data used to identify the specific species. Once the vegetation species are identified, the vegetation parameters in the first category may be determined for the specific species. The vegetation parameters in ET estimation methods, except the Penman-Monteith method, are in the first category. The ET method in the second category, the Penman-Monteith method in addition to the identification of vegetation species, requires the vegetation parameters such as leaf area index (LAI) and stomatal resistance. Because the Penman-Monteith method is a physical-based approach and is usually considered to be important to the understanding of the characteristics of the ET processes in different vegetation types, research on the estimation of the LAI and the stomatal resistance is emphasized. Therefore, the three important vegetation parameters will be studied with efforts using remote sensing techniques.

Generally, different ranges of wavelengths of the reflected radiance observed using remote sensing techniques can identify different vegetation types and their growth stages (de Boer, 1993). To identify the vegetation species by using remote sensing 
requires advance knowledge of their spectral signatures which can then be used as references. Thus, the spectral signatures of wetland vegetations need to be investigated.

The normalized difference vegetation index (NDVI), defined as the combination of reflectance on red and infrared wavebands has been widely used to characterize the vegetation parameters. The relationship between NDVI and LAI has also been studied by several researchers (Curran, 1983; Liu and Huete, 1995). A linear relation for the value of NDVI lower than 3-4, has been observed (Curran, 1983; Nemani and Running, 1989). However, Curran (1983) pointed out an asymptotic regime in which NDVI increases very slowly with increasing LAI for NDVI higher than a certain threshold of 3-4. Carlson and Ripley (1997) suggested the linear relation of LAI and NDVI resulted from the variation in the fractional vegetation cover and was only available when the fractional vegetation cover was less than $100 \%$. Thus, using NDVI to estimate LAI needs further confirmation. In addition, developing suitable vegetation indices other than NDVI may be a good alternative to estimate LAI.

Very few studies have been done on the relationship between spectral reflectance and canopy resistance. Carter (1998) studied the reflectance pattern and indices for stomatal conductance of $\mathrm{CO}_{2}$ assimilation rate in pine canopies. He displayed the significant relations for the net $\mathrm{CO}_{2}$ assimilation at wavelength of $700.2 \mathrm{~nm}$. Given the low availability of relevant research in this area, an experiment with measurements on the canopy resistance of $\mathrm{H}_{2} \mathrm{O}$ and the spectral reflectance is necessary. 


\subsection{Problems in Wetland Vegetation Mapping}

Due to the differences in the physiological structures of different species, the amount of ET changes from species to species even though the outer climatic conditions are similar. Therefore, the main key to applying remote sensing tools to wetland ET would be to accurately identify wetland vegetation species.

Wetland vegetation species are very sensitive to environmental changes and wetland vegetation species may be a good indicator of the environmental changes. In a freshwater marsh, both cattail (Typha spp.) and sawgrass (Cladium jamaicense Crantz) can grow in similar geomorphological and geographical locations and may mix together but sawgrass tends to be found in lower nutrient level conditions (Kadlec \& Knight, 1996). Therefore, government agencies routinely monitor the spatial distribution of the cattail and sawgrass in freshwater marshes. However, both of the species, from a distance, look very similar and are difficult to identify without close observation. Thus, wetland delineation to the specie level usually requires more intensive tasks in the form of field surveys. In order to save the time and labor in field work needed to identify different species, remote sensing was employed as an ideal and convenient tool to serve this purpose (Doren, 1999).

The most frequently used conventional remote sensed data were either satellite images or airborne color infrared (CIR) photos and images (Madden, 1999; Welch, 1996). Most satellite data, however, do not have fine enough spatial resolution to differentiate detailed ground information. Although the airborne CIR photos and images may have fine enough spatial resolution, their spectral wavebands may be too broad to identify two 
similar looking species. Therefore, in order to properly delineate wetlands for study purposes, a new well-developed remote sensing technique is desirable.

\section{$\underline{1.6 \text { Goals and Objectives }}$}

To complete a study of remote sensing application to wetlands ET, fundamental wetland ET, spectral responses to wetland vegetation, and proper remote sensing techniques are the main keys. Therefore, the purpose of this dissertation is to integrate all aspects of fundamental research to estimate wetland ET by remote sensing methods. First, fundamental research on wetland ET with a sound lysimeter system needs to be achieved. Then, to apply remote sensing techniques, the observation, from the micro, meso, and macro scales of spectral responses of wetland vegetation is also necessary. The different scales in this research are defined by the positions of the remote sensors. If a remote sensor is operated at ground surface, then it is considered as micro scale. If remote sensed data is acquired by a low-altitude airplane it is defined as meso scale. If remote sensing is executed by a satellite sensor it is regarded as macro scale. In terms of spatial resolution used in this research, remotely sensed data of micro, meso, and macro scales is smaller than 1 meter, equal to 1 meter, and larger than 1 meter. A scaling-up concept as illustrated in Figure 1.1 was employed in this research. The concept is to study the spectral responses of wetland vegetation at ground micro-scale level, then to analyze the spectral responses using airborne images at mesoscale level based on the observation at microscale and eventually, to apply the results of the previous two scales to satellite images at the macroscale level. This concept is an integrated remote sensing research procedure and is expected to create solid linkage between ground truth situation 


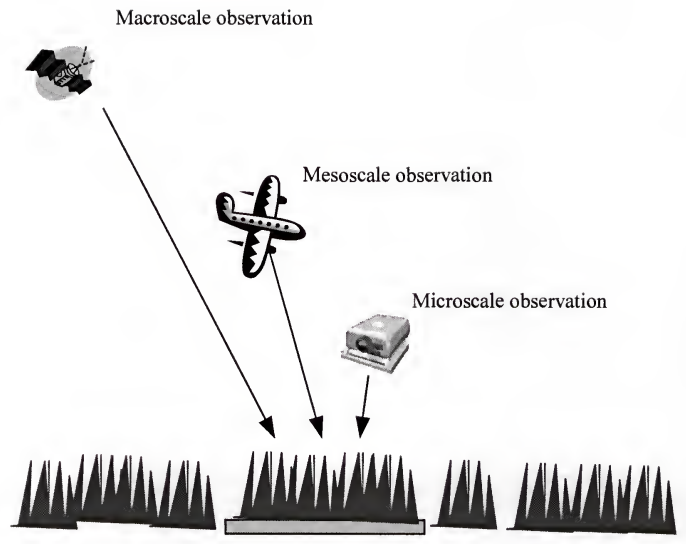

Figure 1.1 Illustration of the scaling-up concept. 
and the remotely sensed data. In summary, the following four goals were involved:

1) Fundamental research on the functions of wetland ET,

2) Fundamental research on the relations between the spectral reflectance of wetland vegetations and the vegetation parameters in the ET estimation equations,

3) Wetland vegetation mapping using remote sensing techniques,

4) Applications of the above three fundamental studies to the wetland ET with remotely sensed data.

In order to complete the proposed research goals, the objectives for different research stages were set as follows:

1) Collect the relevant vegetation parameters,

2) Evaluate, identify and modify existing conventional ET estimation methods,

3) Implement ground-based remote sensing tools to collect spectral information for wetland vegetation species,

4) Develop proper methods to differentiate the vegetation species and to analyze the spectral characteristics of LAI and canopy resistance from the ground-based remotely sensed data,

5) Design and execute an airborne hyperspectral imaging mission,

6) Use satellite images to estimate the regional wetland ET. 


\section{CHAPTER 2}

\section{LITERATURE REVIEW}

The study of multi-scale remote sensing application to wetland ET involves two different disciplines: 1) ET process and estimation methods; 2) remote sensing theory and methods. Therefore, the literature review first started with the concept of ET process and the different estimation methods. Some previous wetland ET studies were also included. Optical characteristics of different ground vegetation objects in different conditions were then reviewed.

\subsection{Evapotranspiration Theories}

ET research includes the study of both ET from soil free water surfaces and transpiration from stomata of live vegetation. The complex ET process involves radiation exchanges, vapor transport, and the physiological structure and growth status of vegetation. There have been many ET studies, however most of them were focused on crop ET. Conventional ET estimation methods were derived basically from an energy balance perspective, aerodynamic vapor transport perspective, or a combination of the two.

The amount of ET is usually expressed as the rate of water volume evopotranspired per unit ground surface area. The unit for this expression is Length/Time. Another common ET expression is the rate of latent heat of evapotranspiration per unit ground surface area. The unit for this expression is 
Energy/Time. To avoid confusion, the terms related to ET as used in this study are defined below.

Evaporation, noted as $E$, is the physical process by which a liquid or solid is transferred to the gaseous rate.

Potential evaporation, noted as $E_{0}$, is the evaporation from a surface when all surface-atmospheric interfaces are wet so that there is no restriction on the rate of evaporation from the surface.

Evapotranspiration, noted as $E T$, is the combined processes of evaporation and transpiration by which water is transferred from the earth's surface to the atmosphere.

Potential evapotranspiration, noted as $E T_{0}$, is the rate at which water, if available, would be removed from wet soil and plant surfaces.

Reference crop evapotranspiration, noted as $E T_{r}$, is the rate at which water, if readily available, would be removed from the soil and plant surfaces for a given crop. When mentioning reference evapotranspiration, also noted as $E T_{r}$, it means the reference evapotranspiration for grass or alfalfa of a given height.

\subsubsection{Energy Balance Approach}

The process of ET requires a large amount of energy in order to transform water from liquid (or solid) form to gaseous form. The primary energy source is from solar radiation. Solar radiation usually supplies 80 to 100 percent of needed energy and is often the limiting factor of ET (Saxton \& McGuinness, 1982). In cold, humid climates only 50 to 60 percent of the net radiation may be converted to ET, where in a hot, arid climate latent heat may exceed net radiation by 10 to 50 percent with sensible heat derived from the air and converted to ET (Jensen et al., 1990). Therefore, an energy 
balance approach was widely developed by early researchers. A typical energy balance equation may be expressed as

$$
R_{n}=H+\lambda E+G+X
$$

and

$$
R_{n}=R_{s}-a R_{s}+R_{l}-R_{l r}
$$

where

$$
\begin{aligned}
& R_{s}=\text { incoming solar radiation (short wave), } \\
& a R_{s}=\text { solar radiation reflected, } \\
& R_{l}=\text { incoming radiation (long wave), } \\
& R_{l r}=\text { emitted long wave radiation, } \\
& R_{n}=\text { net radiation, } \\
& H=\text { sensible heat of air, } \\
& \lambda E=\text { latent heat of water vapor, } \\
& \lambda=\text { latent heat of vaporization, } \\
& E=\text { depth of evaporative water, } \\
& G=\text { soil heat, and } \\
& X=\text { miscellaneous heat sinks, like plant and air heat storage. }
\end{aligned}
$$

Because the contribution of miscellaneous heat sinks is usually much less, the other three components it is often neglected and the energy balance equation is expressed as:

$$
\lambda E=R_{n}-H-G
$$




\subsubsection{Aerodynamic Vapor Transport Approach}

The measurement of water vapor, as it is transported away from an evaporating surface, offers the potential for the most direct measurement of ET. The approach usually involves measuring the vapor pressure of the air at two or more heights above the evaporating vegetation and a profile of wind velocities in order to define moisture gradients and wind transport or fluctuations of vertical velocity and humidity at a single height. All of the measurements are quite sensitive and the amount of required data is voluminous. For adiabatic profiles ET can be determined by using the eddy diffusion equation (Thornthwaite and Holzman, 1939) as

$$
E=\frac{-\rho_{a} k^{2}\left(u_{2}-u_{1}\right)\left(q_{2}-q_{1}\right)}{\left[\ln \left(z_{2} / z_{1}\right)\right]^{2}}
$$

where

$$
\begin{aligned}
& k=\text { von Karman constant, } \\
& \rho_{a}=\text { density of air, } \\
& q_{i}=\text { specific humidity at the position } i, \\
& u_{i}=\text { wind speed measured at the position } i, \text { and } \\
& z_{i}=\text { height at the position } i .
\end{aligned}
$$

\subsubsection{Combination Approach}

The actual ET process is driven by both energy and vapor deficit. Therefore, an ideal ET estimation should combine an energy balance approach and aerodynamic vapor transport approach. Because the atmospheric transport mechanisms of sensible heat are similar to those of water vapor, Bowen (1926) assumed that the sensible heat 
flux and the latent heat flux are proportional and the proportionality constant is called the Bowen ratio.

$$
\beta=\frac{H}{\lambda E}
$$

From the energy balance equation, sensible heat flux $H$ is equivalent to $(R-G)-\lambda E$. Then Equation 2.5 can be rewritten as,

$$
\lambda E=\frac{(R-G)}{(1-\beta)}
$$

If the vapor transport process and heat transfer process are assumed to be involved only in the diffusive process and only the vertical diffusive process is considered, then the latent heat flux and sensible heat flux can be expressed by the following diffusive equation,

$$
\begin{aligned}
& E=-\rho_{a} K_{w} \frac{d q_{v}}{d z} \\
& H=-\rho_{a} C_{p} K_{h} \frac{d T}{d z}
\end{aligned}
$$

where

$$
\begin{aligned}
\rho_{a} & =\text { density of air, } \\
K_{w} & =\text { vapor eddy diffusivity, } \\
q_{v} & =\text { specific humidity, } \\
T & =\text { temperature, } \\
C_{p} & =\text { specific heat at constant pressure, and } \\
K_{h} & =\text { heat diffusivity. }
\end{aligned}
$$

When considering the gradient at near surface, the latent heat and sensible heat can be expressed in the form of two different equations as 


$$
\begin{aligned}
& E=-o_{a} K_{w} \frac{\left(q_{a-} q_{s}\right)}{\left(Z_{a}-Z_{s}\right)} \\
& H=-\rho_{a} C_{p} K_{h} \frac{\left(T_{a}-T_{s}\right)}{\left(Z_{a}-Z_{s}\right)}
\end{aligned}
$$

where

$$
\begin{aligned}
& q_{a}=\text { air specific humidity near above the surface, } \\
& q_{s}=\text { specific humidity at the surface, } \\
& T_{a}=\text { air temperature near above the surface, and } \\
& T_{s}=\text { temperature at the surface. }
\end{aligned}
$$

Thus, the Bowen ratio can be rewritten by substituting $E$ and $H$ with Equations 2.9 and 2.10 as

$$
\beta=\gamma\left(\frac{T_{a}-T_{s}}{e_{a}-e_{s}}\right)
$$

where $\gamma$ is the psychrometric constant and expressed as

$$
\gamma=\frac{C_{p} K_{h} p}{0.622 \lambda K_{w}}
$$

and the ratio $\mathrm{K}_{\mathrm{h}}$ and $\mathrm{K}_{\mathrm{w}}$ of the heat and vapor diffusivities are commonly taken to be 1 (Priestley and Taylor, 1972).

In order to determine the Bowen ratio, measurements of temperature and vapor pressure are required at two different heights. Under the circumstance of saturated water vapor pressure, the relationship between temperature and saturated vapor pressure at that temperature is certain. Thus, the temperature parameters in Equation 2.11 can be defined as the gradient of the saturated vapor pressure curve (Penman, 1948), 


$$
\Delta=\frac{e_{s}^{*}-e_{a}^{*}}{T_{s}-T_{a}} \quad \text { or } \quad T_{s}-T_{a}=\frac{1}{\Delta}\left(e_{s}^{*}-e_{a}^{*}\right)
$$

where $e_{a}{ }^{*}$ is the corresponding saturated vapor pressure at the air temperature and $e_{s}{ }^{*}$ is the corresponding saturated vapor pressure at the surface temperature. Because the surface is considered as wet and very near saturated in the combination approach, $e_{s}$ is assumed to be equal to $e_{s}^{*}$. Thus, the Bowen ratio can be depicted as another form

$$
\beta=\frac{\gamma}{\Delta}\left(1-\frac{e_{a}^{*}-e_{a}}{e_{s}-e_{a}}\right)
$$

Substitution of Equation 2.13 into Equation 2.6 yields

$$
R_{n}-G=\left(1+\frac{\gamma}{\Delta}\right) E-\frac{\gamma}{\Delta}\left(\frac{e_{a}^{*}-e_{a}}{e_{s}-e_{a}}\right) E
$$

The second term of $E$ can be considered as the result of wind effect and water vapor diffusion from surface to air. Thus, it can be described as

$$
E=f(\bar{u})\left(e_{s}-e_{a}\right)
$$

where $f(\bar{u})$ is called wind function. Therefore, substituting Equation 2.15 into Equation 2.14 , the Penman equation is shown as

$$
\lambda E=\frac{\Delta}{\Delta+\gamma}\left(R_{n}-G\right)+\frac{\gamma}{\Delta+\gamma} \lambda f(\bar{u})\left(e_{a}^{*}-e_{a}\right)
$$

In Equation 2.16, the term before the plus sign is the part of ET contributed from energy balance and the term after the plus sign is the part of ET contributed from aerodynamic vapor transport. In the Penman combination method, the assumption is made that the humidity at surface is wet and near saturated. This assumption makes the usage of the Penman equation more convenient by reducing the measurements of temperature and vapor pressure to only one height. Thus, the Penman combination 
method can be widely used wherever a complete weather station is installed. Because the Penman equation combines both energy balance and aerodynamic vapor transport approaches, it usually gives higher accuracy where these two approaches are both important in the real situations. Due to the assumption of a vapor-saturated surface, the Penman equation is more applicable in well-irrigated and water-sufficient conditions that are also similar to the definition of reference ET. Therefore, the Penman equation is often used to calculate reference ET.

\subsubsection{Penman-Monteith Equation and Vegetation Influence to ET}

Penman's combination equation assumes that water is evaporated from an open water surface or well-irrigated short grass surface. In order to introduce the saturated vapor pressure curve and the gradient $\Delta$ in Equation 2.12 into the derivation of the Penman equation, a main assumption of the method is that vapor pressure at the surface is saturated. Nevertheless, a vegetated surface is not usually saturated in humidity except after rainfall or dew formation (Brutsaert 1986). Thus, the assumption of saturated vapor pressure is generally not true for well-grown, tall vegetation. Monteith (1990) modified the Penman equation with the adjustment of resistance within a canopy. In Monteith's approach, instead of using saturated surface vapor pressure $e_{s}{ }^{*}$, the saturation value in open stomata on plant leaf surface was introduced. Monteith considered the bulk effects of open stomata at different layers within the canopy. Canopy resistance was introduced to represent the accumulated effects of each individual stomatal resistance at different layers. It can be related to the concept of bulk resistance of a set of parallel electronic resistances (Figure 2.1). When the vegetation is not actually saturated, the surface vapor

pressure $e_{s}$ is not equal to $e_{s}{ }^{*}$. Monteith adjusted saturated surface vapor pressure as 


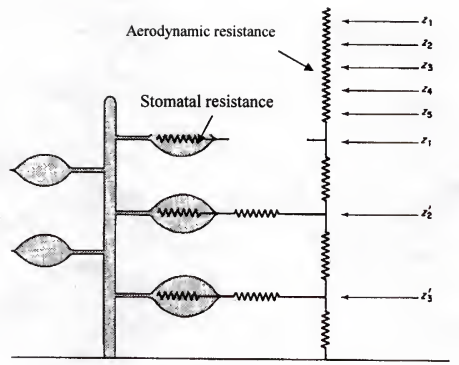

Figure 2.1 Resistance model within canopy (adapted from Monteith \& Unsworth, 1990). 


$$
e_{s}-e_{a}=\left(\frac{r_{a}}{r_{c}-r_{a}}\right)\left(e_{s}^{*}-e_{a}\right)
$$

where $r_{a}$ is the diffusion resistance of air layers and $r_{c}$ is the diffusion resistance within vegetation canopy. Applying the relation of Equation 2.17 instead of Equation 2.12 to substitute into the Bowen ratio (Equation 2.11), the Penman-Monteith can be derived as

$$
\lambda E=\frac{\Delta}{\Delta+\gamma^{\prime}}\left(R_{n}-G\right)+\frac{\rho C_{p}}{\Delta+\gamma^{\prime}}\left(\frac{e_{a}^{*}-e_{a}}{r_{a}}\right)
$$

where

$$
\gamma^{\prime}=\gamma\left(1+\frac{r_{s}}{r_{a}}\right)
$$

Even though Monteith modified the Penman equation to better fit the real mass transport from vegetation and soil to atmosphere in the conditions of non-saturated surface vapor pressure and tall vegetation, how to measure and estimate the canopy resistance still took the diligent efforts of many researchers. The stomatal resistance values for a number of crops have been studied and can be found throughout the literature. However, research on the stomatal resistance for wetland vegetation is still sparse.

Stomatal resistance can be also considered the external display of a vegetation's internal conditions, such as its physiological structures, growth stages, and stress conditions. Physiological structures may vary from one vegetation species to another. Growth stages for the same vegetation species may differ from one year to another. Stress conditions may be influenced by the environmental factors such as flood, drought, freeze, heat, and et al. Therefore, the practical application of the Penman-Monteith equation may be limited to those major crops for which research has been most common, growth environmental factors are well defined, and species are monocultured. Although 
the practical application of the Penman-Monteith equation is limited, in many studies it is still considered better for revealing the process and structure of ET for different plant species.

\subsubsection{Water Budget and Lysimeter}

The value of ET is not directly measurable. Water budget is the main method for calculating ET. To date, the most accurate ET values were usually obtained through water budget calculation and accurately measuring other hydrological components. The water budget equation for wetlands can be expressed as (Mitsch \& Gosselink. 1993)

$$
\frac{d S(l)}{d t}=P+S_{i}+G_{i}-S_{o}-G_{o}+E T
$$

where

$$
\begin{aligned}
& S(l) \quad=\text { storage of water at the water level of } l, \\
& S_{i} \quad=\text { surface inflow, } \\
& G_{i} \quad=\text { recharge from groundwater, } \\
& S_{o} \quad \text { = surface outflow, and } \\
& G_{o} \quad \text { = discharge into groundwater. }
\end{aligned}
$$

Basinwide water budget calculation is complicated by many spatial and temporal uncertainties in the measurement of each hydrological component, so usually, its accuracy is not very high accuracy. Therefore, the use of tanks with proper design and operation is an alternative way to measure actual ET. Specific tanks for ET measurement are called lysimeters. Lysimeters have been used for over 300 years to determine water use by vegetation via the ET process. Precise lysimetry for measuring ET has been developed mainly within the past 60 years (Howell et al., 1991). Designs of lysimeters 
vary with the type of vegetation, the surrounding environment, and the designer's focus and style. Data recording systems were gradually improved and today, fully automatic data recording systems are common. Allen et al. (1991) specifically pointed out several important considerations in lysimeter design, such as evaporative area and vegetative area inside lysimeters, clothesline effects, and oasis effects. The evaporative area and the vegetative area inside lysimeters should represent the ratio of these two areas in the surrounding environments. If the plant heights inside and outside lysimeters are different it may cause a so-called clothesline effect and result in some inaccuracy. Moreover, if the vegetation of the lysimeters are surrounded by a large expanse of drier vegetation, then the oasis effect occurs. Therefore, a proper design of the lysimeter system is very important in obtaining actual ET values.

\subsubsection{Wetland ET Studies}

Compared with the numerous ET studies for crops, fundamental wetland ET studies are rare. Earliest literature related to wetland vegetation lysimeter studies can be traced back to the water hyacinth (Eichhornia crassipes (Mart.) Solms ) and cattail (Typha latifolia L.) lysimeter study by Otis (1914). However, reported ratios of wetland ET to open-water evaporation (potential ET) of lysimeter measurements ranges from 12 to 0.87 (Allen et al., 1997). Allen et al. further pointed out that the wide range of the ratios between ET and potential ET resulted from the oasis effect and clothesline effect caused by inadequate design of the lysimeters. In the literature cited by Allen et al. (1997), some researchers evaporation measurements were obtained from standard Class A pans as the potential ET and some used measurements obtained from open water lysimeters as the potential ET. Therefore, not only the adequate design of lysimeters 
influences the validity of wetland ET study, but also the selection of a standard potential ET for wetland ET studies effects the overall comparison of wetland ET.

Conventional ET estimation methods are still widely used for wetland ET estimation. A particular direct measurement method for wetland ET is to use the diurnal cycles of groundwater or surface water in wetlands (Mitsch \& Gosselink, 1993). This method can be described as

$$
E T=S_{y}(24 h \pm s)
$$

where

$$
\begin{aligned}
S_{y} \quad & =\text { specific yield of aquifer (unitless), } \\
& =1.0 \text { for standing water wetlands, } \\
& <1.0 \text { for groundwater wetlands, } \\
h \quad & =\text { hourly rise in water level from midnight to 4:00 A.M., } \\
s & =\text { net fall }(+) \text { or rise }(-) \text { of water table or water surface in one day. }
\end{aligned}
$$

The method assumes that ET nears zero during midnight to 4:00 A.M. and the recharge water from the aquifer is a constant rate.

A few Florida wetland studies exist. In central Florida, Dolan et al. (1984) studied the daily ET in a marshland along the Palatlakaha river near the city of Clermont. They used water-level records to calculate the daily ET from May 1977 to May 1978. They also developed a simple ET model using biomass and saturated deficiency. The highest daily ET was recorded as $10 \mathrm{~mm}^{-1}$ day $^{-1}$ in September 1977 and in February 1978, the lowest daily ET was recorded as $0.5 \mathrm{~mm}^{-1}$.

The Center for Wetlands at the University of Florida has completed a series of pond cypress (Taxodium ascendens) studies in Alachua County in north-central Florida. 
Heimburg (1984) computed the ET of pond cypress domes using water-level records and water budget methods. Heimburg also pointed out that ET is about $80 \%$ of pan evaporation in spring and autumn dry periods, falls as low as $60 \%$ of pan evaporation during the summer wet season, and is minimal in winter.

In the Everglades Nutrient Removal (ENR) project area in south Florida, Abtew et al. (1995) studied the ET of southern cattail (Typha domingensis Pers.) in a constructed wetland for reducing phosphorus concentrations in agricultural runoff. They installed an automatic lysimeter system in the study area with careful consideration in lysimeter design to avoid oasis effects. The lysimeter was a circular polyethylene tank $3.5 \mathrm{~m}$ in diameter and $90 \mathrm{~cm}$ in depth with a $4.8 \mathrm{~mm}$ thickness. The lysimeter was installed about $80 \mathrm{~m}$ from the major internal levee. The plants and soil were transplanted from the

surrounding environment. The average measurement ET rate was $3.9 \mathrm{~mm}$ day ${ }^{-1}$. Among the estimation methods, they found that the Penman-Monteith method showed the least error of estimation.

\section{$\underline{2.2}$ Remote Sensing Techniques}

Remote sensing is the science of obtaining information about an object area or phenomenon through the analysis of data acquired by a device that is not in contact with the object, area, or phenomenon under investigation (Lillesand \& Kiefer, 1994). Therefore, remote sensing techniques involve sensors, relations between objects and sensed measurements, data interpretation, photogrammetry, data processing and analysis. When remote sensing is applied to natural environments, spectroradiometry and some 
vegetation indices are widely used. Moreover, different resolutions in spectrum, space, and time have different applications and influence on the results.

Spectroradiometry is the science that studies the spectral responses of an object, area, or phenomenon. Field spectroradiometric study allows the fundamental understanding of relations between spectral responses and studied objects or phenomena. This understanding aids in the interpretation of the remote sensed data and the design of proper sensors for desired research goals.

People identify different objects by their color, size and shape. Color of an object is the spectral reflectance in visible light. The size and shape of objects may also change the spectral reflectance at a given scale of observation. Spectral reflectance is the fraction of electromagnetic energy at a given spectral waveband which is reflected by the observed objects. When electromagnetic energy projects onto an object several different interactions can happen. The interactions can be reflectance, absorption, or transmittance. By applying the principle of conservation of energy, we can state the interrelationship between these three energy interactions as (Lillesand \& Kiefer, 1994)

$$
E_{I}(\lambda)=E_{R}(\lambda)+E_{A}(\lambda)+E_{T}(\lambda)
$$

where

$$
\begin{aligned}
& E_{I}(\lambda)=\text { incident energy }, \\
& E_{R}(\lambda)=\text { reflected energy, } \\
& E_{A}(\lambda)=\text { absorbed energy, and } \\
& E_{T}(\lambda)=\text { transmitted energy. }
\end{aligned}
$$

The type of energy that the human eye or most remote sensing sensors pick up is reflected energy or, in some cases, emitted energy. Some light or energy sources emit high amounts of electromagnetic energy but most vegetation objects do not emit 
significant electromagnetic energy. Therefore, in vegetation remote sensing, reflected energy is still the main focus. Because the reflected energy intensity may change with the incident energy intensity spectral reflectance is used mostly to represent the reflectance characteristics of an object. Its mathematical definition is (Jenson, 2000)

$$
\rho_{\lambda}=\frac{E_{R}(\lambda)}{E_{l}(\lambda)}
$$

where $\rho_{\lambda}$ is the spectral reflectance and is often expressed as a percentage.

Spectral reflectance curves for three basic types of earth features: healthy green vegetation, dry bare soil and clear lake water are demonstrated in Figure 2.2. Water absorbs most incident energy and reflection is low. Green vegetation reflects some electromagnetic energy at the green wavelengths but reflection is high at near infrared wavelengths. Electromagnetic energy reflectance by dry bare soil is high, especially at mid-infrared wavelengths. The difference in the spectral characteristics of these three objects is significantly distinguishable.

The main contributions of vegetation pigments are chlorophyll (green), xanthophylls (yellow), carotene (orange), and anthocyanins (red). Different combinations and types of these pigments readily identify different vegetation species (Figure 2.3). Especially two major types of chlorophylls which exist in most plants and have different reflected patterns for their energy needs in powering photosynthesis. Chlorophylls absorb light mainly in the blue and red regions of the spectrum. The general spectral reflectance pattern of a green healthy plant leaf is illustrated in Figure 2.4. Green-yellow chlorophyll $a$ is present in all living plants and plays a dominant role. Higher-level plants and some green algae contain small quantities of blue-green chlorophyll $b$. Chlorophylls absorb most light in the visible region except that absorption 


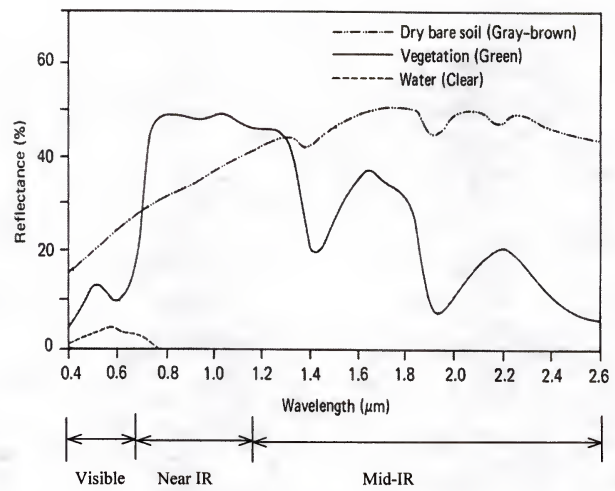

Figure 2.2 Typical spectral reflectance curves for vegetation, soil, and water (adapted from Lillesand \& Kiefer, 1994) 


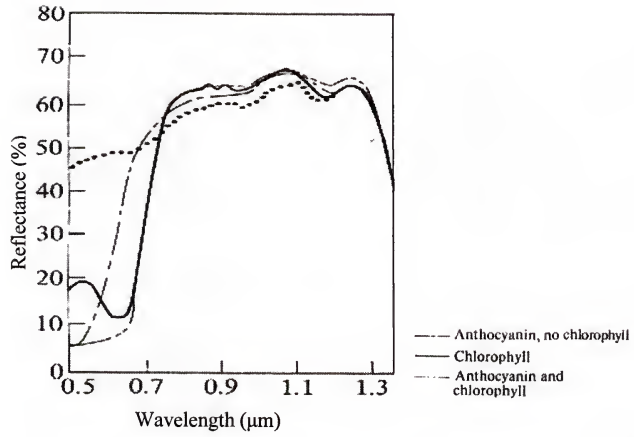

Figure 2.3 Reflected spectra for different combination of chlorophyll, anthocyanin. (adapted from Swain \& Davis, 1978). 


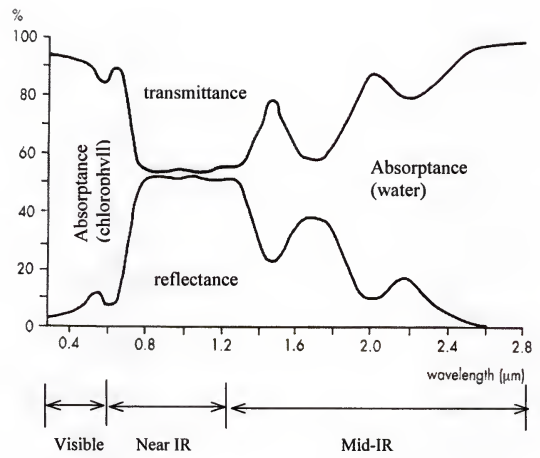

Figure 2.4 Average course of reflectance, absorption, and transmittance of a green healthy plant leaf (adapted from de Boer, 1993) 
in the green region may be slightly less than other visible regions. As a result, the absorption peaks of chlorophylls are approximately $450 \mathrm{~nm}$ and $650 \mathrm{~nm}$, where the reflectance peak is around $540 \mathrm{~nm}$. Most near-infrared light is either reflected or transmitted through leaves. The amount of reflectance in the near infrared region is mainly dependent on leaf mesophyll structure and plant health conditions (Lillesand \& Kiefer, 1994). Mid-infrared light (1300-2500 nm) is mainly absorbed by the water inside plant leaves, so mid-infrared reflectance is a good indicator for the liquid water content of leaves. The water absorption peaks of mid-infrared light falls in the 1400 to $1900 \mathrm{~nm}$ range. Figure 2.5 is an example of how different vegetation species reflect differently. Even though the general reflectance patterns of vegetation are similar, there is still some slight but distinguishable differences between various vegetation species. The spectral characteristics of different vegetation species are usually called spectral signatures. By using spectral signatures of vegetation species one can recognize different vegetation species.

Even for the same plant, spectral reflectance at different growing stages is different. Figure 2.6 shows the spectral reflectance of oak leaves from premature stage to mature stage.

Vegetation spectroradiometry is essential for remote sensing in natural and agricultural environment, and it involves plant physiology. Therefore, for more precise remote sensing application, intensive studies associating vegetation conditions and the relevant spectral responses are desirable. 


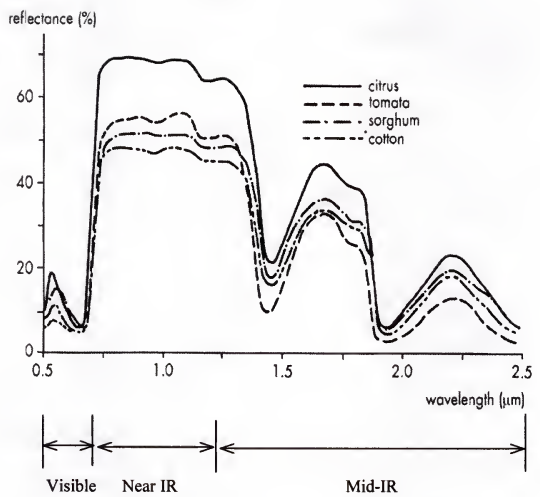

Figure 2.5 Spectral reflectance curves of four agricultural crops (adapted from de Boer, 1993) 
reflectance $(\%)$

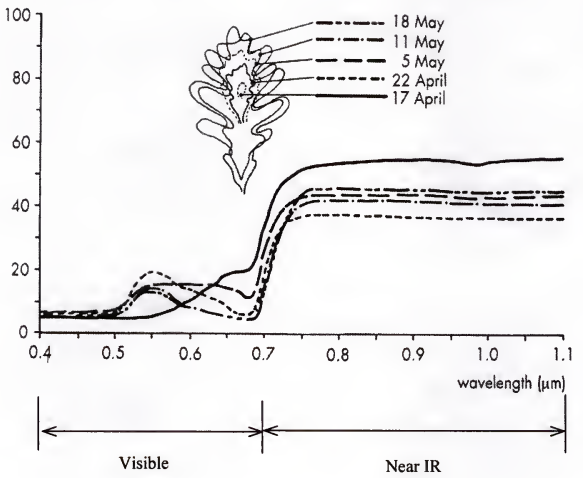

Figure 2.6 Changes in the spectral reflectance of oak leaves during the growing season (adapted from de Boer, 1993). 


\section{CHAPTER 3 \\ MATERIALS AND METHODOLOGY}

\subsection{Study Site Description}

The experimental site is located in the Fort Drum marsh, part of the Fort Drum Marsh Conservation Area (FDMCA), in Indian River county, Florida $\left(27^{\circ} 35^{\prime} 12^{\prime \prime} \mathrm{N}\right.$, $80^{\circ} 41^{\prime} 17^{\prime \prime} \mathrm{W}$, Figure 3.1). The FDMCA is the southern-most headwater area of the St. John's River. It is bordered on the north by State Road 60, on the south by the Florida Turnpike, on the east by a levee adjacent to a private citrus grove, and on the west by the county border between Indian River and Okeechobee counties. The total area of the FDMCA is about 8,300 hectares (Mao \& Rao, 1997). In the central part of the FDMCA is the Fort Drum creek floodplain swamp. The Fort Drum creek floodplain swamp is about 1,200 hectares. The dominant vegetation in the Fort Drum creek floodplain swamp is bald cypress (Taxodium distichum) and Florida elm (Ulmus americana floridana (Chapm.) Little). Most of the land on the west side and southwest side of the Fort Drum creek is dry. The Fort Drum marsh is located on the east side of the Fort Drum creek. The dominant vegetation is sawgrass (Cladium jamaicense Crantz), southern cattail (Typha domingensis Pers.), and ludwigia (Ludwigia spp.) The area of the Fort Drum marsh is around 2,200 hectares

Soils of the Fort Drum marsh are poorly drained hydric organic soils, primarily Gator and Terra Ceia muck (Ponzio, 1995). Under natural conditions, the water table is 


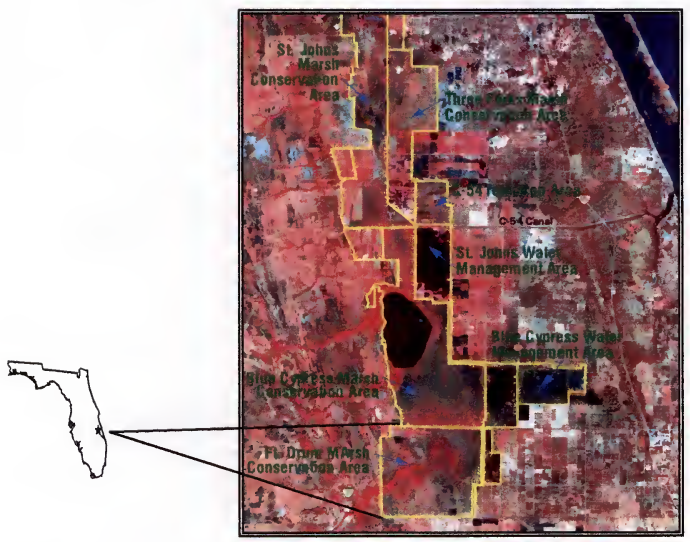

Figure 3.1 Location of the experimental site (adapted from Mao \& Berman, 1999). 
exposed above the surface for most of the year. The soils support vegetation that is typical of freshwater marshes. The sawgrass marsh community is the historical and desired vegetation community in this area (Mao \& Bergman, 1999).

Climate of the study area is subtropical. Summers are long, warm and relatively humid. Winters are generally mild because of the southern latitude and proximity to the Atlantic Ocean. The mean temperature is $22.2 \mathrm{C}$ (Mao \& Bergman, 1999). July and August temperatures are the warmest. December and January are the coolest months. The normal annual rainfall (1960-1990) measured at Fort Drum is $125.5 \mathrm{~mm}$ (Rao et al., 1995). Generally, more than 60 percent of the annual rainfall occurs during a five-month period, June through October (Mao \& Bergman, 1999).

A lysimeter system including three lysimeters and a weather station was installed in the Fort Drum marsh (Figure 3.2, Mao \& Bergman, 1999) in 1996. The three lysimeters installed at the experimental site contain cattail $\left(27^{\circ} 34^{\prime} 51^{\prime \prime} \mathrm{N}, 80^{\circ} 41^{\prime} 19^{\prime \prime} \mathrm{W}\right.$; Figure B.1), sawgrass $\left(27^{\circ} 35^{\prime} 12^{\prime \prime} \mathrm{N}, 80^{\circ} 41^{\prime} 18^{\prime \prime} \mathrm{W}\right)$, and open water $\left(27^{\circ} 35^{\prime} 23^{\prime \prime} \mathrm{N}\right.$, $\left.80^{\circ} 41^{\prime} 14^{\prime \prime} \mathrm{W}\right)$. The vegetation with soil within a given lysimeter was transplanted from the surrounding area so that the lysimeter represents common environmental features.

Each lysimeter, made of polyethylene having a thickness of $5 \mathrm{~mm}$, has a surface area of $9.8 \mathrm{~m}^{2}$ and is $1.0 \mathrm{~m}$ deep. The bases of all three lysimeters were filled with $65 \mathrm{~cm}$ of subsoil from the surrounding area. Mature cattail and sawgrass plants were transplanted to the lysimeters. Marsh water was added to within $7 \mathrm{~cm}$ of the tank top and fluctuations in water level were controlled within a range of $3.8 \mathrm{~cm}$ using an automated inflow-outflow pump. Volume of inflow and outflow was recorded by the flow meters and water level was also monitored using electronic sensors. Data were recorded by data 
loggers (Model CR10, Campbell Scientific, Inc., Logan, Utah) and transmitted via radio transmission.

A weather station $\left(27^{\circ} 35^{\prime} 21^{\prime \prime} \mathrm{N}, 80^{\circ} 41^{\prime} 16^{\prime \prime} \mathrm{W}\right)$ was placed adjacent to the three lysimeters (Figure B.2). Solar radiation, net radiation, photosynthetic photon flux density, air temperature, marsh water temperature, relative humidity, atmospheric pressure, wind speed, wind direction, and rainfall were continuously recorded. Wind speed at a height of $10 \mathrm{~m}$ above ground level was measured every 15 minute. All other parameters were measured every 5 minutes, with average values being recorded every 15 minutes. All recorded data was transmitted via radio transmission.

\section{$\underline{3.2 \text { Fundamental Study of Wetland ET }}$}

The fundamental wetland ET study involved several interests and included several procedures. First, a sound lysimeter system was installed and continuously operated. Then, proper sampling procedures and routine field trips were executed in order to measure the related vegetation parameters. The collected lysimeter data and field measurements were then analyzed statistically and different ET estimation methods were also tested for validity.

\subsubsection{Vegetation Parameters Measurements}

Vegetative parameters related to ET estimation were measured seasonally. A sampling procedure was implemented so that the measurements could represent the total plant community within the lysimeters. Four $59 \times 59 \mathrm{~cm}$ wood frames were placed in four quarters of each lysimeter. The vegetative parameters were sampled and measured 


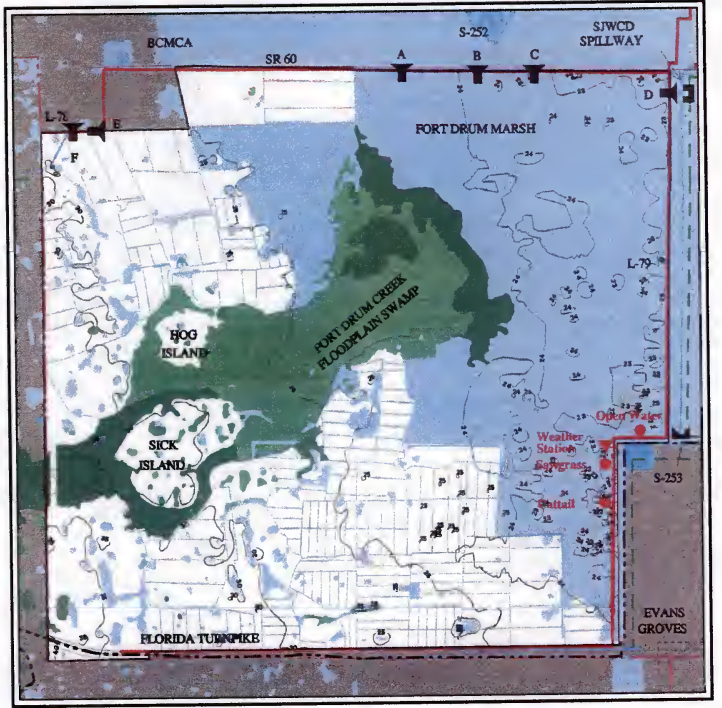

Figure 3.2 Location of lysimeters and Fort Drum marsh (Mao \& Berman, 1999). 
within each frame. This procedure not only reduces the sample size but can also maintain a nearly random sample pattern. The total sampled area is about $1 / 5$ of the total surface area of lysimeter.

The measuring procedure and definition of each parameter was described as follows:

1. Plant canopy height

The plant canopy height (in units of $\mathrm{cm}$ ) is defined as the distance between the canopy component of interest and the water surface. Plant heights were measured by placing a measuring stick vertically adjacent to selected plants and recording the distance from the canopy component to water surface. Three measurements were recorded for each frame. The mean height was the average of the 12 measurements.

2. Plant density

Plant density (in units of stem $\mathrm{m}^{-2}$ ) is defined as the number of plant stems per unit area. The number of plants inside each frame was counted and recorded for each of four frames. Mean plant density was calculated as the average stem count dividing by the area of the frame.

\section{Air temperature and leaf surface temperature}

Air temperature is the temperature of air surrounding the measuring instrument, usually $1.5 \mathrm{~m}$ above the ground surface. Leaf surface temperature is the temperature of the very top layer at the leaf surface. Leaf surface temperature was measured with an infrared thermometer (Model 210, Everest Interscience Inc., Tucson, Arizona). Surface temperature can be read from a thermometer LCD panel by pointing it to a leaf and 
triggering it. The difference of surface temperature and air temperature can also be read from the thermometer LCD pane.

4. Leaf transpiration, stomatal diffusive resistance, and photosynthetic photon flux density (PPFD)

Leaf transpiration (Tr) is defined as the mass rate of water vapor from the leaf per unit area (in unit of $\mu \mathrm{g} \mathrm{cm}^{2} \mathrm{~s}^{-1}$ ). The LI-COR steady state porometer was designed to calculate transpiration by the following equation (LI-COR, 1984):

$$
T_{r}=\frac{m_{w l}}{A_{a p}}
$$

where $m_{w l}$ is the mass rate of water vapor from the leaf and $A_{a p}$ is the area of the aperture in use on the cuvette of the porometer.

Stomatal resistance has several definitions. The following definition was used by the LI-COR steady state porometer to calculate the stomatal resistance:

$$
\text { Stomatal resistance }=\frac{\text { Water vapor density gradient }}{\text { Transpiration }}
$$

Photosynthetic Photon Flux Density (PPFD) is the measurement of the photosynthetically active radiation (PAR) ranged within the wavelengths of 400 to $700 \mathrm{~nm}$. The unit of PPFD is micromoles per square meter per second $\left(\mu \mathrm{mol} \mathrm{m} \mathrm{m}^{-1}\right) .1 \mu \mathrm{mol} \mathrm{m} \mathrm{s}^{-2}=6.023 \times 10^{23}$ photons.

The leaf transpiration, stomatal resistance, and Photosynthetic Photon Flux Density (PPFD) were measured with the LI-COR steady state porometer (Model 1600, LI-COR, Inc., Lincoln, Nebraska). A plant was selected randomly within each sampling frame. Six different locations of the selected plant were measured for their leaf transpiration, stomatal resistance, and PPFD. The plant was first separated 
into three parts: inner, middle, and outer. Then, each part was divided into upper and lower portions. Therefore, measurements were made for each portion in order to describe the spatial difference of measurements.

5. Weighted Stomatal Resistance

In order to compare the stomatal resistance at the same basis of mean PPFD value of several measurements, the weighted value of stomatal resistance was weighted by mean PPFD value and PPFD value at the time of measurement. Stomatal resistance was weighted by mean PPFD value and PPFD value at the time of measurement by the following equation (Abtew et al., 1995):

$$
R_{s w i}=\frac{P P F D_{m e a n} \times R_{s i}}{P P F D_{i}}
$$

where

$$
\begin{aligned}
& R_{s w i}=\text { weighted stomatal resistance of the } i \text {-th measurement, } \\
& P P F D_{\text {mean }} \quad=\text { mean of all PPFD values, } \\
& R_{s i} \quad=\text { the } i \text {-th measurement of stomatal resistance, and } \\
& P P F D_{i}=\text { the } i \text {-th measurement of PPFD. }
\end{aligned}
$$

6. Canopy resistance

The resistance for the water vapor exchange of a canopy which is in terms of integral resistance of leaf stomatal resistance and boundary resistance in each leaf.

The canopy resistance can be calculated by the following equation (Abtew and Obeysekera, 1995):

$$
R_{c}=\frac{R_{i}}{0.5 L A I}
$$

where 


$$
\begin{aligned}
& R_{c} \quad=\text { canopy resistance, } \\
& R_{i} \quad=\text { stomatal resistance, } \text { and } \\
& L A I \quad=\text { Leaf Area Index. }
\end{aligned}
$$

7. Leaf Area Index (LAI)

Leaf area index (LAI) is defined as total area of green leaves (one side only) from plants within a given area divided by the ground surface area from which these plants are grown (in units of percent or dimensionless).

Leaf area index was calculated as the average leaf area per plant multiplied by the average number of plants per frame and further divided by the area of the frame. Three cattail and two sawgrass plants (entire plant) were cut and brought back from the Fort Drum marsh area to the lab for leaf area measurement. All leaves of the plant were separated and measured individually with the LI-COR portable area meter (model LI-3000, LI-COR, Inc., Lincoln, Nebraska). The LAI was calculated by the following equation:

$$
L A I=(\text { mean leaf area per plant }) \times(\text { plant density })
$$

8. Plant fresh biomass

Plant fresh biomass is defined as the mass of fresh plant material within a defined area divided by the area size, and measured in units of $\mathrm{gm}^{-2}$. In order to retain the integrity of the lysimeter, fresh biomass was determined with plants from outside the tank. The aforementioned frame (see 3.2.1) was placed in the cattail and sawgrass marshes outside the lysimeter. All the vegetation within the frame was harvested and weight of all the vegetation was measured using a Mettler PC 440 scale. 
9. Dry biomass

The dry biomass is defined as the mass of dry plant material within a defined area divided by the area size, and measured in units of $\mathrm{g} \mathrm{m}^{-2}$. The dry plant was obtained by oven-drying with a temperature setting at 70 degree centigrade for a 72 hour period.

After the weight of fresh biomass was measured, the vegetation was then placed into an oven for 72 hours with the temperature setting at $70^{\circ} \mathrm{C}$. The weight of all the vegetation after oven-drying was measured using a Mettler PC 440 scale. The dry biomass was the vegetation weight at the end of the 72 hours dry period.

\subsubsection{Estimation of Canopy Resistance}

During the two year monitoring period of this project, a large variability of stomatal resistance was observed. This anomaly has also been observed by other researchers (Saguaro, 1990; Abtew et al., 1995). Abtew et al. (1995) suggested using the combination of stomatal resistance in upper and lower portions of inner, middle, outer parts of leaves to represent the canopy resistance. However, problems still remain because there is still a large variability of stomatal resistance values within each portion of the leaves. Unless the leaves are separated into sufficiently small portions where the variability of stomatal resistance values can be neglected, the suggested method is not practical. Therefore, to reduce the variability of stomatal resistance, an alternative approach is needed.

Some measurements of cattail stomatal resistance in Gainesville, Florida were made in April 1998. The results showed that the stomatal resistance of cattail is very likely to be linearly related to plant height. Therefore, an additional field trip (Aug. 29, 
1998) was made using a different procedure. In this additional field trip, stomatal resistance was measured along the plant height to study the stomatal resistance of cattail and sawgrass in the Fort Drum study area. The revised procedures are described in the following paragraphs,

\subsubsection{Revised procedure of measuring stomatal resistance}

The definition of stomatal resistance and the measuring instrument is the same. However, instead of measuring stomatal resistance in the upper and lower portions of the inner, middle, and outer parts of leaves, the stomatal resistance values were measured along the leaves at locations of different heights.

\subsubsection{Revised procedure of measuring LAI}

The definition and the measuring procedure of LAI is the same LAI. However, instead of measuring the total leaf area above water surface, plant leaves were divided into several sections along different height locations and were measured. To represent the LAI contributed by the leaves above the relevant height location, LAI was calculated as the leaf area above different height locations divided by the sampling ground surface area.

\subsubsection{Methods for Evapotranspiration Estimation}

Among the conventional methods for the calculation of reference crop ET (including pan evaporation techniques), the following methods are most common (Doorenbos and Pruitt, 1977; Smith, 1992), Priestley-Taylor (Jensen et al., 1990), and Penman-Monteith (Monteith, 1990). Because there are various forms for these methods, the forms used in this research are described in the following paragraphs. 


\subsubsection{Modified FAO Penman method}

In the late 1990s, The original FAO-24 Penman combination method (Doorenbos and Pruitt, 1977) was revised by several authors (Jensen et al., 1990; Smith 1992). The modified Penman combination equation has the form:

$$
\begin{aligned}
& \lambda E T=\frac{\Delta}{\Delta+\gamma}\left(R_{n}-G\right)+\frac{\gamma}{\Delta+\gamma} 6.43 W_{f}\left(e_{z}^{0}-e_{z}\right) \\
& W_{f}=a_{w}+b_{w} u_{2}
\end{aligned}
$$

where

$$
\begin{array}{ll}
\lambda & =\text { latent heat of evaporization }\left(\mathrm{MJ} \mathrm{kg}^{-1}\right), \\
\Delta & =\text { slope of vapor pressure curve }\left(\mathrm{kPa}^{\circ} \mathrm{C}^{-1}\right), \\
\gamma & =\text { psychrometric constant }\left(\mathrm{kPa}^{\circ} \mathrm{C}^{-1}\right), \\
R_{n} & =\text { net radiation }\left(\mathrm{MJ} \mathrm{m}^{-2} \mathrm{~d}^{-1}\right), \\
G & =\text { ground heat flux }\left(\mathrm{MJ} \mathrm{m}^{-2} \mathrm{~d}^{-1}\right), \\
W_{f} & =\text { wind function, } \\
u_{2} & =\text { wind speed at } 2-\mathrm{m} \text { height }\left(\mathrm{m} \mathrm{s}^{-1}\right), \text { and } \\
a_{w}, b_{w} & =\text { wind function coefficients. }
\end{array}
$$

\section{Latent heat of vaporization}

Latent heat of vaporization was estimated by an equation provided by Harrison (1963) as:

$$
\lambda=2.501-2.361 \times 10^{-3} T
$$

where

$$
T=\text { air temperature }\left({ }^{\circ} \mathrm{C}\right) \text {. }
$$




\section{$\underline{\text { Saturation vapor pressure }}$}

The saturation vapor pressure was estimated by an expression (Murray, 1967):

$$
e^{0}=\exp \left(\frac{16.78 T-116.9}{T+237.3}\right)
$$

where $T=$ air temperature $\left({ }^{\circ} \mathrm{C}\right)$.

Slope of the saturation vapor pressure curve

The slope of the saturation vapor pressure curve was calculated by differentiating the equation for saturation vapor pressure:

$$
\Delta=\frac{4098 e^{0}}{(T+237.3)^{2}}
$$

where

$$
\begin{array}{ll}
e^{0} & =\text { saturation vapor pressure }(\mathrm{kPa}), \text { and } \\
T & =\text { air temperature }\left({ }^{\circ} \mathrm{C}\right) .
\end{array}
$$

\section{Psychrometric constant}

The psychrometric constant, $\gamma$, represents a balance between the sensible heat gained from air and the sensible heat transformed into latent heat (Brunt, 1952) and is calculated as:

$$
\gamma=\frac{c_{p} P}{0.622 \lambda}
$$

where

$$
\begin{array}{ll}
P & =\text { atmospheric pressure }(\mathrm{kPa}) ; \\
c_{p} & =\text { specific heat of moist air at constant pressure, } 1.013 \mathrm{~kJ} \mathrm{~kg}^{-1}{ }^{\circ} \mathrm{C}, \\
& \text { and } \\
\lambda & =\text { latent heat of vaporization }\left(\mathrm{kJ} \mathrm{kg}^{-1}\right) .
\end{array}
$$




\section{Penman wind function}

The wind function used in the Penman combination equation was determined by Wright (1982) as:

$$
\begin{aligned}
& W_{f}=a_{w}+b_{w} u_{2} \\
& a_{w}=0.4+1.4 e^{-\left(\frac{D-173}{58}\right)^{2}} \\
& b_{w}=0.605+0.345 e^{-\left(\frac{D-243}{80}\right)^{2}}
\end{aligned}
$$

where

$$
\begin{aligned}
& u_{2} \quad=\text { wind speed at } 2 \text { meter height }\left(\mathrm{m} \mathrm{s}^{-1}\right), \text { and } \\
& D \quad=\text { day of the year. }
\end{aligned}
$$

\subsubsection{Priestley-Taylor method}

The Priestley-Taylor method is an empirical radiation-based equation with the following general form (Jensen et al., 1990):

$$
\lambda E T=\alpha \frac{\Delta}{\Delta+\gamma}\left(R_{n}-G\right)
$$

where

$$
\begin{array}{ll}
\lambda & =\text { Latent heat of evaporization }\left(\mathrm{MJ} \mathrm{kg}^{-1}\right), \\
\alpha & =\text { Priestley-Taylor constant with a locally calibrated value of } 1.18 \\
& \text { for cattail (Abtew and Obeysekera, } 1995), \\
\Delta \quad & =\text { slope of vapor pressure curve }\left(\mathrm{kPa}^{\circ} \mathrm{C}^{-1}\right), \\
\gamma & =\text { psychrometric constant }\left(\mathrm{kPa}^{\circ} \mathrm{C}^{-1}\right), \\
R_{n} & =\text { net radiation }\left(\mathrm{MJ} \mathrm{m}^{-2} \mathrm{~d}^{-1}\right), \text { and }
\end{array}
$$




$$
G \quad=\text { ground heat flux }\left(\mathrm{MJ} \mathrm{m}^{-2} \mathrm{~d}^{-1}\right) .
$$

\subsubsection{Penman-Monteith Combination method}

The Penman-Monteith combination method included the addition of a surface and aerodynamic resistance function to the Penman equation:

$$
\lambda E T=\frac{\Delta\left(R_{n}-G\right)+\frac{\rho c_{p}}{r_{a}}\left(e_{z}^{0}-e_{z}\right)}{\Delta+\gamma^{*}}
$$

where

$$
r_{a}=\frac{\ln \left[\frac{\left(z_{w}-d\right)}{z_{o m}}\right] \ln \left[\frac{\left(z_{p}-d\right)}{z_{o v}}\right]}{k^{2} u_{z}}
$$

and

$$
\gamma^{*}=\gamma\left(1+\frac{r_{c}}{r_{a}}\right)
$$

where

$$
\begin{array}{ll}
\rho & =\text { atmospheric density }\left(\mathrm{kg} \mathrm{m}^{-3}\right), \\
c_{p} & =\text { specific heat of moist air }\left(\mathrm{kJ} \mathrm{kg}^{-1}{ }^{\circ} \mathrm{C}^{-1}\right), \\
r_{a} & =\text { aerodynamic resistance }\left(\mathrm{s} \mathrm{m}^{-1}\right), \\
r_{c} & =\text { canopy resistance }\left(\mathrm{s} \mathrm{m}^{-1}\right), \\
z_{w} & =\text { height of the wind speed measurement }(\mathrm{m}), \\
z_{p} & =\text { height of the humidity and temperature measurement }(\mathrm{m}), \\
z_{o m} & =\text { roughness length for momentum transfer }(\mathrm{m}), \\
z_{o v} & =\text { roughness length for vapor transfer }(\mathrm{m}),
\end{array}
$$




$$
\begin{array}{ll}
u_{z} & =\text { wind speed at height } \mathrm{z}_{\mathrm{W}}\left(\mathrm{m} \mathrm{s}^{-1}\right), \text { and } \\
k & =\text { von Karman's constant, } 0.41 \text { (dimensionless). }
\end{array}
$$

Some of the parameters can be computed as:

$$
\begin{aligned}
& z_{o m}=0.123 \mathrm{~h}_{\mathrm{c}}, \mathrm{h}_{\mathrm{c}} \text { is mean height of crop canopy in } \mathrm{mm}, \\
& z_{o v} \quad=0.1 \mathrm{z}_{\mathrm{om}}, \text { and } \\
& d \quad=(2 / 3) \mathrm{h}_{\mathrm{c}} .
\end{aligned}
$$

The above are the common methods for crop ET estimation. The Priestley-Taylor method focuses mainly on energy balance where the Penman and Penman-Monteith methods are combination methods.

\subsection{Spectroradiometry on the Responses of Vegetation Parameters}

The spectral reflectance of different vegetation parameters was analyzed in this section. In addition to the spectral response of different vegetation types, two vegetation parameters related to ET estimation, stomatal resistance and LAI, were also considered.

\subsubsection{Monitoring of Spectral Responses}

The plant spectral response curves were measured with a GER-1500 hand-held spectroradiometer with 512 different wavelength bands ranging from $350 \mathrm{~nm}$ to $1050 \mathrm{~nm}$ (Model GER-1500, Geophysical \& Environmental Research Corp., Millbrook, New York). A Spectralon diffuse white standard plate (SRT-99-50) calibrated by Labsphere (Labsphere, Inc., North Sutton, New Hampshire) was used as a standard to calibrate the reflectance curve. The Spectralon diffuse white standard plate is made of a polytetrafluoroethylene (PTFE) compound which maintains strong spatial and spectral 
uniformity and stability over time (Bruegge et al., 1995). It reflects $99 \%$ of incident light uniformly from ultraviolet, visible to near infrared wavelengths. The measuring process with the standard white plate is to record a measurement of the standard white plate as a reference reading and then to record a measurement of the target object with the same measuring angle. In this manner, one can compare the reflected radiance of the target object using that of the reference white plate. The spectral readings can be stored and downloaded using a RS-232 serial port. The spectroradiometer can also be operated in a laptop PC with a RS-232 serial port connection. After the spectral readings were downloaded, the spectral reflectance was calculated (in an expression of percentage) by dividing the plant spectral reading with the spectral reading of the white standard plate.

$$
R_{\text {tar }}=\frac{\operatorname{Rad}_{\text {tar }}}{\operatorname{Rad}_{\text {ref }}} \times 100 \%
$$

where

$$
\begin{aligned}
& R_{\text {tar }} \quad=\text { spectral reflectance of a target object (\%), } \\
& \operatorname{Rad}_{\text {tar }}=\text { reflected radiance form a target object }\left(\mathrm{W} \mathrm{cm}^{-2} \mathrm{~nm}^{-1} \mathrm{sr}^{-1} \times\right. \\
& \left.10^{-10}\right) \text {, and } \\
& \operatorname{Rad}_{\text {ref }}=\text { reflected radiance form a target object }\left(\mathrm{W} \mathrm{cm}^{-2} \mathrm{~nm}^{-1} \mathrm{sr}^{-1} \times\right. \\
& \left.10^{-10}\right) \text {. }
\end{aligned}
$$

From 1996 to 1997, during the field trips for measuring the vegetation parameters, the spectral reflectance of sawgrass and cattail were also measured for further analysis

Normalized difference vegetation index (NDVI), Green NDVI, and different band ratios were applied to examine the spectral reflectance of cattail and sawgrass. NDVI is widely used for identifying the spectral characteristics of vegetation. The definition of NDVI is 


$$
N D V I=\frac{(N I R-R)}{(N I R+R)}
$$

where

$$
\begin{aligned}
& N I R \quad=\text { the spectral reflectance in the near infrared region, and } \\
& R \quad=\text { the spectral reflectance in the red region. }
\end{aligned}
$$

Gitelson et al. (1996) analyzed the spectral reflectance of different concentration of algae, and found that by using a green waveband instead of a red waveband in the NDVI definition, it could better distinguish different algae concentration. Therefore, they suggested the green NDVI as

$$
\text { Green } N D V I=\frac{(N I R-G)}{(N I R+G)}
$$

where $G$ is the spectral reflectance in the green region.

Band ratios are also commonly used to observe the features of different objects. The definition of band ratio is

$$
\text { Band ratio }=\frac{\text { Band } 1}{\text { Band } 2}
$$

where Band 1 and Band 2 are the wavebands selected by users.

The regions of blue, green, red, and near infrared regions wavebands were selected to match the spectral regions of the wavebands in the Landsat-7 ETM+ scanner (Table 3.1; Landsat Project Science Office, 2001 ). 
Table 3.1 Spectral regions of different wavebands in the Landsat-7 ETM+ scanner.

\begin{tabular}{ll}
\hline Spectral waveband & Spectral region \\
\hline Blue & $450-520 \mathrm{~nm}$ \\
Green & $520-600 \mathrm{~nm}$ \\
Red & $630-690 \mathrm{~nm}$ \\
Near infrared & $760-900 \mathrm{~nm}$ \\
\hline
\end{tabular}

\subsubsection{Spectral Analysis of Stomatal Resistance}

On May 28, 1999 a field trip was made to measure the stomatal resistance and spectral responses of cattail and sawgrass. The measuring equipment was the same as described in the previous section. In order to show significant spectral responses at different stomatal resistance, the measuring process started at 7:00 AM. Due to the increasing available solar radiation stomatal resistance decreased with the rising sun.

A mature leaf was selected from each sawgrass and cattail lysimeter. In each leaf, around $15 \mathrm{~cm}$ from the leaf top, a point was marked and selected to be the measuring point. The dew, if present, on the measuring points was wiped off by tissues. Then, stomatal resistance was measured first, followed by the measurement of spectral reflectance. Measuring first started in the cattail lysimeter. After the measurements in the cattail lysimeter were completed, all equipment was moved to the sawgrass lysimeter and the measuring process resumed. The measuring procedures were switched and repeated back and forth between the measuring points in the sawgrass and cattail 
lysimeters until the stomatal resistance did not show significant change. In other words, the measuring ceased when the stomatal resistance neared the lowest values.

NDVI, Green NDVI, and different band ratios were also applied to examine the spectral reflectance of cattail and sawgrass. As in the previous section, the spectral regions of different wavebands were selected to match the spectral regions of the wavebands in the Landsat-7 ETM+ scanner

\subsubsection{Spectral Analysis of LAI}

LAI is another important vegetation parameter for ET estimation. Higher LAI tends to result in higher transpiration. A field trip was made on May 26, 1999 to measure the LAI of cattail and sawgrass and the corresponding spectral reflectance. The assistance of an airboat was not available at that time and without an airboat it was difficult to measure LAI inside the marsh. Therefore, the measuring points were acquired along the dike and this limited the number of measuring points.

Along the dike, as many measuring points as possible were selected. At each measuring point the spectral reflectance was measured using the GER-1500 spectroradiometer. Then, the dead leaves were cleared and the LAI of live leaves was measured.

In addition, to display the spectral reflectance curves, some indices frequently used in remote sensing were entered into the analyses. As in the previous section, those indices were NDVI, green NDVI, and band ratios with different band combinations. The spectral regions of different wavebands were selected. 


\subsection{Aerial Hyperspectral Imaging}

In this research, aerial imaging as the meso-scale remote sensing technique is the key linkage between the ground microscale remote sensing study and the satellite macroscale remote sensing study. Therefore, the design and execution of the aerial imaging mission was important in this research.

There are many different types of aerial images. Traditionally, the available remote sensed data from an airplane were aerial photos. As technology has developed, the available remote sensed data can now be obtained from different types of digital imagers. Moreover, many different new types of sensors for aerial imaging are being developed and under experiment.

With the courteous assistance of the Institute of Technology Development, Stennis Space Center, NASA, flights with an experimental hyperspectral imager were employed. The hyperspectral imager is band-adjustable and can have a maximum of 128 wavebands. Due to the limitation of the transfer rate and the storage capacity, the number of available wavebands is directly related to the pixel size and therefore inversely to the imaged area. In this research, 64 wavebands with the pixel size of 1 meter and a wavelength range from $399.2 \mathrm{~nm}$ to $920.5 \mathrm{~nm}$ were selected. Moreover, because of the storage capacity of the hyperspectral imager systems, the imaging area was limited to within $1500 \times 2000$ meters. As a result of the limitation, the aerial imaging area was limited to the parts of the Fort Drum marsh around the lysimeters (Figure 3.3). 


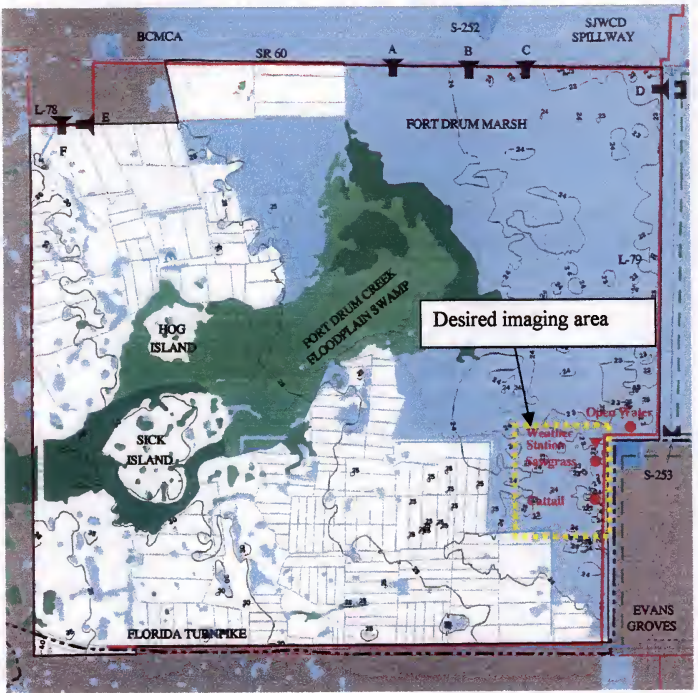

Figure 3.3 Desired aerial hyperspectral imaging area (the yellow square). 


\subsubsection{Preparations Before Aerial Imaging}

Utilizing aerial hyperspectral images usually generates two main concerns. First, due to the current data transferring speed and storage capacity of storage devices, many hyperspectral imagers are not fixed-frame imaging systems. In other words, hyperspectral imagers may scan line by line along a track or scan back and forth across a track. Because of the flying instability of the airplane, keeping the imager scanning ground areas exactly along the designated route is difficult, so it usually results in more distortion than fixed-frame imagers (Lee et al., 2000). Under this circumstance, a set of dense ground control points is required.

Secondly, the hyperspectral imager measures reflected radiances of ground objects which may change with respect to incoming radiances and may be compared with other images of the same objects taken under different light conditions. The more useful measuring unit to represent the signatures of measured objects is the ratio of the reflected radiance of an object to the incoming radiance. In order to convert the values of spectral radiance to spectral reflectance, a set of reference calibration panels is essential.

Therefore, to complete an aerial imaging mission, a set of bright white geolocation targets and a set of calibration panels with different gray levels, from visible wavebands and infrared wavebands, were made and placed in the target imaging area.

\subsubsection{Preparation of geolocation targets}

Because the imaging area was a marsh, the geolocation targets needed to be water-proof, floatable, and anchorable in the marsh. One meter by one meter white foam boards coated with plastic films were used as geolocation targets. They were used because they are water-proof, floatable and, with plastic films, are more resistant to 
bending stress. Two wooden sticks crossing each other were affixed on the back of each white foam board to increase its resistance to wind and waves. A fishing line with 100 lbs resistance was tied onto the wood frame and linked to a concrete block serving as an anchor (Figure B.3). If the geolocation targets were placed adjacent to plants, then the targets were taped to the plants to ensure higher fixation.

Before the imaging day, an airboat trip was taken in the Ft. Drum Marsh toplace the geolocation targets and record their coordinates using a code differential GPS unit (Model Pathfinder Pro XR, Trimble Navigation, California).

\subsubsection{Preparation of calibration panels}

There are few companies that make large size calibration panels with an assortment of standard reflectance gray shades. Such calibration panels are ideal for this type of research but sometimes beyond the budgets of research centers at university and local government levels. Therefore, other alternative materials were used.

Spectral reflectance of cloths in local textile stores were examined using the GER1500 spectroradiometer. An ideal fabric is expected to be able to reflect a similar percentage of incident light at each wavelength through the ultra violet, visible and nearinfrared spectral regions. Most white, gray, or black cloths were found to be unsuitable and did not uniformly reflect in the near-infrared spectral region. After an extensive search through local fabric stores, some black, white and white-meshy fabrics were found to reflect uniformly from the blue waveband through near infrared wavebands. Those fabrics were purchased, sewed, and properly layered to make five calibration panels with a size of $3.7 \times 3.7$ meters (Figure B.4). To prevent the spectral quality from being influenced by moisture and dirt, each calibration panel was attached to a piece of black 
plastic tarpaulin. The spectral reflectance of the calibration panels is $4 \%, 10 \%, 25 \%, 45 \%$, and $56 \%$, respectively (Figure 3.4 ).

\subsubsection{Setup for Aerial Hyperspectral Imaging}

In order to obtain the most significant information from the results of the airborne hyperspectral images and their comparison to the satellite images, the ideal imaging data would be calculated on or nearest to the days when the Landsat 7 would pass over the study area. In Florida, spring is usually the least cloudy season. Thus, the imaging days around April 25 and May 11, 2000, which were Landsat 7 satellite flyover days, were considered. Before aerial imaging on the imaging day the calibration panels and extra geolocation targets were placed along the dike of the Ft. Drum Marsh. In order to avoid shadowing from the airplane and tall vegetation, the aerial imaging was taken from two different directions, north to south and west to east.

\subsubsection{Ground Truthing}

After the aerial imaging was completed, ground truthing was performed via airboat. Based upon the results of an unsupervised classification performed in a 1999 aerial image (Figure 3.5), there were some classes of vegetation, based upon the spectral characteristics, which were identifiable. The same basic flyover pattern used in the collection of the 1999 images was followed for this second serial image collection. Each geographical location point was first measured by the GPS unit. Then, the plants as well as their growth stages were identified. The spectral reflectance was also measured using a spectroradiometer. 


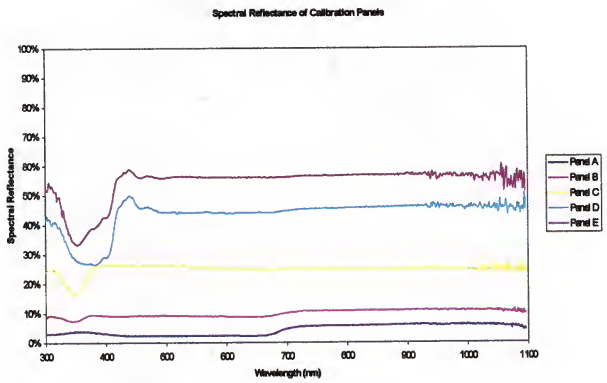

Figure 3.4 Spectral reflectance of the calibration panels. 


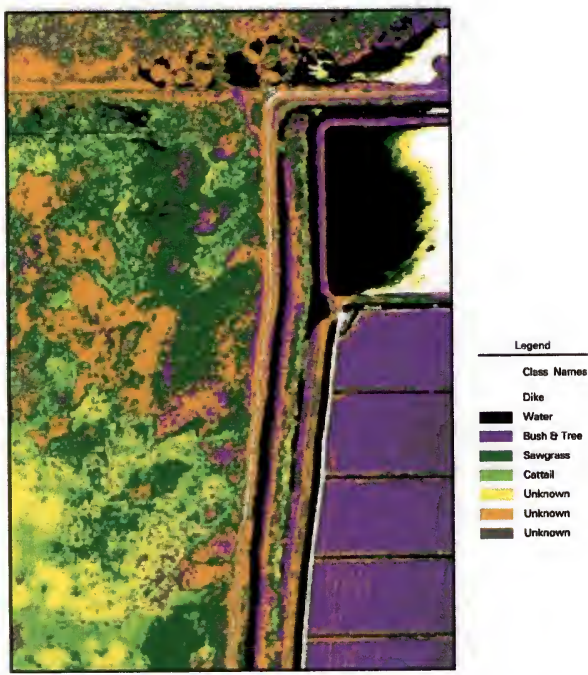

Figure 3.5 Possible classes in the aerial hyperspectral imaging area according to the 1999 aerial image of the same fly over path. 


\subsubsection{Hyperspectral Image Processing and Calibration}

Raw images usually contain some spatial distortion and the digital number in each pixel only represents the relative reflected radiance. Therefore, for further application, geometric rectification and radiometric calibration is required.

\subsubsection{Geometric rectification}

Raw digital images usually are not suitable for use as maps because they contain significant geometric distortion. These distortions may be a result of platform instability and airplane motions such as roll, pitch, and yaw, when using an along-track type hyperspectral imager. This distortion may be corrected by analyzing a set of well distributed ground control points (GCPs) in the imaging area. The actual coordinates of the GCPs need to be known and the positions (column and row) of these GCPs must be identifiable from the images. The relationship between the actual coordinates and the positions on the image can be tested using different test functions. The most desirable function is the one containing the minimum errors. Once the function is selected and the relevant coefficients are obtained, the raw image can be transferred into the map coordinate system by applying the function and coefficients. This process can be explained by the following mathematic expression (Lillesand \& Kiefer, 1994)

$$
\begin{aligned}
& x=f_{1}(X, Y) \\
& y=f_{2}(X, Y)
\end{aligned}
$$

where

$$
\begin{aligned}
& (x, y)=\text { map coordinates, } \\
& (X, Y)=\text { image position (column, row), and } \\
& f_{1}, f_{2}=\text { transformation functions. }
\end{aligned}
$$


Typical transformation functions can be linear or of various order polynomial functions. However, depending on the type of distortion, other functions may be applicable.

\subsubsection{Radiometric calibration}

In most digital images, the digital number in each pixel may only represent relative reflected radiance. The actual reflectance in each pixel requires further calibration.

The task of the radiometric calibration in hyperspectral imaging contains two steps. The first step is to calculate the wavelength of each waveband. Because the employed hyperspectral imager is tunable, the actual wavelength of each waveband may vary at every adjustment. At certain wavelengths, when solar radiation permeates the atmosphere, radiation is absorbed by some gases such as carbon dioxide, water vapor, and ozone. At those wavelengths, the actual radiance is minute (Figure 3.6). Therefore, these atmosphere-absorbed wavelengths can be easily identified from the hyperspectral images and the wavelength of each hyperspectral waveband can be calibrated using these known atmosphere-absorbed wavelengths.

The employed imager uses a liquid crystal filter to spread the incoming radiance into different spectra. Because the imager is still under experiment, and of different adjustments, the spectral spreading of liquid crystal may vary. Therefore, a piecewise linear function was used for the calibration function. Because the spectral reflectance percentage from the calibration panels was known and used as references, digital numbers at each waveband in the uncalibrated image were linearly interpolated. This method can be expressed mathematically as 


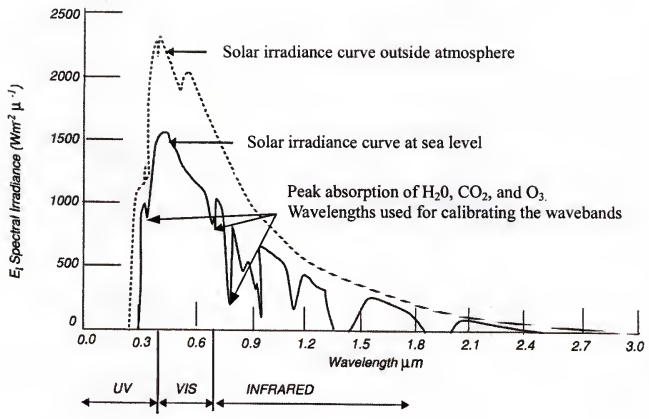

Figure 3.6 Atmospheric absorption effects especially at some particular wavelengths (adapted from Erdas, 1995). 


$$
\begin{aligned}
& \text { IF } D N \in\left(D N_{i}, D N_{i+1}\right) \\
& \text { then } R=\frac{R_{i+1}-R_{i}}{D N_{i+1}-D N_{i}} \times\left(D N-D N_{i}\right)+R_{i}
\end{aligned}
$$

where

$$
\begin{aligned}
& D N \quad=\text { digital number of a pixel } \\
& R \quad=\text { spectral reflectance of a pixel } \\
& D N_{i} \quad=\text { digital number of the } i^{\text {th }} \text { reference, } \\
& D N_{i+1}=\text { digital number of the } i+l^{\text {th }} \text { reference, } \\
& R_{i} \quad=\text { spectral reflectance of the } i^{\text {th }} \text { reference, and } \\
& R_{i+1} \quad=\text { spectral reflectance of the } i+I^{\text {th }} \text { reference. }
\end{aligned}
$$

\subsubsection{Vegetation Mapping Using Aerial Hyperspectral Image}

Without knowing the species, the vegetation parameters of ET estimation methods cannot be applied. Therefore, the essential task for further ET estimation is to clearly delineate sawgrass, cattail, and other wetland vegetation species

After the raw image was geometrically rectified and radiometrically calibrated, the areas with known vegetation species at the ground truth points were selected from the hyperspectral image. Those selected areas were later used as training data for supervised classification. Because the classification of this study was expected to be by species and the training data were available, the supervised training method was exploited.

The desired classes for identification were sawgrass, cattail, water lily (Nymphaea spp.) and other emergent species, ludwigia (Ludwigia spp.) and other deciduous shrubs, wax myrtle (Myrica cerifera, an evergreen shrub), and bald cypress (Taxodium distichum). Among the emergent species in the Fort Drum marsh, the water lily was 
dominant, so the water lily was specified in the class name. Also ludwigia was the dominant species among the deciduous shrubs in the Fort Drum marsh, so, in order to represent its dominance, it was shown in the class name.

\subsubsection{Test of contingency for the selection of decision rules}

Because the pixels of the training data are not always so homogeneous that every pixel in a training group will actually be classified to its corresponding class, selection of decision rules for the classification was based on the contingency test. The misclassification of these distinct points may be caused by the improper utilization of decision rules or by the inherency of divergence in the data. If it is caused by the latter, systematic improvements are needed in the whole remote sensing approach, such as obtaining images with proper spectral and spatial resolution in the proper time frame. If the mis-classification is caused by the former reason, then the proper decision rule will improve the results. A contingency test is a quick classification of the training data using different decision rules. By using the selected decision rule, each test will generate a matrix of percentage of pixels that were classified as expected. Then, the decision rule with highest contingency will be selected. The test of contingency can represent the validity of the results of classification before further assessment of accuracy.

\subsubsection{Test of separability for the selection of the most effective wavebands}

The separability test is a statistical measurement of the distance between two classes in training data. The higher value in separability means a higher possibility of separating these two classes. The separability test can be calculated for any combination of bands used in the classification. Therefore, the separability test can test the separability of two classes as well as test separability of chosen bands. 
Even though the hyperspectral image has the advantage of numerous narrow wavebands, the efficiency of using all those numerous wavebands may be doubted. Some wavebands may provide a crucial contribution to the classification, but some may not. Some wavebands may be redundant because the pixel values at these wavebands are very similar to those at their adjacent wavebands. Therefore, it is very possible to use fewer but more crucial wavebands to get similar results of classification.

The Jeffries-Matusita (JM) distance was used to calculate the measurement of separability. The JM distance is expressed mathematically as (Swain \& Davis, 1978)

$$
\begin{aligned}
& \alpha=\frac{1}{8}\left(\mu_{i}-\mu_{j}\right)^{T}\left(\frac{C_{i}+C_{j}}{2}\right)^{-1}\left(\mu_{i}-\mu_{j}\right)+\frac{1}{2} \ln \left(\frac{\left|\left(C_{i}+C_{j}\right) / 2\right|}{\sqrt{\left|C_{i}\right|+\left|C_{j}\right|}}\right) \\
& J M_{i j}=\sqrt{2\left(1-e^{-\alpha}\right)}
\end{aligned}
$$

where

$$
\begin{aligned}
& i, j \quad=\text { the two classes being compared, } \\
& C_{i} \quad=\text { the covariance matrix of class } i, \\
& \mu_{i} \quad=\text { the mean vector of class } i \text {, and } \\
& \left|C_{i}\right| \quad=\text { the determinant of } C_{i} .
\end{aligned}
$$

The value of JM distance is between 0 and 1414. The higher value means higher separability. If a value of JM distance reaches the upper boundary, then it means that the two compared classes are totally separable. Conversely, if a value of JM distance is equal to 0 , then the two compared classes are inseparable.

There are three steps of executing the test of separability. For example, if the selection of the three most effective wavebands is desired, the first step is to find out the possible combination of the three bands out of all 64 wavebands. The second step is to 
calculate the JM distance of all selections of two compared classes and get the average $\mathrm{JM}$ distance of this waveband combination. The third step is to compare all the average JM distance of all the waveband combinations and choose the highest waveband combination. This process is tedious and the computation time increases exponentially as the number of total calculated wavebands increases.

\subsection{Application of Satellite Images}

Application of satellite images to this study is a challenge because the study area is comparatively small. The current commercial satellite providing images of smallest spatial resolution is IKONOS which has a spatial resolution of 4 meters in its four available multispectral wavebands of blue, green, red, and near-infrared. However, comparatively, it is very expensive, the available spectral wavebands are limited, and the historical images are not available. The available satellite images of the second smallest spatial resolution are Landsat-7 ETM+, SPOT, and IRS images. They all have multispectral images with spatial resolutions between 20 to 30 meters. However, the Landsat-7 ETM+ images have additional wavebands in thermal and mid infrared regions. Considering the desired spectral information and availability of data, the Landsat-7 ETM+ images were chosen.

Two Landsat-7 ETM+ (Enhanced Thematic Mapper Plus) images were acquired. One was taken on May 11, 2000 which was a day before the aerial hyperspectral imaging day. Therefore, it could represent the ground situation of Fort Drum marsh for essentially the same time as the aerial hyperspectral images. Another ETM+ image was taken on Feb 05,2000 . It was kindly offered by SJRWMD. 


\subsubsection{Spectral Calibration of ETM+ Images}

The pixel values of raw ETM+ images are shown as the relative degree of reflected radiance from 0 to 255 . Those same pixel values in different images may represent different radiance. Thus, the comparison of different images will be difficult due to differences in the original pixel values. In order to compare the different images and take advantage of spectral analyses at ground and aerial levels, the radiometric calibration of images is necessary.

The task of radiometric calibration involves two steps. The first step is to calculate spectral radiance, and the second step is to calculate at-satellite planetary reflectance or at-satellite temperature for TM band 6 (thermal band).

\subsubsection{Calculation of spectral radiance}

The MSS, TM, and ETM+ sensors and the data systems were designed to produce a linear response to incident spectral radiance (Markman \& Barker, 1984; Landsat Project Science Office, 2001). Each satellite sensor has its own response functions for each waveband. The ETM+ sensor has onboard calibration lamps and temperature references. The parameters in the response functions can be calibrated using these onboard calibration lamps and temperature references. Those parameters can be later used for post-processing radiometric calibration of images.

The conversion of digital numbers of each image pixel to the absolute spectral radiance can be expressed mathematically as follows (Landsat Project Science Office, 2001):

$$
L=\left(\frac{L_{\max }-L_{\min }}{255}\right) \times D N+L_{\min }
$$


where

$$
\begin{aligned}
& L \quad=\text { spectral radiance }\left(\mathrm{mW} \mathrm{cm}^{-2} \operatorname{ster}^{-1} \mu \mathrm{m}^{-1}\right), \\
& D N \quad=\text { digital number, } \\
& L_{\text {max }} \quad=\text { max radiance when } \mathrm{DN}=255\left(\mathrm{~mW} \mathrm{~cm} \operatorname{ster}^{-1} \mu \mathrm{m}^{-1}\right), \text { and } \\
& L_{\text {min }} \quad=\text { min radiance when } \mathrm{DN}=0\left(\mathrm{~mW} \mathrm{~cm}^{-2} \operatorname{ster}^{-1} \mu \mathrm{m}^{-1}\right) .
\end{aligned}
$$

\section{$\underline{\text { 3.5.1.2 Calculation of at-satellite planetary reflectance }}$}

Because the sun can be considered to constantly emit the same amount of irradiance, the solar irradiance at a given location on the earth's surface is influenced by sun angle, sun-earth distance, and atmospheric effects. If atmospheric effects are ignored, the solar irradiance can be determined by the known sun angle and sun-earth distance. The sun-earth distance is usually expressed in astronomical units. An astronomical unit is the mean distance between the earth and the sun, approximately $149.6 \times 10^{6} \mathrm{~km}$ (Lillesand \& Kiefer, 1994). The solar irradiance on the earth's surface can be expressed mathematically as (Landsat Project Science Office, 2001)

$$
S=\frac{S_{0} \cos \theta}{d^{2}}
$$

where

$$
\begin{array}{ll}
S & =\text { solar irradiance }\left(\mathrm{mW} \mathrm{cm}^{-2} \mu \mathrm{m}^{-1}\right), \\
S_{0} & =\text { solar irradiance at mean earth-sun distance }\left(\mathrm{mW} \mathrm{cm} \mathrm{mm}^{-1}\right), \\
\theta_{0} & =\text { solar zenith angle, and } \\
d & =\text { earth sun distance in astronomical units. }
\end{array}
$$


If the emission from the earth objects is also neglected, the at-satellite planetary reflectance is the ratio of spectral radiance to solar irradiance, and can be expressed as (Landsat Project Science Office, 2001)

$$
R=\frac{\pi L d^{2}}{S_{0} \cos \theta_{s}}
$$

where $R=$ at-satellite planetary reflectance.

\subsubsection{Calculation of at-satellite temperature}

After the calculation of spectral radiance of each waveband, the calculation of atsatellite temperature is different from that of at-satellite planetary reflectance. The atsatellite temperature can be calculated as the following function (Landsat Project Science Office, 2001)

$$
T_{\text {rad }}=\frac{K_{2}}{\ln \left(\frac{K_{1}}{L}+1\right)}
$$

where

$$
\begin{array}{ll}
T_{r a d} & =\text { at-satellite radiant temperature }(\mathrm{K}), \\
K_{2} & =\text { calibration constant } 2, \\
K_{I} & =\text { calibration constant } 1, \text { and } \\
L & =\text { spectral radiance }\left(\mathrm{mW} \mathrm{cm} \mathrm{ster}^{-1} \mu \mathrm{m}^{-1}\right) .
\end{array}
$$

The temperature computed by Equation 3.27 is radiant temperature. Radiant temperature is the measurement from a thermal sensor. The actual temperature has to be adjusted by the emissivity of the measured object. The adjustment can be expressed as (Lillesand \& Kiefer, 1994) 


$$
T=\frac{T_{r a d}}{\varepsilon^{1 / 4}}
$$

where

$$
\begin{array}{ll}
T & =\text { actual temperature }(\mathrm{K}), \text { and } \\
\varepsilon & =\text { broadband thermal emissivity. }
\end{array}
$$

The emissivity for freshwater marsh can be considered to be 0.99 (Tan, 1998).

\section{$\underline{\text { 3.5.2 Vegetation Mapping Using ETM+ Images }}$}

Vegetation identification to species level using satellite images is much more difficult than using aerial hyperspectral images. The latter provides much better spatial and spectral resolutions than the former. The method of vegetation mapping using Landsat-7 ETM+ images in this research is not to directly use any classification scheme but to develop a feasible method based on the vegetation mapping results of hyperspectral imaging.

\subsubsection{Spectral analysis of different vegetation types on the ETM+ image}

To determine the best strategy of vegetation mapping using Landsat-7 ETM+ images, one must first understand the spectral characteristics of different vegetation types in ETM+ images. Because the vegetation types were mapped through the analysis of the aerial hyperspectral image, the satellite image within the boundary of the hyperspectral imaging area could be recognized. Thus, spectral responses of different vegetation types shown on the satellite image could be observed by extracting the spectral values of the pixels within the vegetation map generated from the hyperspectral image. 


\subsubsection{Knowledge based classification}

Even though the spatial and spectral resolutions of ETM+ images are much larger than those of hyperspectral images, there were some small but noticeable differences between different vegetation types from the results of the spectral analysis of different vegetation types in ETM+ images. For instance, cattail and sawgrass have close values in visible and near-IR bands but cattail has higher values in mid-IR bands. Another good example is that the ludwigia may be confused with water lily or wax myrtle in spring time (the image on May 11,2000) but leaves of ludwigia mostly drop out in winter (the image on February 05, 2000).

To form a reliable set of training data, typical supervised classification requires many ground truth points. As the study site is relatively small, the appropriate number of training data points is not available for ETM+ images. However, the knowledge obtained from the spectral analysis of different vegetation types can be used in another type of classification, knowledge based classification.

Knowledge based classification utilizes the knowledge of the characteristics of different classes to perform classification rules. In essence, the knowledge of classification system is a hierarchy of rules, or a decision tree, that describes the conditions under which a set of low level constituent information gets abstracted into a set of high level informational classes. The constituent information consists of userdefined variables and includes raster imagery, vector coverages, spatial models, external programs, and other data sources. Each rule is a conditional statement, or list of conditional statements, about the variable's data values and/or attributes that determine an informational component or hypotheses. Multiple rules and hypotheses can be linked 
together into a hierarchy that ultimately describes a final set of target informational classes or terminal hypotheses.

Based on the knowledge of the results for the spectral analysis in the different vegetation types obtained in the previous section, the rules for different vegetation types were formed. Each rule utilized the spectral characteristics of each vegetation type in the spring and winter images and set up the upper and lower bound of those key wavebands. For example, if the red and mid-infrared values are both high in the winter and spring images, then it will be classified as cattail. Thus, the vegetation types over the Fort Drum Marsh were identified using the knowledge-based classification method.

\subsection{Accuracy Assessment of Vegetation Maps}

After classification is performed, the accuracy of the classification results need to be further assessed. To assess the accuracy, another set of ground truth points is required. Ideally, the ground truth points are randomly selected and include every class of vegetation.

Because the water table was very low in 2000 and 2001, an airboat was not able to penetrate some very high, dense vegetation. With the assistance of SJRWMD, two more field trips were performed using a special vehicle, a marshmaster. A marshmaster looks like a bulldozer without a blade but can float on water. Usually, a marshmaster destroys the vegetation in its path so can only be used after imaging. One field trip for collecting ground truth points in the hyperspectral imaging area was completed on April 3, 2001. The other field trip of the whole marsh was completed on April 13, 2001. 
The accuracy assessment is usually displayed as an error matrix of reference (true) classes and mapped classes (Table 3.2). Each number in the error matrix indicates the percentage (or number of points) that are in one reference class and mapped into another class. Therefore, the diagonal of the matrix reveals the accuracy of each class. The overall accuracy can be obtained by dividing the total accurate points with the total reference points.

Table 3.2 Typical error matrix display for accuracy assessment.

Reference

\begin{tabular}{lcccccc} 
& Class & 1 & 2 & $\cdots$ & $\mathrm{q}$ & \\
\hline & 1 & $\mathrm{P}_{11}$ & $\mathrm{P}_{12}$ & $\cdots$ & $\mathrm{P}_{1 \mathrm{q}}$ & $\mathrm{P}_{1+}$ \\
& 2 & $\mathrm{P}_{21}$ & $\mathrm{P}_{22}$ & $\cdots$ & $\mathrm{P}_{2 \mathrm{q}}$ & $\mathrm{P}_{2+}$ \\
& & & & $\ldots$ & & \\
& $\vdots$ & & & & & \\
& $\mathrm{q}$ & $\mathrm{P}_{\mathrm{q} 1}$ & $\mathrm{P}_{\mathrm{q} 2}$ & $\cdots$ & $\mathrm{P}_{\mathrm{qq}}$ & $\mathrm{P}_{\mathrm{q}^{+}}$ \\
& & $\mathrm{P}_{+1}$ & $\mathrm{P}_{+2}$ & & $\mathrm{P}_{+\mathrm{q}}$ & \\
\hline
\end{tabular}

However, even if the classification is done by random assignment of pixels, there is still a random chance of accuracy. Therefore, to display the accuracy without the random chance, the Kappa coefficient is considered. The Kappa coefficient can be calculated by the following equation (Stehman, 1999), 


$$
K=\frac{P_{c}-\sum_{i}^{q} P_{i+} P_{+i}}{1-\sum_{i}^{q} P_{i+} P_{+i}}
$$

where

$$
\begin{aligned}
& P_{c}=\text { overall accuracy } \\
& P_{i+}=\sum_{k=1}^{q} P_{i k}, \\
& P_{+i} \quad=\sum_{k=1}^{q} P_{k i} \text {, and } \\
& P_{i j} \quad=\text { the percentage of points which are in the } \mathrm{j} \text { class and mapped as } \\
& \quad \text { the i class. }
\end{aligned}
$$

\subsection{Estimation of ET over the Fort Drum Marsh}

The available spatial information of the Fort Drum marsh was obtained from the vegetation map and the temperature distribution came from the thermal band of ETM+ images. Therefore, the marsh-wide ET in the Fort Drum marsh was computed using this information. Since the Priestley-Taylor equation performed better than the other methods (see the results of 4.1.4), the marsh-wide ET in the Fort Drum marsh was estimated using the Priestley-Taylor equation. The temperature information was plugged into the calculation. In addition to temperature, the Priestley-Taylor equation also requires net radiation information. Unfortunately, the 2000 weather data were not available. Therefore, the required weather parameters using the historical mean values of May were used. By this approach, the ET of the Fort Drum marsh on May 11, 2000 was computed. 


\section{CHAPTER 4 \\ RESULTS AND DISCUSSION}

\subsection{Fundamental Study of Wetland ET}

\subsubsection{Conditions of the Lysimeters}

Seven field visits were scheduled for vegetation monitoring and measuring in Oct.19, 1996, Dec. 23, 1996, Mar. 28, 1997, May 30, 1997, Aug. 11, 1997, Nov. 11, 1997, Apr. 23, 1998, respectively. In each field trip, vegetation parameters were carefully measured. The growth conditions of cattail and sawgrass inside the lysimeters were similar as those outside the lysimeters. The conditions of lysimeters in each field trip were depicted as follow:

On Mar. 28, $199770 \%$ of cattail was found dry, but only $20 \%$ sawgrass was dry. The cattail was flowering.

On May 30, 1997 after some of the cattail died off, young cattail was growing up and had almost reached mature status. However, $50 \%$ of the cattail was still dry, but 70 $\%$ of the leaves of the dry cattail had dropped off. The sawgrass inside the lysimeter was growing but had not reached the mature status.

On Aug. 11, 1997 both the cattail and sawgrass grew well and reached mature status. Due to July's abundant rainfall, the water level of the marsh was higher than the lysimeters. 
On Nov. 11, 1997 approximately half of the cattail was dead and dry inside the lysimeter. The dead and dry situation also occurred outside the lysimeter. The sawgrass grew well and only about $20 \%$ of sawgrass was dead.

On Apr.23, 1998 about half of the cattail was dead. To date, the cattail outside the lysimeter grew to its greatest height. It was about $30 \mathrm{~cm}$ higher than that inside lysimeter. The reason for higher growth of the cattail outside the lysimeter may have been caused by the flood in Feb and Mar, 1998. Sawgrass grew fine. About $25 \%$ of the sawgrass was dead.

Generally, areas of sawgrass and cattail died off during the winter, but the cattail tended to have a greater percentage of die off. When cattail died off, the dead leaves would form a layer of dead biomass. Because the cattail leaves have many inside pores, layers of dead cattail biomass would float and cover the water surface.

\subsubsection{Vegetation Parameter Measurements}

Each vegetation parameter was properly measured and recorded. The vegetation parameters were calculated and are summarized in Tables 4.1 and 4.2

The summarized results provide information on the characteristics of wetland vegetation. Mean canopy height of the cattail was $183.9 \mathrm{~cm}$ with a standard deviation of $9.3 \mathrm{~cm}$ and that of the sawgrass was $139.5 \mathrm{~cm}$ with a standard deviation of $12.6 \mathrm{~cm}$. Mean density of cattail was 21.9 plants $\mathrm{m}^{-2}$ with a standard deviation of 13.9 plants $\mathrm{m}^{-2}$ and that of the sawgrass was 24.3 plants $\mathrm{m}^{-2}$ with a standard deviation of 1.2 plants $\mathrm{m}^{-2}$. Mean canopy temperature of the cattail was $27.9 \quad$ C with a standard deviation of 3.8
$\mathrm{C}$, and that of the sawgrass was 28.0
$\mathrm{C}$ with a standard deviation of 5.5
C. Mean leaf area index of the cattail was 3.74 with a standard deviation of 2.14 and that of the 


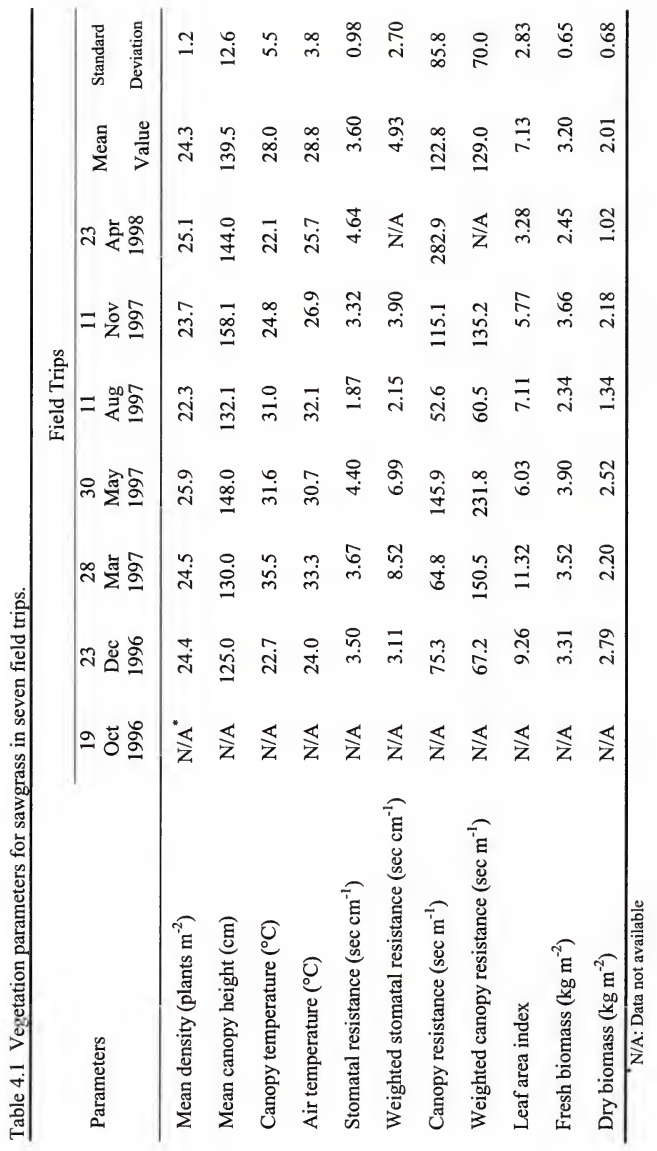




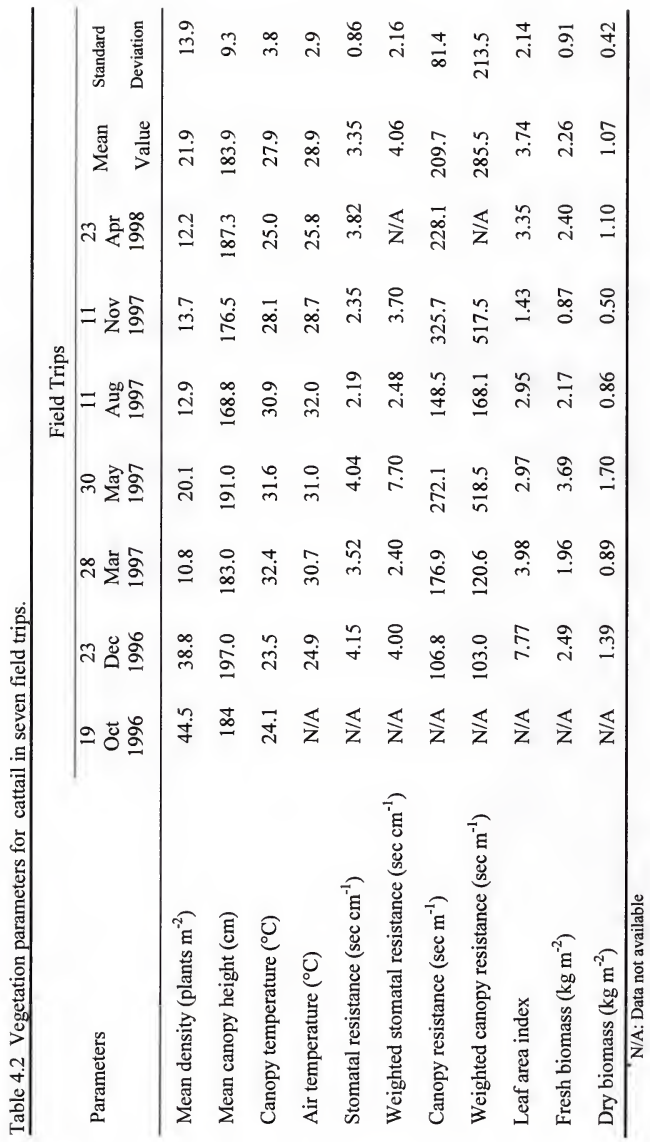


sawgrass was 7.13 with a standard deviation of 2.83 . Mean fresh biomass of the cattail was $2.26 \mathrm{~kg} \mathrm{~m}^{-2}$ with a standard deviation $0.91 \mathrm{~kg} \mathrm{~m}^{-2}$ and that of sawgrass was $3.20 \mathrm{~kg}$ $\mathrm{m}^{-2}$ with a standard deviation of $0.65 \mathrm{~kg} \mathrm{~m}^{-2}$. Mean dry biomass of the cattail was 1.07 $\mathrm{kg} \mathrm{m}^{-2}$ with a standard deviation of $0.42 \mathrm{~kg} \mathrm{~m}^{-2}$ and that of dry biomass was $2.01 \mathrm{~kg} \mathrm{~m}^{-2}$ with a standard deviation of $0.68 \mathrm{~kg} \mathrm{~m}^{-2}$. Among the vegetation parameters, the cattail showed higher standard deviation in plant density, leaf area index, and fresh biomass while the sawgrass showed higher standard deviation in canopy height and dry biomass. Generally, the cattail displayed more seasonal variation than the sawgrass.

Mean stomatal resistance of the cattail was $3.35 \mathrm{~s} \mathrm{~cm}^{-1}$ with a standard deviation of $0.86 \mathrm{~s} \mathrm{~cm}^{-1}$, and that of the sawgrass was $3.60 \mathrm{~s} \mathrm{~cm}^{-1}$ with a standard deviation of 0.98 $\mathrm{s} \mathrm{cm}^{-1}$. Cattail mean weighted stomatal resistance was $4.06 \mathrm{~s} \mathrm{~cm}^{-1}$ with a standard deviation of $2.16 \mathrm{~s} \mathrm{~cm}^{-1}$ and that of the sawgrass was $4.93 \mathrm{~s} \mathrm{~cm}^{-1}$ with a standard deviation of $2.70 \mathrm{~s} \mathrm{~cm}^{-1}$. Because the LAI for different locations of leaves were not measured, the LAI for different locations of leaves were assumed equal when calculating the canopy resistance. Mean canopy resistance of the cattail was $209.7 \mathrm{~s} \mathrm{~m}^{-1}$ with a standard deviation of $81.4 \mathrm{~s} \mathrm{~m}^{-1}$ and that of the sawgrass was $122.8 \mathrm{~s} \mathrm{~m}^{-1}$ with a standard deviation of $85.8 \mathrm{~s} \mathrm{~m}^{-1}$. Mean weighted canopy resistance of the cattail was $285.5 \mathrm{~s} \mathrm{~m}^{-1}$ with a standard deviation of $213.5 \mathrm{~s} \mathrm{~m}^{-1}$ and that of the sawgrass was $129.0 \mathrm{~s} \mathrm{~m}^{-1}$ with a standard deviation of $70.0 \mathrm{~s} \mathrm{~m}^{-1}$. For both cattail and sawgrass, the weighted stomatal resistance showed higher mean value and higher variation than the stomatal resistance before weighting. The results from using the equation of weighted stomatal resistance were not as useful as expected. In addition, canopy resistance varied widely, because the 
stomatal resistance and the LAI which were used to calculate the canopy resistance were so variable.

\subsubsection{Estimation of Canopy Resistance}

The values of stomatal resistance and LAI were found to be linearly related to the values of height. The measured and estimated values of stomatal resistance and LAI were plotted against the height in Figures 4.1 to 4.4. Using linear regression methods, the relationships of stomatal resistance and height could be defined as follows:

For sawgrass,

$$
\text { stomatal resistance }=-5.50 \times \text { height }+8.63
$$

For cattail,

$$
\text { stomatal resistance }=-3.27 \times \text { height }+6.89
$$

The correlation coefficients of the linearly regressed stomatal resistance and the measured stomatal resistance were 0.84 for sawgrass and 0.95 for cattail.

Equations 4.1 and 4.2 can be expressed as the following general form:

$$
r_{s}=a h+b
$$

where

$$
\begin{aligned}
& r_{s}=\text { stomatal resistance, } \\
& h=\text { height, and } \\
& a, b=\text { coefficients. }
\end{aligned}
$$

The relationship of LAI and height could be defined as follows:

$$
L A I(h)=\frac{L A I}{H}(H-h)
$$

where 


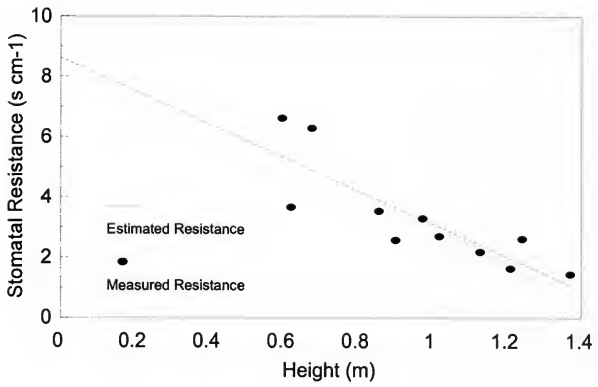

Figure 4.1 Stomatal resistance of sawgrass versus height. 


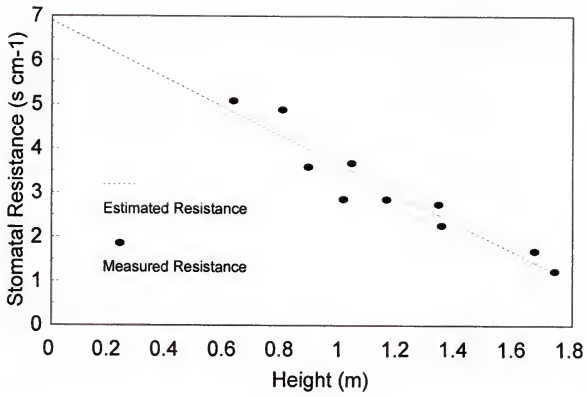

Figure 4.2 Stomatal resistance of cattail versus height. 


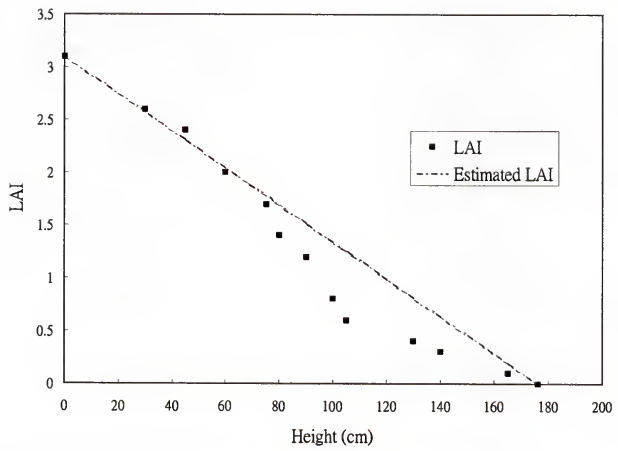

Figure 4.3 Measured and estimated LAI of sawgrass versus height. 


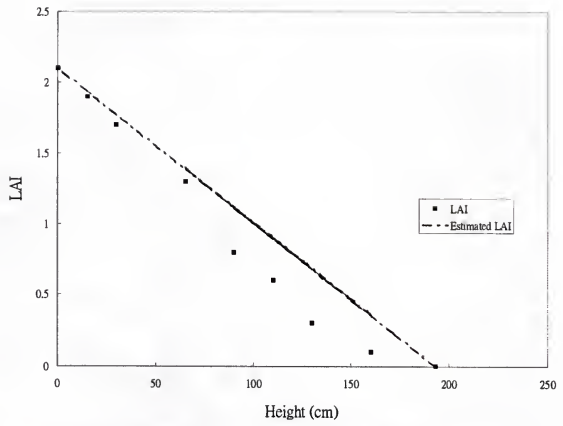

Figure 4.4 Measured and estimated LAI of cattail versus height. 


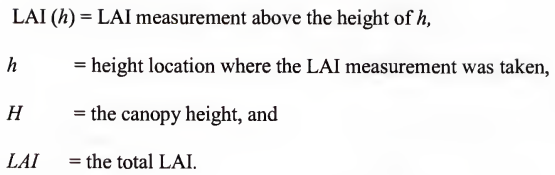

Using Equation 4.4, the correlation coefficients of the computed LAI and measured LAI were found to be 0.89 for sawgrass and 0.90 for cattail.

Saugier and Katerji (1991) divided plant leaves into a finite number of layers according the height. At each layer, stomatal resistance of upper/lower sides of leaves and the LAI within this layer were measured. They proposed an equation to estimate canopy resistance as follows:

$$
\frac{1}{r_{c}}=\sum\left(\frac{1}{r_{i}^{u}}+\frac{1}{r_{i}^{l}}\right) L A I_{i}
$$

where

$$
\begin{aligned}
& r_{c} \quad=\text { canopy resistance, } \\
& r_{i}^{u} \quad=\text { stomatal resistance of the upper side of leaf at layer } i, \\
& r_{i}^{\prime} \quad=\text { stomatal resistance of the lower side of leaf at layer } i, \text { and } \\
& L A I_{i} \quad=\text { LAI at layer } i .
\end{aligned}
$$

The stomatal resistances at the upper and lower sides of the same leaf were measured and found to be very close for sawgrass and cattail. Because the relationship of LAI and stomatal resistance to height was continuously linear, the summation form in Equation 4.5 can be expressed as the following continuous integral equation,

$$
\frac{1}{r_{c}}=\int_{0}^{H} \frac{2}{r_{s}(h)} d L A I(h)
$$


Substituting Equations 4.3 and 4.4 into Equation 4.6, canopy resistance could be estimated using the following equation,

$$
r_{c}=\frac{1}{\frac{2 L A I}{a H} \ln \left(\frac{a H+b}{b}\right)}
$$

Using Equation 4.7, the canopy resistances of sawgrass and cattail on August 29, 1998 were computed as 83.6 and $96.6 \mathrm{~s} \mathrm{~m}^{-1}$, respectively. Different canopy resistance values were plugged into the Pen-Monteith equation to compute ET. The computed ET versus the different canopy resistance was plotted in Figures 4.5 and 4.6. The x-axes in Figures 4.5 and 4.6 were located at the actual lysimeter ET values. Thus, the intercepts of the estimated curves and the $\mathrm{x}$-axes were the best fitting canopy resistance. The best fitting canopy resistances of sawgrass and cattail were found to be 82.5 and $101.7 \mathrm{~s} \mathrm{~m}^{-1}$, respectively. The difference of canopy resistance estimated by these two methods were $1.3 \%$ and $-5.0 \%$ for sawgrass and cattail, respectively. Therefore, the proposed method for canopy resistance estimation can be considered.

\subsubsection{Methods for Evapotranspiration Estimation}

Lysimeter and weather data were collected from May 1996 to December 1999. However, some data were not collected in 1996 and 1998. In 1996 some data were not collected because the system had just started and was under adjustments. The uncollected data situation in 1998 was caused by the high water table which flooded over the lysimeters. Therefore, only the1997 and 1999 data were used. The 1997 data were used for evaluation of the estimation methods and calibration of parameters. The 1999 data were used for verification. The correlations between the weather parameters and 


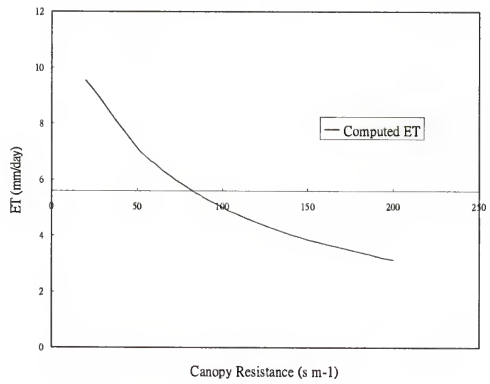

Figure 4.5 Computed ET of sawgrass versus different canopy resistance. The $\mathrm{x}$-axis was located at the actual lysimeter ET. 


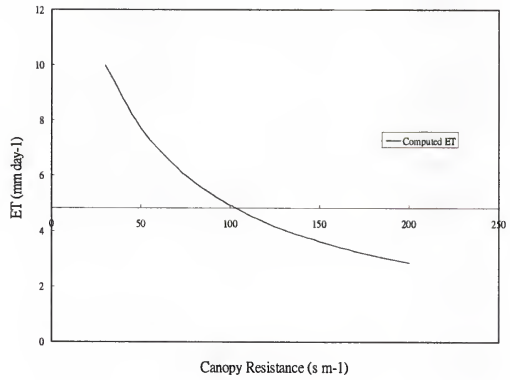

Figure 4.6 Computed ET of cattail versus different canopy resistance. The $\mathrm{x}$-axis was located at the actual lysimeter ET. 
ET are depicted in section 4.1.4.1, followed by the evaluation and verification of the ET estimation methods in sections 4.1.4.1 and 4.1.4.2.

\subsubsection{Correlations between weather parameters and ET}

The correlation coefficients between parameters and ET were calculated and summarized in Tables 4.3 and 4.4

Table 4.3 Correlation coefficients of weather parameters and ET values

\begin{tabular}{lrrrr}
\hline & Cattail ET & Sawgrss ET & Open Water & Pan Evap. \\
\hline Net Radiation & 0.71 & 0.78 & 0.48 & 0.78 \\
Temperature & 0.37 & 0.32 & 0.12 & 0.44 \\
Relative Humidity & -0.40 & -0.51 & -0.44 & -0.39 \\
Wind Speed & -0.08 & -0.12 & -0.11 & 0.02 \\
\hline
\end{tabular}

Table 4.4 Correlation coefficients between the weather parameters.

\begin{tabular}{lrrrr}
\hline & Net Radiation & Temperature & $\begin{array}{r}\text { Relative } \\
\text { Humidity }\end{array}$ & Wind Speed \\
\hline Net Radiation & 1.00 & 0.48 & -0.41 & -0.02 \\
Temperature & 0.48 & 1.00 & 0.40 & -0.18 \\
Relative Humidity & -0.41 & 0.40 & 1.00 & -0.02 \\
Wind Speed & -0.02 & -0.18 & -0.02 & 1.00 \\
\hline
\end{tabular}

The correlation coefficients between the weather parameters and ET values show that net radiation was the major contributing parameter of ET. The influence of net radiation was significant for cattail, sawgrass and pan evaporation. Temperature and relative humidity were also highly correlated to ET values where wind speed showed a lower correlation to ET. Therefore, the main weather parameters influencing the wetland ET values were net radiation, temperature, and relative humidity. 
To test the correlation between the weather parameters, more calculations were completed and summarized in the following table.

Table 4.4 suggests that relative humidity and temperature are, to some degree, correlated to net radiation. The wind speed shows low correlation to other weather parameters.

\subsubsection{Evaluation of the ET Methods for sawgrass}

The 1997 data were used to evaluate different ET methods. For the PriestleyTaylor method, to minimize the root mean squared error (RMSE), an optimization approach was used to obtain the optimal Priestly-Taylor constant. As a result, the optimal Priestley-Taylor constant for sawgrass was 1.05 . The average canopy height and canopy resistance was used in the Penman-Monteith equation. All the calculations were performed on a daily basis.

For sawgrass, the estimated ET for different methods versus lysimeter ET is displayed in Figures 4.7, 4.8 and 4.9.

As shown in Figures 4.7, 4.8, and 4.9, the estimated ET using the PenamMonteith equation seemed to be overestimated. The estimated ET using the PriestleyTaylor and Penman-Monteith equations seemed to be more accurate but the estimated ET using Penman-Monteith seemed to be more scattered. The annual mean ET and RMSE of the three methods was calculated and listed in Table 4.5.

According to the RMSE, the Priestly-Taylor method performed best while the Penman method was least accurate. The performance of the Penman-Monteith was only adequate. However, when the annual mean ET was considered, the Priestly-Taylor and Penman-Monteith methods were both acceptable, but not the Penman method. 


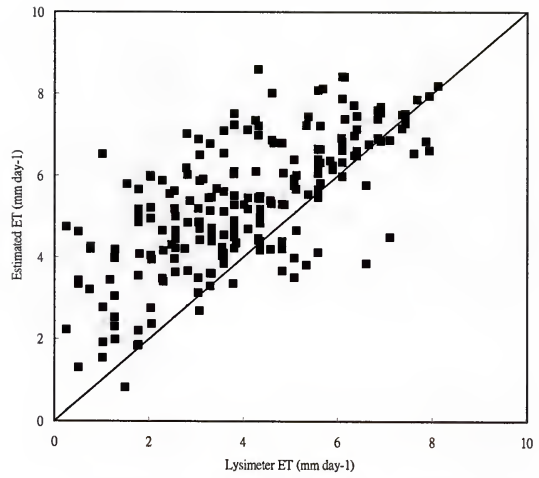

Figure 4.7 Estimated ET using Penman equation versus lysimeter ET for sawgrass in 1997. 


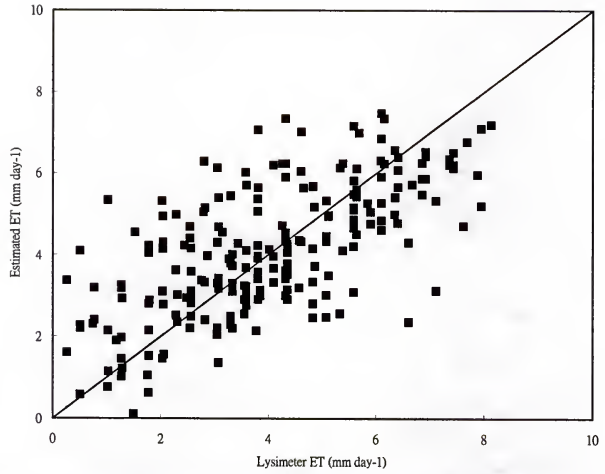

Figure 4.8 Estimated ET using Priestley-Taylor equation versus lysimeter ET for sawgrass in 1997. 


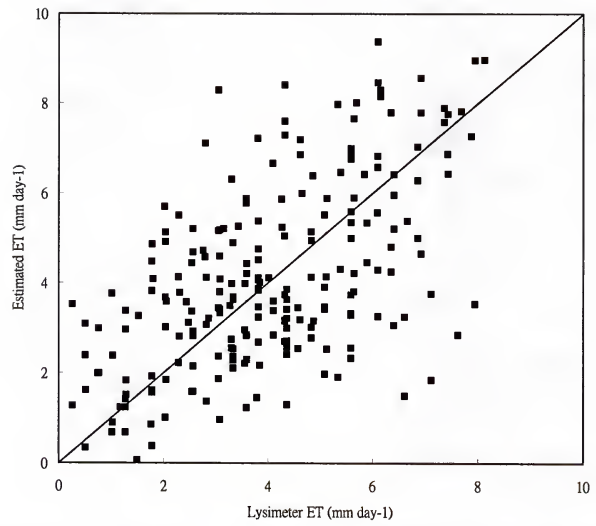

Figure 4.9 Estimated ET using Penman-Monteith equation versus lysimeter ET for sawgrass in 1997. 
Table 4.5 Annual mean ET and RMSE of different estimation methods for sawgrass in 1997.

Penman Priestley-Taylor Penman-Monteith Lysimeter

\begin{tabular}{lcccc}
\hline Annual mean ET (mm) & 5.17 & 4.13 & 4.11 & 4.02 \\
RMSE (mm) & 1.47 & 1.12 & 1.45 & -- \\
\hline
\end{tabular}

\subsubsection{Evaluation of the ET methods for cattail}

The 1997 weather and lysimeter data were used for the evaluation of the ET methods for cattail. To determine the optimal Priestley-Taylor constant, an optimization approach to minimize the RMSE of estimated ET was used. The optimal PriestleyTaylor constant was 0.70 for cattail. The average canopy height and canopy resistance was used in the Penman-Monteith equation. The estimated results versus the lysimeter ET are shown in Figures 4.10, 4.11, and 4.12.

Observing Figure 4.10, the estimated ET using the Penman-Monteith equation was obviously overestimated. According to the Figures 4.11 and 4.12, the estimated ET using the Priestley-Taylor and Penman-Monteith equations was more accurate, but the estimated ET using Penman-Monteith seemed more scattered.

Further calculations of the estimated annual mean ET and the RMSE of the three methods are listed in Table 4.6.

Observing the results of the RMSE, the Priestly-Taylor method showed the lowest RMSE followed by the Penman-Monteith. The Penman method had the highest RMSE. For the annual mean ET, the Priestley-Taylor had the closest estimate. The PenmanMonteith equation was the second best and the Penman equation was the worst. 


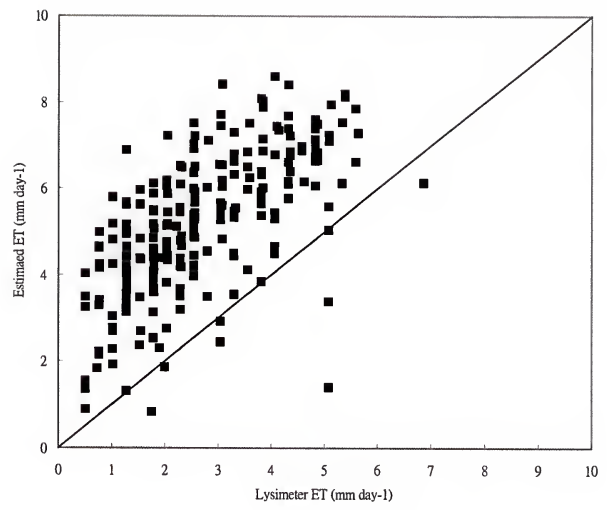

Figure 4.10 Estimated ET using Penman equation versus lysimeter ET for cattail in 1997. 


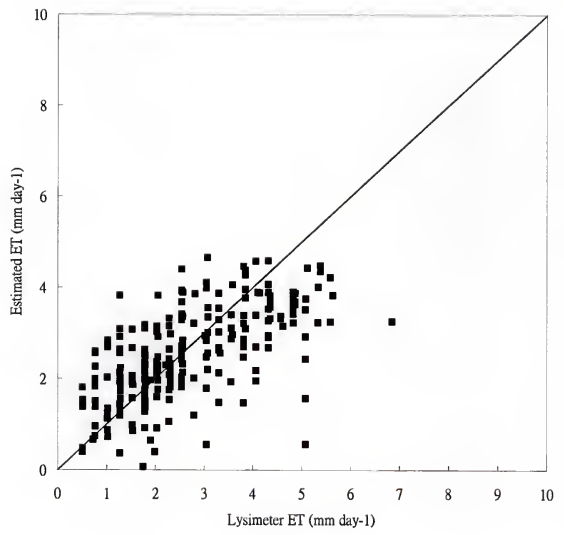

Figure 4.11 Estimated ET using Penman equation versus lysimeter ET for cattail in 1997. 


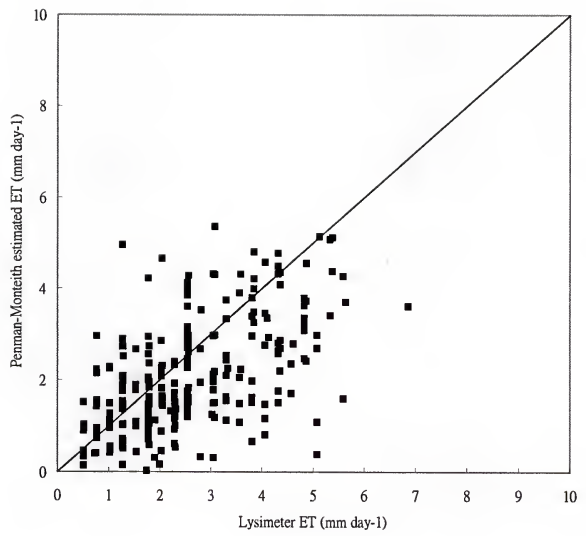

Figure 4.12 Estimated ET using Penman-Monteith equation versus lysimeter ET for cattail in 1997. 
Table 4.6 Annual mean ET and RMSE of different estimation methods for cattail in 1997.

Penman Priestley-Taylor Penman-Monteith Lysimeter

\begin{tabular}{llllc}
\hline Annual mean ET (mm) & 5.17 & 2.51 & 2.12 & 2.66 \\
RMSE (mm) & 2.57 & 0.79 & 1.01 & - \\
\hline
\end{tabular}

\subsubsection{Overall evaluation of different ET methods}

Several findings were observed regarding the overall performance for sawgrass and cattail. The Penman equation was designed to estimate the standard reference ET of short grass or alfalfa, so it overestimated both the sawgrass and cattail ET. Apparently the Penman equation is not suitable for wetland ET estimation. In theory, the PenmanMonteith should demonstrate the best performance. However, the Penman-Monteith equation was designed to estimate ET in agricultural environments where plant growth was uniform and stable. In wetland environments plant growth is uncontrolled and unstable, and the vegetation parameter can vary over a much larger region. Therefore, unless long-term observation of the vegetation parameters has been completed, the Penman-Monteith equation cannot provide very accurate results.

Given that the optimal Priestly-Taylor constant for cattail was lower than 1 implies that some energy is absorbed for the vegetation's internal use. Another explanation is that the net radiation sensor, which was placed at the weather station, could not accurately represent the actual net radiation at the nearby lysimeters. Also, the dead cattail leaves in the Fort Drum marsh usually form a cover over the water. This cover may absorb or more likely reflect more radiation. Moreover, it may prevent water loss 
from vapor deficit. Therefore, the observation in this study area that cattail ET was less than the sawgrass ET, was probably due to cattail "mulch" effect. Presumably such a "mulch" effect would be reduced under conditions of controlled or natural burning. If cattail grows in higher nutrient-level and standing water conditions, less cattail will die off. Under this condition, a "mulch" effect will be also reduced.

The average monthly ET of different estimation methods and the average monthly lysimeter ET is listed in Table 4.7.

Table 4.7 Monthly estimated and lysimeter ET in 1997.

\begin{tabular}{|c|c|c|c|c|c|c|c|c|c|}
\hline & \multicolumn{5}{|c|}{ Estimated ET } & \multicolumn{4}{|c|}{ Actual lysimeter ET } \\
\hline & Penman & $\begin{array}{c}\mathrm{PT}^{*} \\
\text { cattai) }\end{array}$ & $\begin{array}{c}\text { PT }^{*} \\
\text { sawgrass }\end{array}$ & $\begin{array}{l}\mathrm{PM}^{\mathrm{NI}} \\
\text { cattail }\end{array}$ & $\begin{array}{c}\text { PM }^{\prime \prime} \\
\text { sawgrass }\end{array}$ & cattail & sawgrass & water & $\operatorname{Pan}^{* * *}$ \\
\hline$\overline{\text { Jan }}$ & 3.80 & 1.62 & 2.45 & 1.31 & 2.49 & 1.27 & 2.31 & 2.18 & 2.63 \\
\hline Feb & 4.41 & 1.95 & 2.95 & 1.39 & 2.76 & 1.94 & 3.16 & 2.76 & 3.68 \\
\hline Mar & 5.36 & 2.55 & 3.86 & 1.99 & 3.88 & 2.71 & 4.56 & 3.44 & 4.93 \\
\hline Apr & 5.41 & 2.61 & 3.95 & 1.88 & 3.75 & 3.16 & 4.40 & 3.90 & 5.06 \\
\hline May & 6.19 & 3.27 & 4.95 & 2.77 & 5.27 & 3.83 & 4.96 & 3.27 & 5.53 \\
\hline Jun & 6.36 & 3.41 & 5.17 & 3.19 & 5.91 & 3.07 & 4.68 & 3.27 & 5.33 \\
\hline Jul & 6.69 & 3.60 & 5.45 & 4.17 & 7.23 & 2.89 & 5.04 & 3.26 & 5.56 \\
\hline Aug & 5.92 & 3.12 & 4.73 & 3.71 & 6.35 & N/A & N/A & 2.76 & 4.43 \\
\hline Sep & 5.08 & 2.59 & 3.92 & 2.53 & 4.62 & 4.00 & N/A & N/A & 4.46 \\
\hline Oct & 4.44 & 2.18 & 3.30 & 2.05 & 3.78 & 2.07 & N/A & N/A & 3.80 \\
\hline Nov & 3.58 & 1.58 & 2.39 & 1.18 & 2.33 & 2.18 & 3.68 & 1.45 & 2.48 \\
\hline Dec & 3.95 & 1.84 & 2.79 & 1.19 & 2.42 & 1.83 & 3.46 & 1.46 & 2.50 \\
\hline Annual & 5.17 & 2.51 & 4.13 & 2.12 & 4.11 & 2.66 & 4.02 & 2.60 & 4.02 \\
\hline
\end{tabular}

PT: Priestly-Taylor

- PM: Penman-Monteith

-.. Pan evaporation

The light green color grids indicate the ET method with the monthly estimation closest to sawgrass lysimeter ET and those of light yellow color indicate the ET method with monthly estimation closest to cattail ET. The Priestley-Taylor method dominated most colored grids and demonstrated the best estimation. Even though the Penman- 
Monteith method had few color grids it still outperformed the Penman method. Therefore, the Penman-Monteith was still considered the second best and the Penman method was the least useful of the three methods.

The highest monthly ET for sawgrass occurred in July, September for cattail, and April for open water. According the 1997 lysimeter ET records, the lowest monthly ET was in January for both sawgrass and cattail, and November for open water.

The standard A pan is commonly used to represent potential ET or the reference ET. A simple vegetation coefficient can then be used to multiply the pan evaporation to estimate ET. Another optimization process was performed to identify optimal pan coefficients. The optimal pan coefficients for sawgrass, cattail, and open water were 0.91 , 0.60 , and 0.70 , respectively. All of them were less than 1 . The RMSE was $1.07,0.78$, and $1.05 \mathrm{~mm}$ for sawgrass, cattail, and open water, respectively. The results indicate that the pan evaporation with appropriate coefficients can be a useful reference for wetland ET. However, the standard A pan was originally designed for upland vegetation ET and may need some revision for wetland systems. Moreover, although the standard A pan was installed on ground and surrounded by short grass per the required standard, the pan is still very close to the marsh. Thus, the pan evaporation is influenced by the "oasis effect" from the marsh. In order to use the pan evaporation to represent potential ET in wetlands, the pan standards for wetlands need to be carefully re-defined.

The average daily open water lysimeter ET was very low. A possible reason is that a large portion of incoming radiation energy is absorbed by water for heating up the water temperature and not contributed to ET. Because the specific heat of water is higher than that of soil, water is circulating, and the depth of the lysimeter is 1.0 meter, to raise 
the water temperature in the lysimeter requires more energy. Therefore, a lagged sink exists, and less energy is used for ET.

The lysimeter ET data showed differences between open water, cattail, and sawgrass ET. The difference between open water lysimeter ET, cattail lysimeter ET, and sawgrass lysimeter ET can be explained by normalizing the ET values with the relevant LAI values. Higher LAI means more leaves involving transpiration process and may result in higher ET. However, the relationship between ET and LAI shouldn't be linear because the leaves under the top leaf layer only receive transmitted light from the upper layer and diffusive light. The leaves more toward the bottom should have less contribution to ET. Therefore, the normalized ET is obtained by dividing ET with the natural logarithm of LAI. Because the LAI measurements were only available from 1996 to 1998 , the normalization of ET was only calculated for the 1997 data. The normalized ET for cattail is 2.02 , where that for sawgrass is 2.05 . The open water normalized ET is unavailable, because its LAI is zero.

The average LAI of sawgrass and cattail in the Fort Drum marsh was 7.12 and 3.74, repsectively (Tables 4.1 and 4.2). Kock \& Rawlik (1993) reported the LAI of cattail (Typha domingensis Pers.) in the Water Conservation Area 2A in the Everglades ecosystem, Florida was from 3.21 to 5.78 . They also reported the LAI of sawgrass (Cladium jamaicense Crantz) in the same area was 3.77 to 6.10 . Comparatively, the cattail was in a relatively poor growth status and the sawgrass was in a very nice growth status in the Fort Drum marsh. Sawgrass and cattail ET under normal growth conditions may be very different. Therefore, the ET measurements in the Fort Drum marsh 
represent should be considered to only represent cattail and sawgrass under the similar weather and growth conditions.

\subsubsection{Verification of different ET methods}

The 1999 weather and lysimeter data were used for verification. The PriestleyTaylor constant values of 1.05 and 0.7 for sawgrass and cattail came from the previous calibrated optimal results. The average canopy height and canopy resistance from in the Penman-Monteith equation. The annual mean ET and the RMSE of the estimated ET is listed in Table 4.8.

Table 4.8 Annual mean ET and RMSE of different ET methods in 1999.

\begin{tabular}{lcccc}
\hline & Penman & \multicolumn{1}{c}{$\begin{array}{c}\text { Priestley- } \\
\text { Taylor }\end{array}$} & $\begin{array}{c}\text { Penman- } \\
\text { Monteith }\end{array}$ & Lysimeter \\
\hline & \multicolumn{5}{c}{ Sawgrass } \\
\cline { 2 - 5 } Annual mean ET (mm) & 5.66 & 4.62 & 5.20 & 4.87 \\
RMSE (mm) & 1.60 & 1.37 & 1.65 & -- \\
\hline & \multicolumn{5}{c}{ Cattail } \\
Annual mean ET (mm) & 5.66 & 3.10 & 3.58 & 3.42 \\
RMSE (mm) & 2.62 & 0.84 & 1.09 & -- \\
\hline
\end{tabular}

The results of RMSE demonstrate that the Priestly-Taylor performed best. Comparing the Penman and the Penman-Monteith methods, the Penman-Monteith method estimated better for cattail but not for sawgrass. Regarding the results of annual mean ET, the Priestley-Taylor still had the best performance, and the Penman-Monteith method was still second best with the Penman method the least useful. Among these 
three estimation methods, the Priestly-Taylor method was considered the most appropriate method for wetland ET estimation. The performance of the PenmanMonteith was fair. The Penman method was not considered applicable for wetland ET estimation.

\subsection{Spectral Radiometric Analysis}

\subsubsection{Spectral Response of Different Vegetation Types}

Six field trips were made for data collection on Oct. 19, 1996, Dec. 23, 1996, Mar. 23, 1997, May 30,1997, Aug. 11, 1997 and Nov. 11, 1997. To understand the seasonal changes of cattail and sawgrass, the field trips are scheduled seasonally. The spectral reflectance of cattail and sawgrass acquired during the six field trips were shown in Figures 4.13 to 4.18 .

Observing the spectral reflectance curves in Figures 4.13 to 4.18 , though there was not an extremely significant difference between the reflectance curves of cattail and sawgrass, some spectral characteristics of cattail and sawgrass were observed. Visually, for both sawgrass and cattail, infrared was reflected most and green was reflected second most, but there was no certain pattern regarding whether or not cattail reflected infrared and green more than sawgrass. However, cattail reflected more red than sawgrass among all figures. It meant that cattail appeared yellower and sawgrass a deeper green. This characteristic was most obvious during the fall and winter as in Figures 4.13, 4.14, 4.15, and 4.16. Another characteristic was that the reflectance curves of cattail during winter in Figure 4.14 smoothly increased from blue to near infrared and nearly the same occurred during the height of the dry-season (Figure 4.16). In winter, cattail turned to 


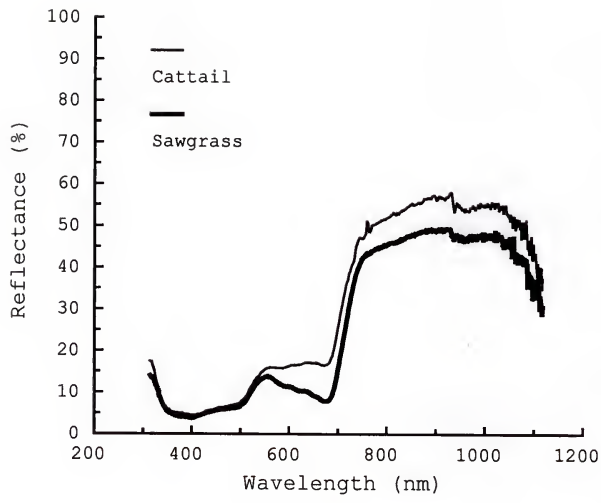

Figure 4.13 Reflectance curves of cattail and sawgrass measured on 19 October 1996. 


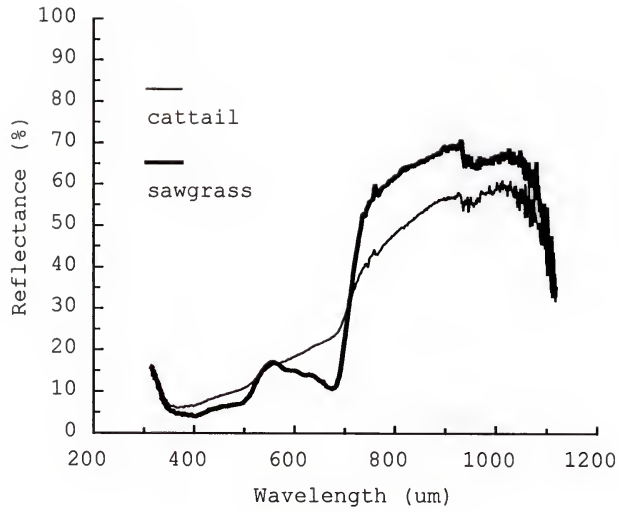

Figure 4.14 Reflectance curves of cattail and sawgrass measured on 23 December 1996. 


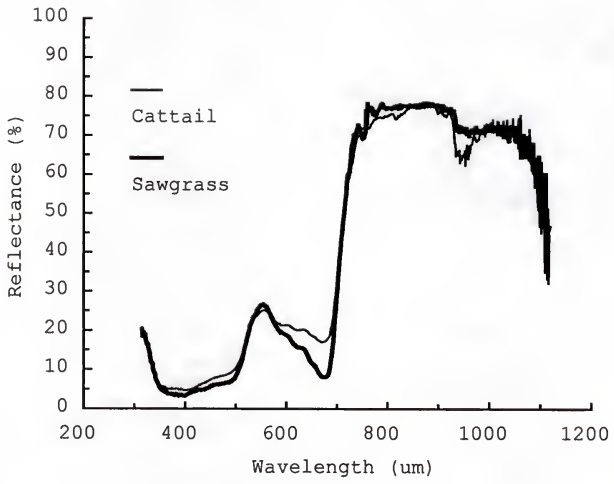

Figure 4.15 Reflectance curves of cattail and sawgrass measured on 28 March 1997. 


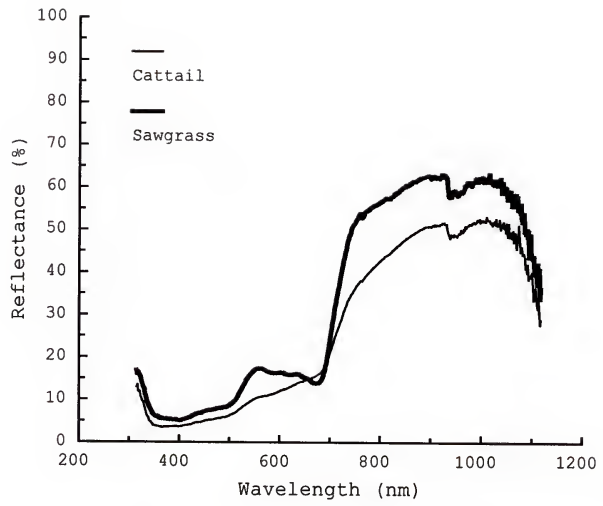

Figure 4.16 Reflectance curves of cattail and sawgrass measured on 30 May 1997. 


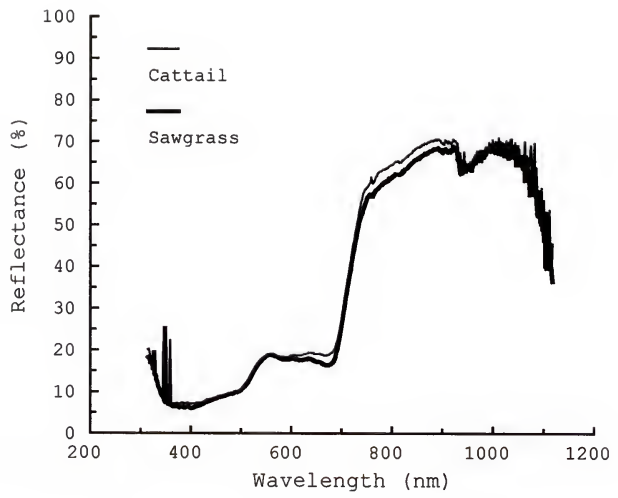

Figure 4.17 Reflectance curves of cattail and sawgrass measured on 11 August 1997. 


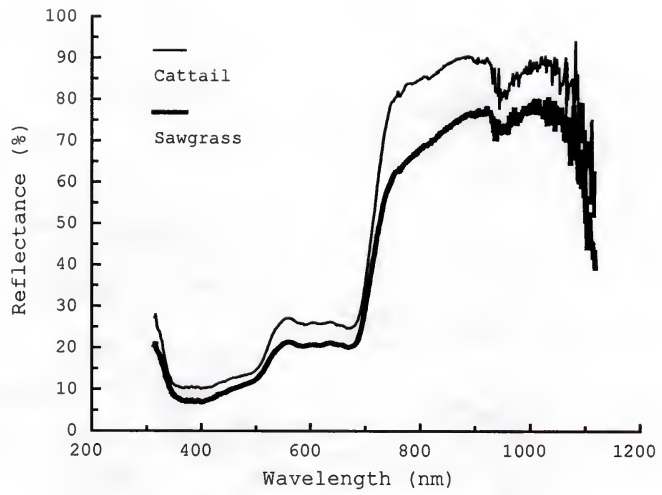

Figure 4.18 Reflectance curves of cattail and sawgrass measured on 11 November 1997. 
yellow and half of it died out, while sawgrass did not demonstrate such an extreme change. These two spectral characteristics can be used to distinguish cattail and sawgrass using other remotely sensed data such as aerial color-infrared photographs. The computed NDVI values of cattail and sawgrass are listed in Table 4.9.

Table 4.9 Computed NDVI of sawgrass and cattail from spectral measurements in each field trip.

\begin{tabular}{lcccccc}
\hline & \multicolumn{7}{c}{ Sampling field trips } \\
\cline { 2 - 7 } & $\begin{array}{c}\text { First } \\
\text { Oct. 19 }\end{array}$ & $\begin{array}{c}\text { Second } \\
\text { Dec. 23 } \\
1996\end{array}$ & $\begin{array}{c}\text { Third } \\
\text { Mar. 28 } \\
1997\end{array}$ & $\begin{array}{c}\text { Fourth } \\
\text { May 30 } \\
1997\end{array}$ & $\begin{array}{c}\text { Fifth } \\
\text { Aug. 11 } \\
1997\end{array}$ & $\begin{array}{c}\text { Sixth } \\
\text { Nov. 11 } \\
1997\end{array}$ \\
\hline Sawgrass & 0.64 & 0.56 & 0.51 & 0.55 & 0.69 & 0.58 \\
\hline Cattail & 0.49 & 0.48 & 0.40 & 0.52 & 0.45 & 0.38 \\
\hline
\end{tabular}

The NDVI values between cattail and sawgrass showed a remarkable difference. The mean NDVI value of sawgrass was 0.59 , while that of cattail was 0.45 which was $24 \%$ less than that of sawgrass. Because cattail reflected more red than sawgrass, the spectral difference of cattail between the red and near-infrared regions was smaller than sawgrass. This fact resulted in the lower NDVI value of cattail.

\subsubsection{Spectral Responses of Different Stomatal Resistance}

Spectral reflectance and spectral reflected radiance at different stomatal resistance values for cattail and sawgrass were plotted in Figures 4.19, 4.20, 4.21 and 4.22 , respectively. It was obvious that the stomatal resistance decreased as the reflected radiance increased. The stomatal resistance is therefore shown to be inversely related to 


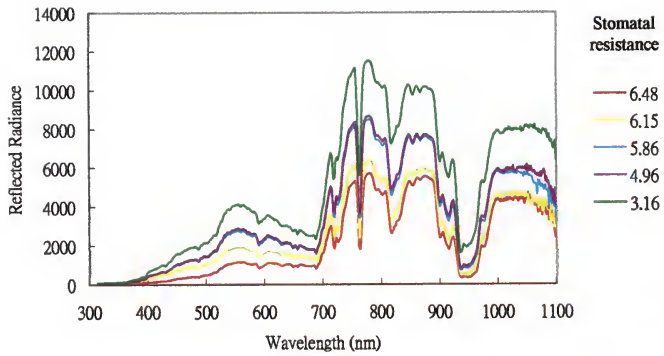

Figure 4.19 Spectral reflected radiance of cattail at the different values of stomistal resistance. 


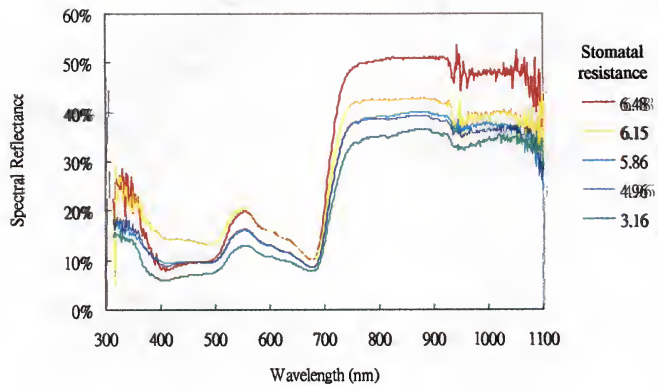

Figure 4.20 Spectral reflectance of cattail at the different values of stomatal resistance. 


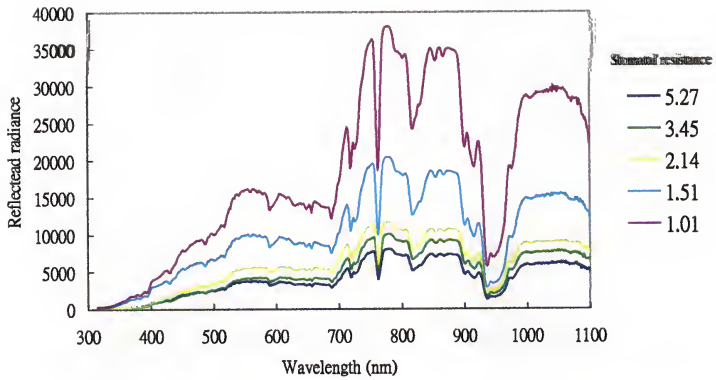

Figure 4.21 Spectral reflected radiance of sawgrass at the different values of stomatal resistance. 


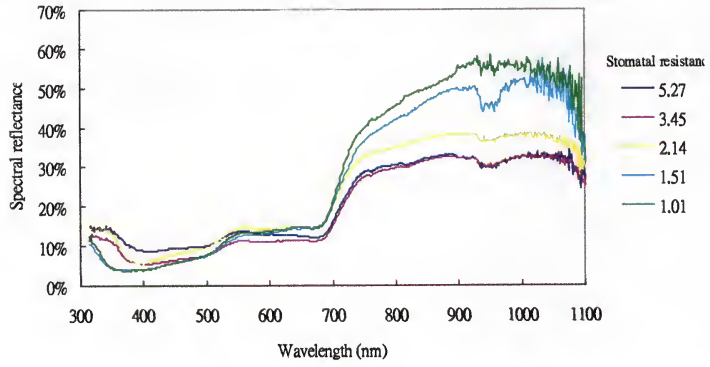

Figure 4.22 Spectual reflectance of sawgrass at the different values of stomatal resistance. 
spectral reflectance in the near-infrared wavelengths, but not related to the visible wavelengths.

The vegetation indices were calculated as in Tables 4.10 and 4.11. For sawgrass, the most significant vegetation indices correlating the stomatal resistance were the band ratios of blue with green and blue with red, while that for cattail was the band ratio of green and red.

Table 4.10 Different vegetation indices at different stomatal resistance values (sawgrass).

Stomatal Resistance

\begin{tabular}{lrrrrrr} 
& 5.27 & 3.45 & 2.14 & 1.51 & 1.01 & Coef. \\
\hline NDVI & 0.430 & 0.454 & 0.415 & 0.498 & 0.524 & -0.665 \\
Green NDVI & 0.386 & 0.454 & 0.419 & 0.548 & 0.559 & -0.837 \\
Blue/Green & 0.698 & 0.591 & 0.562 & 0.480 & 0.463 & 0.980 \\
Blue/Red & 0.776 & 0.590 & 0.556 & 0.416 & 0.417 & 0.974 \\
Blue/IR & 0.310 & 0.222 & 0.230 & 0.140 & 0.130 & 0.935 \\
Green/Red & 1.112 & 0.999 & 0.988 & 0.868 & 0.901 & 0.940 \\
Green/IR & 0.443 & 0.375 & 0.408 & 0.291 & 0.282 & 0.843 \\
Red/IR & 0.399 & 0.376 & 0.414 & 0.336 & 0.313 & 0.658 \\
\hline
\end{tabular}

Table 4.11 Different vegetation indices at different stomatal resistance values (cattail).

Stomatal Resistance

\begin{tabular}{|c|c|c|c|c|c|c|}
\hline & \multicolumn{5}{|c|}{ о } & \multirow{2}{*}{$\begin{array}{r}\text { Correlation } \\
\text { Coef. }\end{array}$} \\
\hline & 6.48 & 6.15 & 5.86 & 4.96 & 3.16 & \\
\hline NDVI & 0.651 & 0.593 & 0.628 & 0.621 & 0.630 & -0.040 \\
\hline Green NDVI & 0.448 & 0.366 & 0.430 & 0.417 & 0.470 & -0.543 \\
\hline Blue/Green & 0.489 & 0.700 & 0.614 & 0.603 & 0.551 & 0.161 \\
\hline Blue/Red & 0.882 & 1.274 & 1.072 & 1.063 & 0.876 & 0.427 \\
\hline Blue/IR & 0.186 & 0.325 & 0.245 & 0.248 & 0.199 & 0.334 \\
\hline Green/Red & 1.804 & 1.820 & 1.746 & 1.763 & 1.590 & 0.942 \\
\hline Green/IR & 0.381 & 0.465 & 0.399 & 0.412 & 0.361 & 0.533 \\
\hline Red/IR & 0.211 & 0.255 & 0.228 & 0.234 & 0.227 & 0.048 \\
\hline
\end{tabular}




\subsubsection{Spectral Responses of Different LAI Values}

Spectral responses of different LAI values were plotted in Figures 4.23 and 4.24. The green and red regions decreased as the LAI increased. It meant that there were more yellow leaves and less green leaves when the LAI decreased. Different vegetation indices were calculated in Tables 4.12 and 4.13. Among the vegetation indices, NDVI was highly correlated to LAI both for cattail and sawgrass.

Table 4.12 Vegetation indices of sawgrass at different LAI values.

\begin{tabular}{lrrrrr}
\hline & \multicolumn{2}{c}{ LAI } & \multicolumn{2}{r}{ Correlation. } \\
\cline { 2 - 6 } & 3.17 & 2.7 & 2.67 & 2.37 & Coef. \\
\hline NDVI & 0.723 & 0.687 & 0.651 & 0.553 & 0.984 \\
Green NDVI & 0.682 & 0.646 & 0.665 & 0.539 & 0.922 \\
Blue/Green & 0.515 & 0.491 & 0.451 & 0.481 & -0.307 \\
Blue/Red & 0.603 & 0.566 & 0.427 & 0.498 & 0.971 \\
Blue/IR & 0.097 & 0.105 & 0.090 & 0.143 & 0.287 \\
Green/Red & 1.171 & 1.152 & 0.946 & 1.037 & 0.208 \\
Green/IR & 0.188 & 0.214 & 0.200 & 0.299 & 0.066 \\
Red/IR & 0.161 & 0.186 & 0.211 & 0.288 & 0.931 \\
\hline
\end{tabular}

Table 4.13 Vegetation indices of cattail at different LAI values.

\begin{tabular}{lrrrrr}
\hline & \multicolumn{2}{c}{ LAI } & \multicolumn{2}{r}{ Correlation } \\
\cline { 2 - 5 } & 3.57 & 2.67 & 2.13 & 1.33 & Coef. \\
\hline NDVI & 0.646 & 0.516 & 0.454 & 0.271 & 0.989 \\
Green NDVI & 0.656 & 0.577 & 0.471 & 0.394 & 0.970 \\
Blue/Green & 0.693 & 0.607 & 0.604 & 0.577 & 0.877 \\
Blue/Red & 0.666 & 0.508 & 0.577 & 0.436 & 0.908 \\
Blue/IR & 0.143 & 0.162 & 0.217 & 0.250 & -0.712 \\
Green/Red & 0.961 & 0.837 & 0.957 & 0.756 & -0.540 \\
Green/IR & 0.207 & 0.267 & 0.359 & 0.433 & -0.602 \\
Red/IR & 0.215 & 0.319 & 0.376 & 0.573 & 0.964 \\
\hline
\end{tabular}




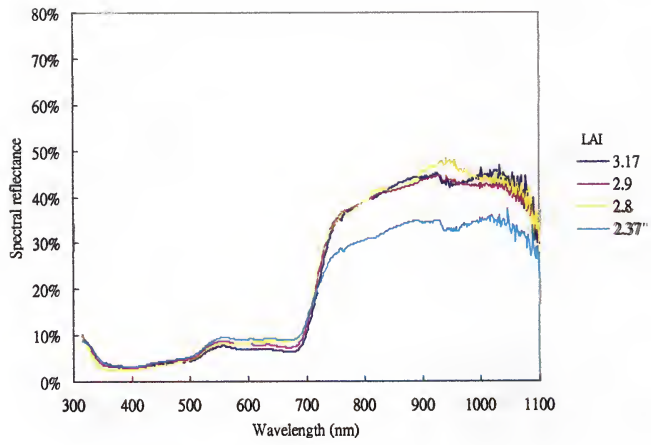

Figure 4.23 Spectral reflectance of sawgrass at different LAI values. 


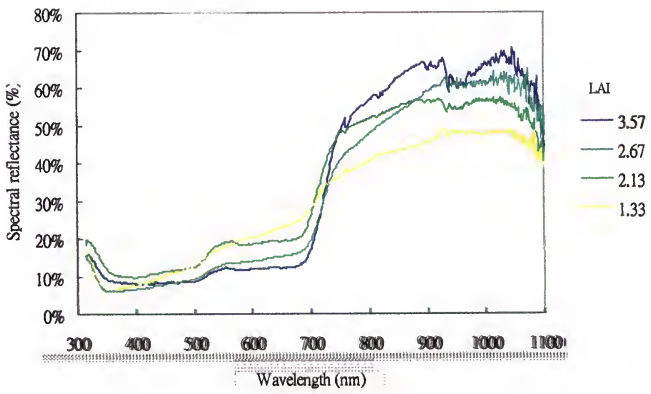

Figure 4.24 Spectral reflectance of cattail at different LAI values. 


\subsection{Hyperspectral Imaging}

\subsubsection{Geometric Rectification}

Ten geolocation targets were placed in the marsh on April 29, 2000. The aerial imaging was performed on May 12,2000, and the field ground truthing was completed on May 17, 2000. The hyperspectral images were rectified by a piecewise polynomial rectification procedure.

Observing the image, the straight dike appeared skewed. It was obvious that the airplane changed direction slightly during the imaging (Figure 4.25). Therefore, according to the observation of the ground truth of the dike, the image was subset into two images. In each subset image, the dike was shown as straight. Then, each subset image was geographically rectified using a third order polynomial function. Afterwards, the two rectified subset images were mosaiced together. By this piecewise polynomial rectification procedure, the root mean of square error of the GCPs was 5.8 meters. The mosaiced image is demonstrated in Figure 4.26.

\subsubsection{Radiometric Calibration}

The hyperspectral image was spectrally calibrated using the measured spectral characteristics of the calibration panels. In the ground truthing field trip, several different vegetation types were identified by their species and their geographical locations were recorded using a GPS unit. Spectral reflectance of the different vegetation species were also measured using a spectroradiometer. However, because tree and shrub vegetation grew much higher than the grassy species in the Fort Drum marsh, only side-view spectral measurements could be obtained. Therefore, only grassy species and young 
shrub species were measured. Figure 27 displayed the average spectral reflectance of four different species, sawgrass, cattail, water lily (Nymphaea spp.), and bulrush (Scirpus spp.).

Where the known vegetation species were observed, the pixels at the ground truth locations were extracted from the hyperspectral image. Because each pixel contains spectral information from as many as 64 different wavebands, the spectral information of each waveband in a single pixel can be plotted as a spectral reflectance curve.

Therefore, the spectral information of four pixels containing the same vegetation species shown in Figure 27 was displayed in Figure 28. In both Figures 4.27 and Figure 4.28 , the spectral reflectance of different species was obviously dissimilar except for sawgrass and cattail. In Figure 4.27 the difference of spectral reflectance between sawgrass and cattail was noticeable but insignificant, whereas in Figure 4.28 the difference between sawgrass and cattail was significant. When cattail dies off, the dead leaves fall and layer above the water surface but do not quickly break down. Therefore, the aerial images viewing from perpendicular showed more spectral influence of dead leaves of cattail than the spectral radiometer measurements from the inclined top-down view. 


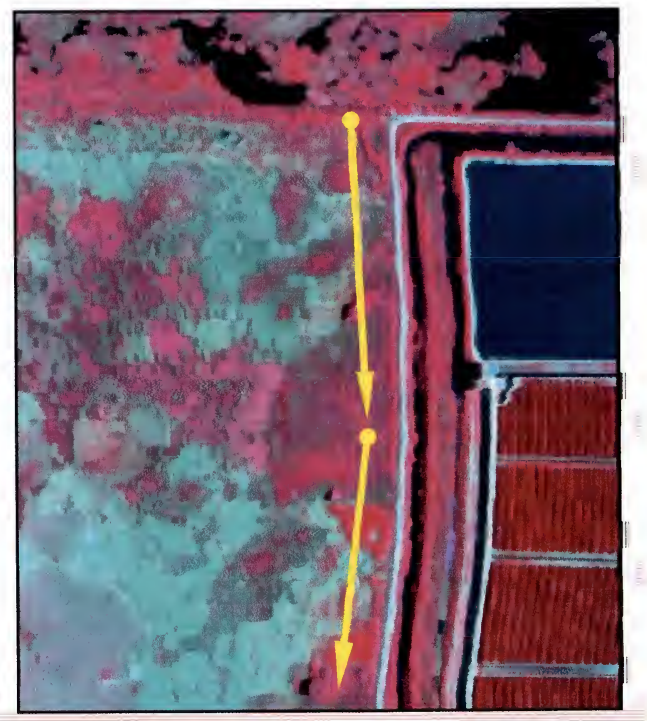

Figure 4.25 Hyperspectral image with the observed flight direction change. 


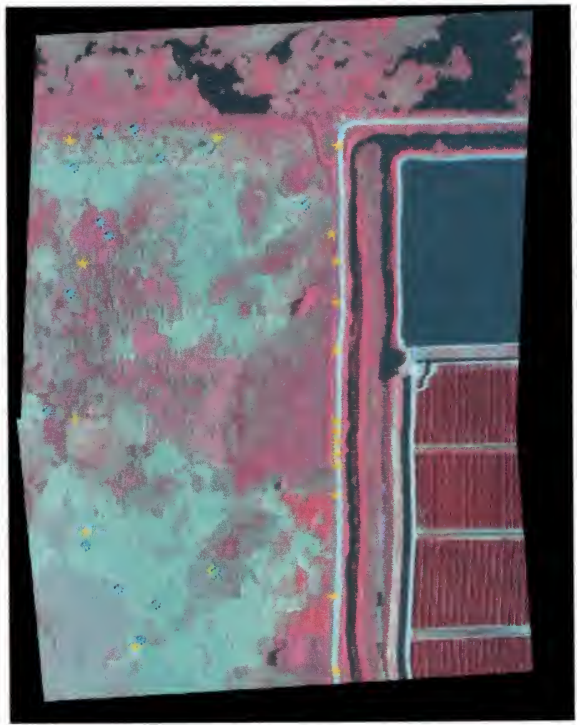

Figure 4.26 Aerial hyperspectral image after piecewise polynomial rectification procedure. 


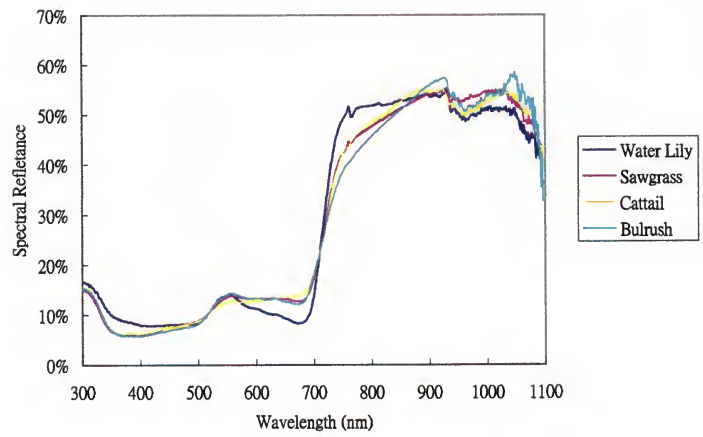

Figure 4.27 Spectral reflectance of different wetland vegetation species measured by a hand-held spectroradiometer. 


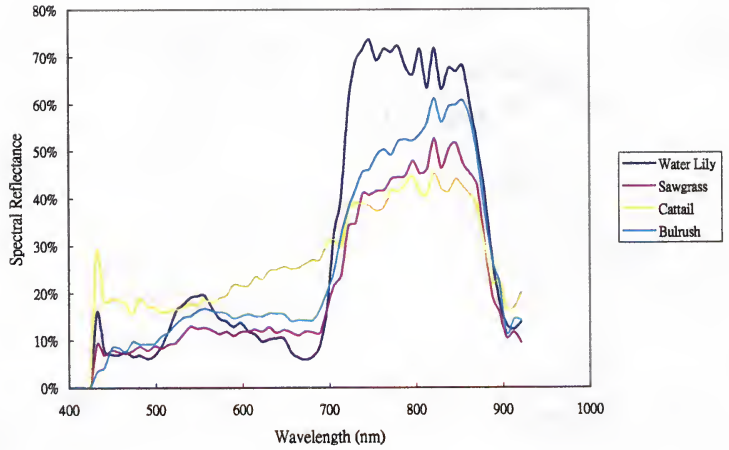

Figure 4.28 Spectral reflectance of different wetland vegetation species from the spectrally calibrated hyperspectral image. 


\subsubsection{Vegetation Mapping Using the Aerial Hyperspectral Image}

Four different decision rules for supervised classification, parallelipiped, maximum likelihood, minimum distance, and Mahalanobis distance were plugged into the test of contingency. The test results demonstrate that all four decision rules have above $95 \%$ accuracy. The high accuracy was caused by the fact that the spectral reflectance of each different species was noticeably different in the hyperspectral image. Among these four decision rules, the parallelipiped method had the highest accuracy (over 99.5\%) and therefore the parallelipiped method was chosen for classification. The classification results are shown in Figure 4.29.

The test of separability using the JM distance was executed for choosing the best combination of three, four, or five wavebands from all of the available 64 wavebands. For choosing the best combination of three wavebands, the best three wavebands were $506.8 \mathrm{~nm}, 672.3 \mathrm{~nm}$, and $813.0 \mathrm{~nm}$ and the relevant JM distance was 1369 . The wavelengths of $506.8 \mathrm{~nm}, 672.3 \mathrm{~nm}$, and $813.0 \mathrm{~nm}$ are located in the blue-green, red edge, and near-infrared regions, respectively. For choosing the best combination of four wavebands, the best four wavebands were $515.0 \mathrm{~nm}, 672.3 \mathrm{~nm}, 721.9 \mathrm{~nm}$, and $837.8 \mathrm{~nm}$ and the relevant JM distance was 1389. Among the four best wavebands, the $515.0 \mathrm{~nm}$ waveband is in the blue-green spectral region, the $672.3 \mathrm{~nm}$ waveband is in the red edge area, and the $721.9 \mathrm{~nm}$ and 837.8 wavebands are within the near-infrared region. For choosing the best combination of five wavebands, the best five wavebands were $515.0 \mathrm{~nm}$, $672.3 \mathrm{~nm}, 697.1 \mathrm{~nm}, 746.8 \mathrm{~nm}$, and $862.6 \mathrm{~nm}$ and the relevant JM distance was 1395 . Among the five wavebands, the first waveband is in the blue-green spectral region, the next two wavebands are in the red edge area, and the highest two wavebands are located 
in the near-infrared regions. Therefore, it appears that the blue-green, red edge, and nearinfrared narrowband spectra are critical for the classification of wetland vegetation. Moreover, given the high JM distances of all three separability tests, which almost reached the highest JM distance value (1414), indicates that these wavebands can have high contribution to the classification of wetland species.

Using these three different combinations, the classifications were re-executed. Figure $4.30,4.31$, and 4.32 represented the vegetation maps generated by using the best combination of three, four, and five wavebands, respectively. These three vegetation maps seemed to be almost identical as Figure 4.29. Comparing vegetation maps in Figures 4.30, 4.31, and 4.32 with that in Figure 4.29, it was found that the percentage of identical pixels was as high as $84.9 \%, 87.5 \%$, and $86.4 \%$ of the total pixels. The high similarity points out that these wavebands are crucial in wetland vegetation mapping. 


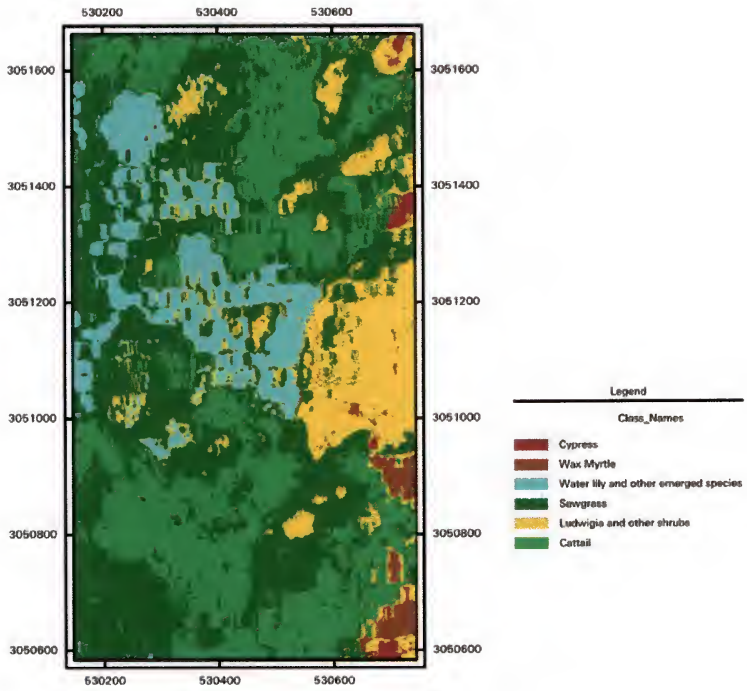

Figure 4.29 Vegetation map of Ft. Drum marsh generated from the aerial hyperspectral image. 


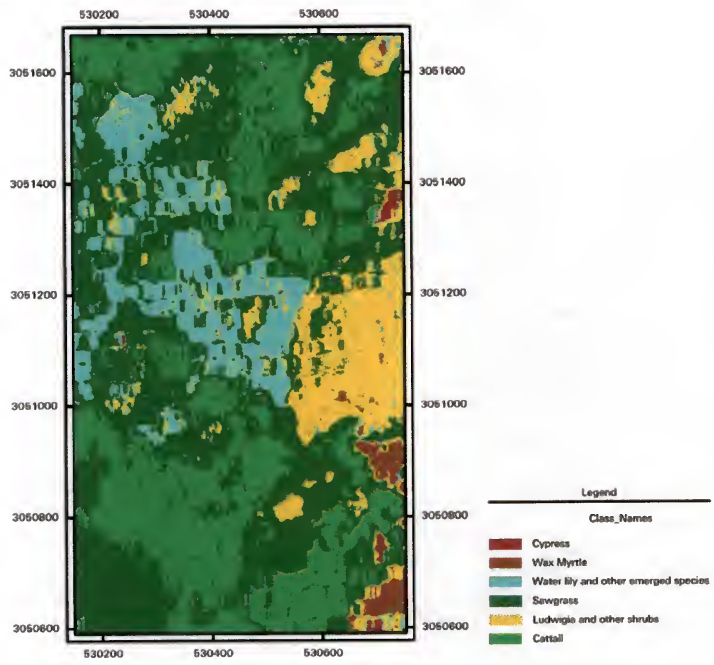

Figure 4.30 Vegetation map of the Fort Drum marsh generated from the hyperspectral image using $506.8 \mathrm{~nm}, 672.3 \mathrm{~nm}$, and $813.0 \mathrm{~nm}$ wavebands. 


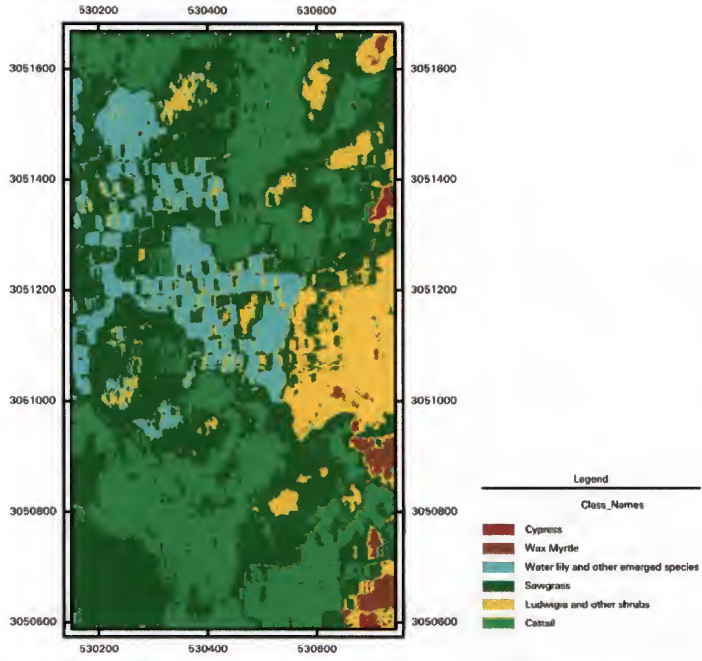

Figure 4.31 Vegetation map of the Fort Drum marsh generated from the hyperspectral image using $515.0 \mathrm{~nm}, 672.3 \mathrm{~nm}, 721.9 \mathrm{~nm}, 837.8 \mathrm{~nm}$ wavebands. 


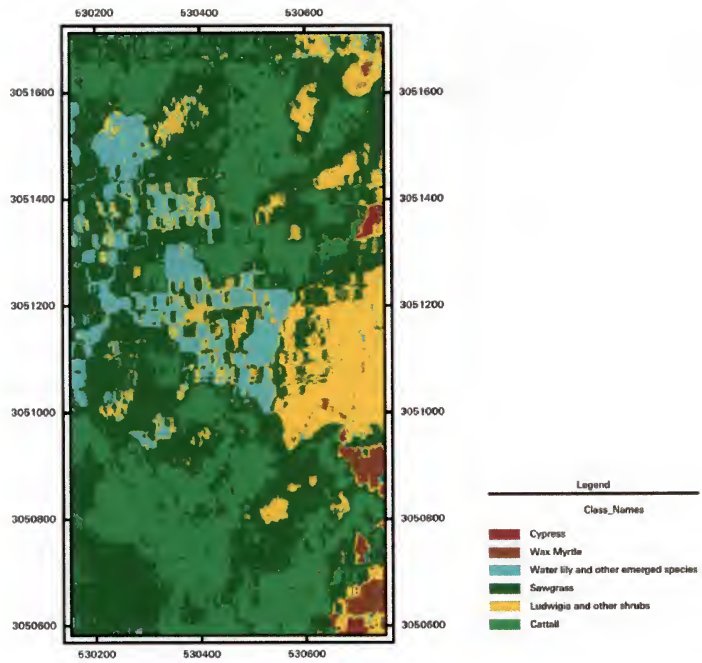

Figure 4.32 Vegetation map of the Fort Drum marsh generated from the hyperspectral image using $515.0 \mathrm{~nm}, 672.3 \mathrm{~nm}, 697.1 \mathrm{~nm}, 746.8 \mathrm{~nm}, 862.6 \mathrm{~nm}$ wavebands. 


\subsection{Application of Satellite Images}

The radiometric calibration of two Landsat-7 ETM+ images were completed. By overlapping the ETM+ images with the vegetation map generated from the hyperspectral image, the pixels of different vegetation types in the calibrated ETM+ images were identified. The pixel values from the visible to mid-infrared wavebands of different vegetation types are displayed in Figure 4.33 and Figure 4.34. From the observation of Figures 4.33 and 4.34, some information was obtained for the rules in knowledge-based classification method. For example, wax myrtle has high near infrared reflectance but low mid-infrared reflectance, cattail has intermediate near infrared reflectance but high mid-infrared reflectance, etc. Moreover, the spectral reflectance of water lily and ludwigia was very similar in the May 11, 2000 image (as shown in Figure 4.33), but the mid-infrared of water lily was lower than ludwigia and the near-infrared was higher than ludwigia in the Feb. 05, 2000 image (as shown in Figure 4.34). Therefore, using the spectral information of the two seasonally different images, the knowledge rules could be more precisely constructed. The knowledge rules are listed in Table 4.14.

Using the knowledge-based classification method, the vegetation in the Fort Drum marsh was classified into species levels as shown in Figure 4.35. There were some black pixels which were either undefined or water in Figure 4.35. Because the knowledge rules were very concisely constructed, only pixels dominated by the same vegetation types could be identified. Therefore, those undefined pixels were more likely to be the complicated mixture of several different vegetation types. 
Table 4.14 Knowledge rules for classification of wetland vegetation using the ETM+ images

\begin{tabular}{|c|c|c|c|c|c|c|c|}
\hline \multirow[t]{2}{*}{ Waveband } & \multicolumn{7}{|c|}{ Class } \\
\hline & Water & Cattail & Sawgrass & $\begin{array}{l}\text { Emergent } \\
\text { Species }\end{array}$ & Shrub & Cypress & $\begin{array}{l}\text { Wax } \\
\text { Myrtle }\end{array}$ \\
\hline \multicolumn{8}{|c|}{ Criteria used in the Feb 05, 2000 image } \\
\hline \multirow{2}{*}{ Red } & & $<0.12$ & $<0.08$ & $<0.055$ & $<0.1$ & & $<0.07$ \\
\hline & & $>0.08$ & $>0.05$ & & $>0.05$ & & $>0.25$ \\
\hline \multirow{2}{*}{$\begin{array}{l}\text { Near } \\
\text { Infrared }\end{array}$} & $<0.045$ & & $<0.225$ & $<0.22$ & $<0.25$ & $<0.2$ & $<0.25$ \\
\hline & & $>0.18$ & $>0.145$ & $>0.15$ & $>0.1$ & $>0.165$ & $>0.22$ \\
\hline & $<0.045$ & $<0.24$ & $<0.165$ & $<0.11$ & $<0.15$ & $<0.16$ & $<0.17$ \\
\hline infrared & & $>0.15$ & $>0.145$ & & $>0.06$ & $>0.14$ & $>0.13$ \\
\hline \multicolumn{8}{|c|}{ Criteria used in the May 11, 2000 image } \\
\hline $\begin{array}{l}\text { Near- } \\
\text { Infrared }\end{array}$ & & & $<0.25$ & & $>0.23$ & $>0.22$ & \\
\hline $\begin{array}{l}\text { Mid- } \\
\text { infrared }\end{array}$ & & & $>0.168$ & & & $\begin{array}{l}<0.17 \\
>0.14\end{array}$ & \\
\hline
\end{tabular}




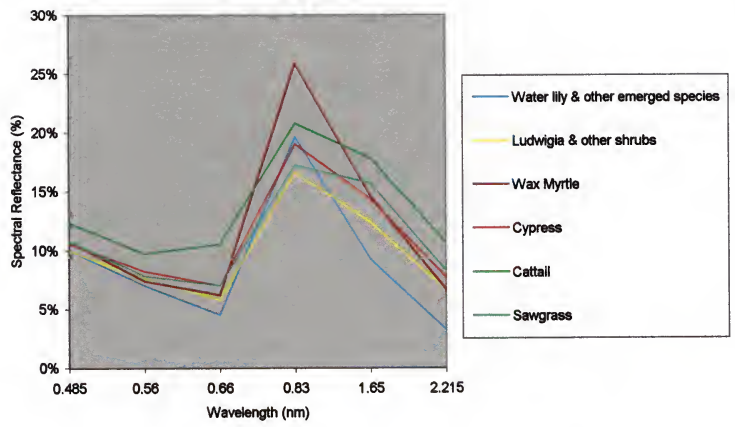

Figure 4.33 Spectral reflectance of different vegetation types extracted from Feb 05, 2000 ETM+ image. 


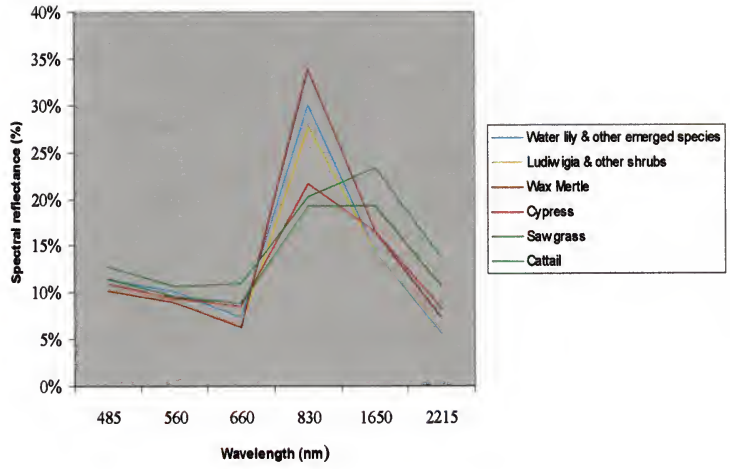

Figure 4.34 Spectral reflectance of different vegetation types extracted from May 11, $2000 \mathrm{ETM}+$ image. 


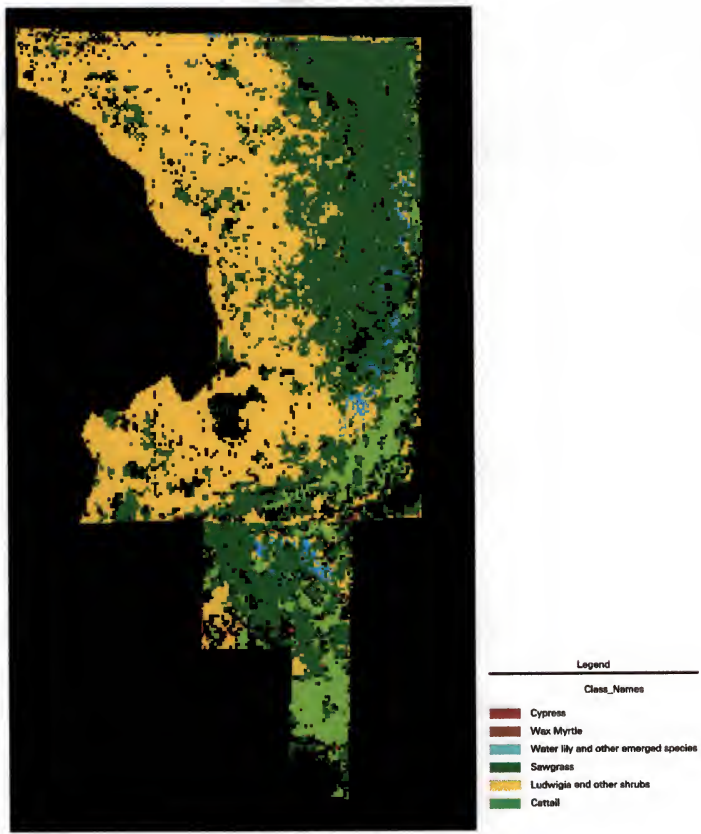

Figure 4.35 Vegetation map of Fort Drum marsh generated from the ETM+ images of Feb 5, 2000 and May 11, 2000. 


\subsection{Accuracy Assessment of Vegetation Maps}

In the field trip on April 3, 2001, 35 ground truth points were collected for the hyperspectral image coverage area. The ground truth results for the hyperspectral vegetation map are shown in Table 4.15. The few mis-classified points were located in the mixture area, so the spectral reflectance of these points was not within any classes. In the case, it was classified to the most statistically similar class. The overall accuracy is 0.914 , and the Kappa value is 0.889 . Therefore, overall performance of the classification using the hyperspectral image was very accurate.

In the field trip on April 13, 2001, 41 ground truth points were collected for the whole study area. The ground truth results for the Landsat vegetation map are displayed in Table 4.16. The ground truth results of cattail, sawgrass, and shrub had high accuracy of classification. Emergent species had fair classification accuracy. However, wax myrtle and cypress were not well classified. Because the spatial resolution of ETM+ images is 30 meters, pixels with one dominant species tend to be successfully identified. In the Fort Drum marsh, the dominant vegetation types are cattail, sawgrass, and shrub, so these vegetation types are more effectively classified. However, wax myrtle and cypress are present as lone specimens or sparse clumps in the Fort Drum marsh. Therefore, these two vegetation types had higher errors in classification. The overall accuracy was 0.803 , and the Kappa value was 0.731 . Though the accuracy and the Kappa coefficient were lower than the those of using the hyperspectral image, the performance of classification using ETM+ images was still satisfactory. 
Table 4.15 Matrix of accuracy of the classification using the hyperspectral image.

Ground truth points in each class

\begin{tabular}{cccccc}
\hline Cattail Sawgrass & $\begin{array}{c}\text { Emergent } \\
\text { species }\end{array}$ & $\begin{array}{c}\text { Wax } \\
\text { myrtle }\end{array}$ & Cypress & Shrub & $\begin{array}{c}\text { Total } \\
\text { points }\end{array}$
\end{tabular}

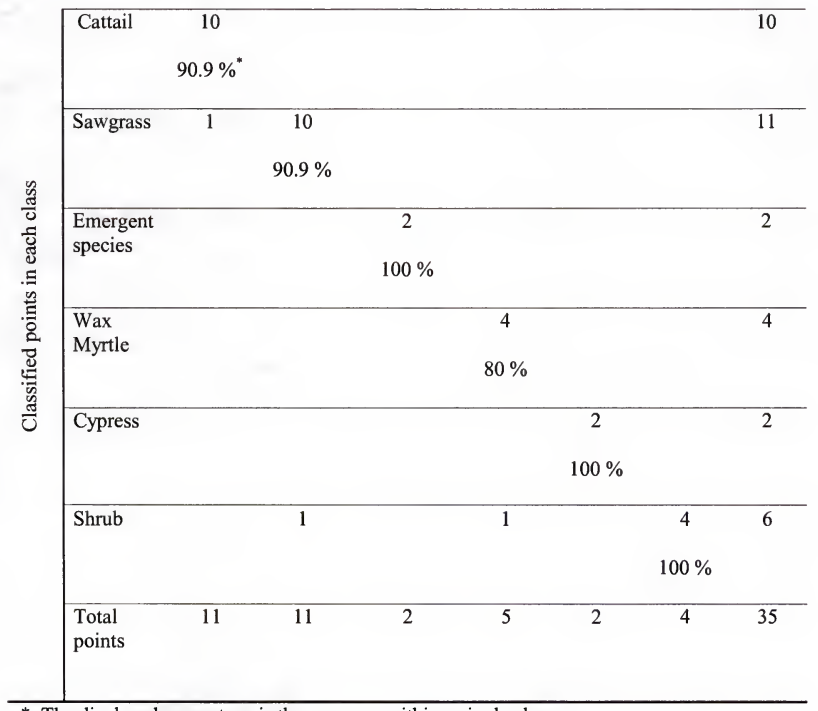

* The displayed percentage is the accuracy within a single class. 
Table 4.16 Matrix of accuracy of the classification using the ETM+ images.

Ground truth points in each class

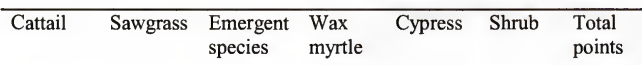

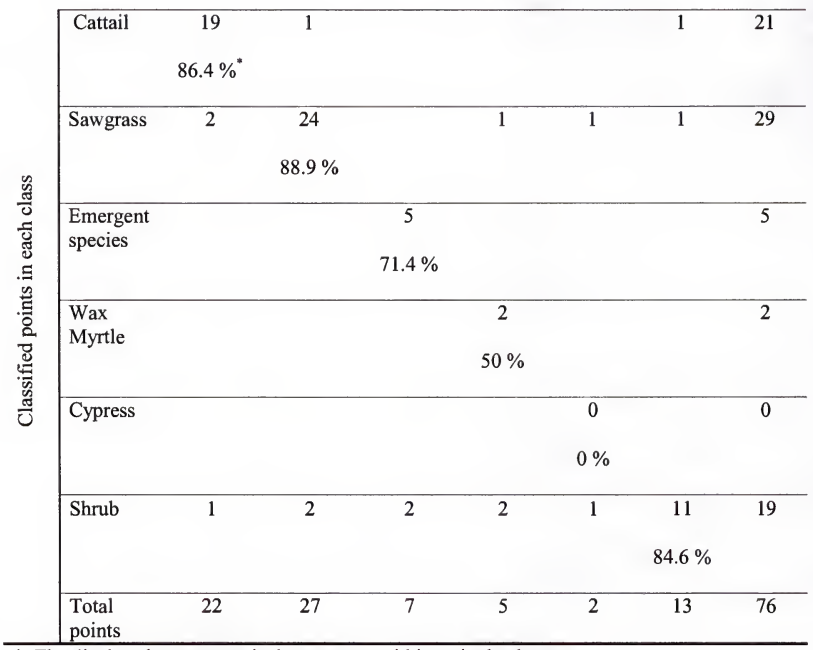

* The displayed percentage is the accuracy within a single class. 


\subsection{Estimation of ET over the Fort Drum Marsh}

Using the temperature distribution generated from ETM+ thermal band, the vegetation map generated from ETM+ image, the vegetation parameters of each species determined from previous section, and the historical mean May net radiation of the Fort Drum marsh, the marsh ET on May 11, 2000 was estimated using the Priestly-Taylor equation. The distribution of ET over the marsh is displayed in Figure 4.36. The average ET of the Fort Drum marsh was estimated as $5.02 \mathrm{~mm} /$ day on May 11, 2000. Every procedure in this research was finally integrated to estimate the marsh-wide ET. 


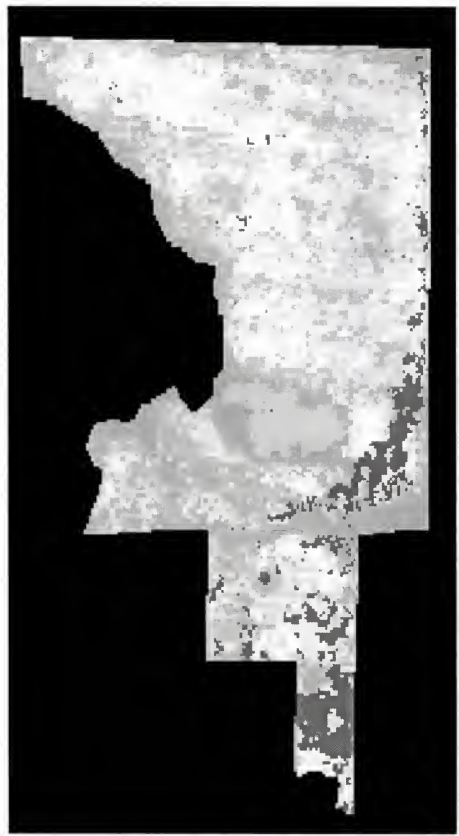

Figure 4.36 Estimated ET distribution in the Fort Drum marsh on May 11, 2000. The whiter color represents higher ET value. 


\section{CHAPTER 5 \\ CONCLUSION AND RECOMMENDATION}

\section{$\underline{5.1 \text { Conclusion }}$}

This research covered several different aspects of studies for wetland ET estimation. In each part, there were several conclusions.

For the fundamental lysimeter study of wetland ET, the average stomatal resistance for sawgrass and cattail was found to be 3.60 and $3.35 \mathrm{sec} \mathrm{cm}^{-1}$ with a standard deviation of 0.98 and 0.86 , respectively. The average canopy resistance for sawgrass and sawgrass was 122.8 and $209.7 \mathrm{sec} \mathrm{cm}^{-1}$ with a standard deviation of 85.8 and 81.4, respectively (Tables 4.1 and 4.2). The fact that sawgrass has higher LAI resulted in lower canopy resistance. In other words, even though sawgrass had lower transpiration rate per unit leaf area, the higher total leaf area resulted in a higher transpiration rate (lower canopy resistance). In addition, the proposed method for estimating the canopy resistance was found to be more suitable for cattail and sawgrass than the conventional methods.

According to the 1997 lysimeter data, the average daily ET values for cattail, sawgrass, and open water were $2.66,4.02$, and $2.60 \mathrm{~mm}$ (Table 4.7 ), respectively. The ET values normalized by the natural logarithm of LAI were $2.02 \mathrm{~mm}$ for cattail and 2.05 mm for sawgrass. Among the various ET estimation methods, the Priestley-Taylor method was most applicable. The optimal Priestley-Taylor constants for sawgrass and 
cattail were found to be 1.05 and 0.7 , respectively. The Penman-Monteith method performed satisfactorily but not as well as the Priestley-Taylor. The Penman method was found least applicable for wetland ET estimation.

The ground spectral response measurements of sawgrass and cattail demonstrated a distinguishable difference in red wavebands and normalized difference vegetation index (NDVI), which indicated the spectral separability of the two wetland species. Spectral reflectance demonstrated a high correlation to stomatal resistance. Among the different vegetation indices, the band ratio of blue and green bands had the best correlation to stomatal resistance for sawgrass, while the band ratio of green and red bands was most correlated to stomatal resistance for cattail. Spectral reflectance also demonstrated high correlation to LAI. Among all the different vegetation indices, the NDVI for both cattail and sawgrass has the best correlation coefficient.

With proper ground calibration panels, the aerial hyperspectral image can ensure a higher quality of classification. Because hyperspectral imagers scan line by line along a track, the vibration and low stability of an airplane can influence the image quality. For best adjustment, one needs to mount a high accuracy GPS with an inertial navigation unit onto the airplane and apply function corrections. This is costly and was not available for this research. However, satisfactory results were obtained using the technique of piecewise polynomial rectification. The vegetation map generated from the hyperspectral image has a very high accuracy of $90.0 \%$, which demonstrated the applicability of using hyperspectral images to delineate wetland vegetation.

Using the tests of separability, a few crucial narrow wavebands from the available 64 wavebands in the hyperspectral image were found to perform over $84 \%$ similar 
classification results as using all 64 wavebands. If only three wavebands are utilized, the best combination of the three wavebands is $506.8 \mathrm{~nm}, 672.3 \mathrm{~nm}$, and $813.0 \mathrm{~nm}$. If only four wavebands are utilized, the best combination is $515.0 \mathrm{~nm}, 672.3 \mathrm{~nm}, 721.9 \mathrm{~nm}$, and $837.8 \mathrm{~nm}$. If only five wavebands are utilized, the best combination of the five wavebands is $515.0 \mathrm{~nm}, 672.3 \mathrm{~nm}, 697.1 \mathrm{~nm}, 746.8 \mathrm{~nm}$, and $862.6 \mathrm{~nm}$. From the results of the three separability tests, blue-green, red edge, and near infrared narrow wavebands are important for classifying wetland vegetation species.

Because the satellite images have coarser spectral and spatial resolutions, the $80 \%$ accuracy of vegetation map generated from the ETM+ images suggested that the classification approach of using the knowledge based classification method and two seasonal images can be considered to perform more than satisfactorily. The PriestleyTaylor methods were applied to estimate marsh-wide ET with the synergy of the information of the vegetation map and temperature distribution generated from the ETM+ images. This ET estimation approach reflected more significantly the spatial and temporal distribution of parameters in the studied marsh.

\section{$\underline{5.2}$ Recommendation for Future Research}

The observation that the average ET of the open water lysimeter is lower than that of the sawgrass lysimeter is attributed to the higher heat absorption of open water than for wet soil. Therefore, much less energy is contributed to ET in the open water lysimeter than for the sawgrass and cattail lysimeters. In order to prove this, the temperature profile of open water and wet soil inside lysimeters, and the specific heat of the water and wet soil, is recommended to be further explored. Moreover, even though the standard A 
pan is surrounded by short grass, the small piece of upland ground holding the weather station and the standard A pan is still inside the much larger marsh. The pan evaporation may be influenced by the oasis effect from the surrounding marsh environments. Thus, the standard installation of evaporation pan and operational definition of potential ET in a wetland could be different from the conventional upland system and needs further study.

The separability tests in hyperspectral images showed the crucial narrow wavebands to be in the blue-green, red edge, and near infrared regions for wetland vegetation mapping. Therefore, it is recommended to design a multi-spectral narrowwaveband imager using these crucial wavebands for more practical application to satisfy the needs of frequent wetland mapping for wetland monitoring and management.

In this research, only winter and spring ETM+ images were used. If more seasonal ETM+ images in summer and autumn are available, the resulting classification may be even more accurate. Moreover, if the elevation model of the marsh bed can be obtained, identification of vegetation species can be assisted by the knowledge of normal depth of the habitat. 


\section{APPENDIX A \\ WEATHER DATA}

\begin{tabular}{rrrrrrrrr}
\hline & \multicolumn{9}{c}{ Weather Data } & \multicolumn{4}{c}{ Lysimeter ET } \\
\cline { 2 - 8 } Day & $\begin{array}{rrrrrr}\text { NRAD } \\
\text { MJ m }\end{array}{ }^{-2} \mathrm{~d}^{-1}$ & RH & TEMP & ATMP & WZ & Cattail & Sawgrass Open Water \\
\hline $1997 / 1 / 1$ & 12.32 & 79.6 & 22.32 & 101.32 & 1.03 & 0.77 & 2.56 & 1.45 \\
$1997 / 1 / 2$ & 8.99 & 80.17 & 19.93 & 101.88 & 1.02 & 0.77 & 2.31 & 2.62 \\
$1997 / 1 / 3$ & 8.49 & 83.18 & 19.41 & 101.83 & 0.77 & 1.28 & 1.79 & 1.45 \\
$1997 / 1 / 4$ & 9.38 & 79.1 & 20.02 & 101.85 & 1.36 & 1.79 & 3.33 & 2.91 \\
$1997 / 1 / 5$ & 9.3 & 74.53 & 20.4 & 101.65 & 1.57 & 0.32 & 3.08 & 3.49 \\
$1997 / 1 / 6$ & 8.99 & 79.17 & 20.63 & 101.8 & 1.25 & 1.28 & 3.33 & 2.33 \\
$1997 / 1 / 7$ & 9.28 & 76.14 & 20.65 & 101.74 & 1.01 & 1.79 & 3.08 & 2.91 \\
$1997 / 1 / 8$ & 6.58 & 91.87 & 19.06 & 101.67 & 1.24 & 1.02 & 1.02 & 1.71 \\
$1997 / 1 / 9$ & 8.02 & 80.15 & 20.87 & 101.25 & 3.39 & 1.78 & 1.78 & 2.29 \\
$1997 / 1 / 10$ & 7.67 & 69.07 & 14.56 & 101.24 & 1.97 & 0.77 & 0.51 & 0.87 \\
$1997 / 1 / 11$ & 8.96 & 69.07 & 14.13 & 101.64 & 1.27 & 1.28 & 3.59 & 2.91 \\
$1997 / 1 / 12$ & 7.85 & 80.56 & 15.31 & 102.08 & 3.17 & 1.79 & 2.82 & 3.49 \\
$1997 / 1 / 13$ & 2.06 & 81.64 & 16.83 & 102.29 & 3.04 & 1.99 & 1.78 & 2.29 \\
$1997 / 1 / 14$ & 5.16 & 86.5 & 17.83 & 102.3 & 2.17 & 0.00 & 0.00 & 1.87 \\
$1997 / 1 / 15$ & 4.21 & 86.84 & 19.35 & 102.08 & 2.75 & 0.00 & 0.00 & 0.00 \\
$1997 / 1 / 16$ & 7.2 & 75.85 & 19.38 & 101.34 & 2.24 & 0.77 & 0.76 & 0.25 \\
$1997 / 1 / 17$ & 11.31 & 69.86 & 8.54 & 102.09 & 3.44 & 1.28 & 3.59 & 2.04 \\
$1997 / 1 / 18$ & 11.84 & 47.86 & 6.31 & 102.51 & 3.13 & 2.31 & 4.36 & 2.33 \\
$1997 / 1 / 19$ & 11.06 & 57.94 & 6.95 & 102.59 & 1.83 & 1.54 & 3.84 & 5.82 \\
$1997 / 1 / 20$ & 10.75 & 67.69 & 10.71 & 102.45 & 0.92 & 1.28 & 3.08 & 2.04 \\
$1997 / 1 / 21$ & 10.49 & 69.87 & 13.96 & 102.59 & 1.65 & 2.31 & 2.82 & 2.33 \\
$1997 / 1 / 22$ & 8.91 & 73.96 & 17.28 & 102.47 & 1.43 & 1.79 & 2.48 & 1.43 \\
$1997 / 1 / 23$ & 10.52 & 75.71 & 17.75 & 102.24 & 0.97 & 1.28 & 2.56 & 0.51 \\
$1997 / 1 / 24$ & 8.16 & 76.27 & 20.12 & 102.09 & 1.76 & 2.05 & 2.56 & 2.04 \\
$1997 / 1 / 25$ & 6.47 & 84.1 & 18.83 & 101.91 & 1.84 & 1.79 & 3.33 & 1.74 \\
$1997 / 1 / 26$ & 9.11 & 80.11 & 17.49 & 102.3 & 3.05 & 0.77 & 1.28 & 2.62 \\
$1997 / 1 / 27$ & 3.36 & 89.76 & 17.85 & 102.43 & 1.94 & 0.73 & 1.76 & 1.77
\end{tabular}




\begin{tabular}{|c|c|c|c|c|c|c|c|c|}
\hline \multirow[b]{2}{*}{ Day } & \multicolumn{5}{|c|}{ Weather Data } & \multicolumn{3}{|c|}{ Lysimeter ET } \\
\hline & $\begin{array}{r}\text { NRAD } \\
\mathrm{MJ} \mathrm{m}^{-2} \mathrm{~d}^{-1} \\
\end{array}$ & $\begin{array}{r}\text { RH } \\
\% \\
\end{array}$ & $\begin{array}{r}\text { TEMP } \\
{ }^{\circ} \mathrm{C} \\
\end{array}$ & $\begin{array}{r}\text { ATMP } \\
\text { kpa } \\
\end{array}$ & $\begin{array}{r}\mathrm{WZ} \\
\mathrm{m} \mathrm{sec}^{-1} \\
\end{array}$ & $\begin{array}{r}\text { Cattail } \\
\mathrm{mm} \\
\end{array}$ & $\begin{array}{r}\text { Sawgrass } \\
\mathrm{mm}\end{array}$ & $\begin{array}{r}\text { Open Water } \\
\mathrm{mm} \\
\end{array}$ \\
\hline $1997 / 1 / 28$ & 6.74 & 85.44 & 20.27 & 102.4 & 1.49 & 0.25 & 0.51 & 0.00 \\
\hline $1997 / 1 / 29$ & 9.55 & 82.86 & 20.92 & 102.18 & 1.78 & 0.77 & 0.76 & 2.79 \\
\hline $1997 / 1 / 30$ & 3.72 & 90.24 & 17.16 & 101.76 & 2.01 & 1.03 & 1.03 & 0.87 \\
\hline $1997 / 1 / 31$ & 4.31 & 83.72 & 12.86 & 101.451 & 0.75 & 0.26 & 1.28 & 2.04 \\
\hline $1997 / 2 / 1$ & 12.52 & 66.26 & 13.57 & 101.43 & 0.98 & 1.79 & 3.33 & 2.33 \\
\hline $1997 / 2 / 2$ & 10.46 & 67.33 & 15.76 & 101.72 & 0.82 & 2.56 & 3.08 & 2.62 \\
\hline $1997 / 2 / 3$ & 11.1 & 75.96 & 17.6 & 101.93 & 1.62 & 1.79 & 4.36 & 1.74 \\
\hline $1997 / 2 / 4$ & 9.03 & 81.33 & 19.57 & 102.1 & 1.68 & 1.79 & 2.56 & 3.49 \\
\hline $1997 / 2 / 5$ & 8.07 & 83.04 & 21.93 & 102.25 & 1.04 & 1.28 & 2.05 & 1.45 \\
\hline 1997/2/6 & 6.94 & 87.5 & 20.88 & 102.14 & 1.17 & 0.77 & 2.31 & 1.16 \\
\hline $1997 / 2 / 7$ & 9.42 & 78.83 & 22.37 & 102.13 & 1.7 & 1.52 & 3.05 & 2.79 \\
\hline $1997 / 2 / 8$ & 9.64 & 78.87 & 22.76 & 102.11 & 1.68 & 0.26 & 0.26 & 1.16 \\
\hline $1997 / 2 / 9$ & 9.52 & 81.7 & 19.53 & 102.02 & 2.41 & 1.79 & 3.59 & 3.20 \\
\hline $1997 / 2 / 10$ & 7.5 & 85.98 & 17.96 & 101.77 & 2.04 & 1.28 & 2.56 & 2.62 \\
\hline $1997 / 2 / 11$ & 12.75 & 76.12 & 13.76 & 101.73 & 2.59 & 2.31 & 3.33 & 3.78 \\
\hline $1997 / 2 / 12$ & 11.04 & 76.55 & 16.67 & 101.8 & 1.67 & 2.05 & 4.10 & 2.62 \\
\hline $1997 / 2 / 13$ & 10.07 & 78.64 & 22.3 & 102.11 & 2.18 & 2.05 & 4.36 & 3.20 \\
\hline $1997 / 2 / 14$ & 9.02 & 78.95 & 23.88 & 102.24 & 2.66 & 2.31 & 3.33 & 2.62 \\
\hline $1997 / 2 / 15$ & 5.51 & 83.29 & 21.75 & 102.21 & 3.51 & 1.27 & 1.17 & 2.03 \\
\hline $1997 / 2 / 16$ & 0.37 & 89.43 & 17.4 & 102.1 & 3.7 & 1.74 & 1.50 & 0.00 \\
\hline $1997 / 2 / 17$ & 9.84 & 71.95 & 17.95 & 102.52 & 3.86 & 1.28 & 2.56 & 1.45 \\
\hline $1997 / 2 / 18$ & 4.22 & 77.83 & 19.95 & 102.67 & 2.62 & 1.54 & 3.08 & 1.74 \\
\hline $1997 / 2 / 19$ & 9.8 & 81.16 & 22.54 & 102.66 & 2.78 & 1.79 & 3.33 & 2.62 \\
\hline $1997 / 2 / 20$ & 12.53 & 78.97 & 22.85 & 102.49 & 2.44 & 2.56 & 4.36 & 3.49 \\
\hline $1997 / 2 / 21$ & 10.69 & 74.57 & 23.59 & 102.35 & 2.67 & 2.22 & 3.58 & 3.42 \\
\hline $1997 / 2 / 22$ & 10.68 & 72.94 & 23.18 & 102.32 & 1.81 & 1.78 & 4.36 & 4.36 \\
\hline $1997 / 2 / 23$ & 12.06 & 82.68 & 20.81 & 102.61 & 3.12 & 1.78 & 4.36 & 4.94 \\
\hline $1997 / 2 / 24$ & 6.43 & 87.03 & 21.21 & 102.7 & 2.97 & 7.62 & 3.78 & 0.86 \\
\hline $1997 / 2 / 25$ & 6.91 & 87.51 & 21.73 & 102.41 & 2.04 & 0.23 & 0.74 & 0.00 \\
\hline $1997 / 2 / 26$ & 11.39 & 76.64 & 23 & 102.32 & 2.34 & 2.05 & 4.10 & 4.94 \\
\hline
\end{tabular}




\begin{tabular}{|c|c|c|c|c|c|c|c|c|}
\hline \multirow{3}{*}{ Day } & \multicolumn{5}{|c|}{ Weather Data } & \multicolumn{3}{|c|}{ Lysimeter ET } \\
\hline & NRAD & RH & TEMP & ATMP & WZ & Cattail & Sawgrass & Open Water \\
\hline & MJ m $\mathrm{m}^{-2} \mathrm{~d}^{-1}$ & $\%$ & ${ }^{\circ} \mathrm{C}$ & $\mathrm{kpa}$ & $\mathrm{m} \mathrm{sec}^{-1}$ & $\mathrm{~mm}$ & $\mathrm{~mm}$ & $\mathrm{~mm}$ \\
\hline $1997 / 2 / 27$ & 10.58 & 76.09 & 24.06 & 102.46 & 2.43 & 2.56 & 4.87 & 3.49 \\
\hline $1997 / 2 / 28$ & 10.29 & 78.68 & 23.58 & 102.63 & 2.34 & 2.31 & 4.36 & 3.49 \\
\hline $1997 / 3 / 1$ & 9.22 & 79.41 & 23.36 & 102.63 & 2.62 & 1.90 & 4.36 & 3.49 \\
\hline $1997 / 3 / 2$ & 9.56 & 75.28 & 23.93 & 102.43 & 2.32 & 2.31 & 4.10 & 3.20 \\
\hline $1997 / 3 / 3$ & 11.64 & 74.91 & 24.06 & 102.34 & 1.69 & 3.33 & 5.38 & 3.49 \\
\hline $1997 / 3 / 4$ & 12.06 & 77.66 & 23.56 & 102.53 & 1.24 & 2.56 & 3.44 & 3.49 \\
\hline $1997 / 3 / 5$ & 11.69 & 77.1 & 23.56 & 102.54 & 1.75 & 3.08 & 3.59 & 5.53 \\
\hline $1997 / 3 / 6$ & 13.64 & 71.29 & 23.12 & 102.45 & 2.01 & 3.59 & 5.89 & 5.82 \\
\hline $1997 / 3 / 7$ & 14.35 & 61.91 & 20.51 & 102.47 & 3.2 & 2.32 & 6.41 & 4.00 \\
\hline $1997 / 3 / 8$ & 13.32 & 69.26 & 21.56 & 102.59 & 2.18 & 2.56 & 5.64 & 4.36 \\
\hline $1997 / 3 / 9$ & 10.43 & 74.62 & 21.76 & 102.56 & 2.73 & 3.08 & 4.36 & 4.07 \\
\hline $1997 / 3 / 10$ & 13.07 & 72.31 & 22.4 & 102.3 & 1.38 & 2.56 & 3.15 & 3.78 \\
\hline $1997 / 3 / 11$ & 8.91 & 81.37 & 23.53 & 102.13 & 1.11 & 2.05 & 3.84 & 2.91 \\
\hline $1997 / 3 / 12$ & 11.04 & 75.59 & 23.28 & 102.02 & 2.26 & 2.29 & 3.27 & 2.03 \\
\hline $1997 / 3 / 13$ & 3.55 & 86.6 & 22.65 & 102.2 & 2.6 & 0.76 & 0.00 & 0.51 \\
\hline $1997 / 3 / 14$ & 2.66 & 91.23 & 21.14 & 101.75 & 2.53 & 0.00 & 0.00 & 0.00 \\
\hline $1997 / 3 / 15$ & 12.87 & 82.44 & 20.94 & 102.03 & 2.06 & 0.25 & 2.03 & 0.25 \\
\hline $1997 / 3 / 16$ & 14.58 & 75.72 & 20.04 & 102.42 & 2.85 & 3.08 & 5.59 & 2.29 \\
\hline $1997 / 3 / 17$ & 13.25 & 76.46 & 21 & 102.59 & 2.48 & 2.56 & 5.08 & 5.33 \\
\hline $1997 / 3 / 18$ & 12.56 & 68.83 & 21.93 & 101.68 & 2.18 & 2.29 & 2.44 & 4.06 \\
\hline $1997 / 3 / 19$ & 14.01 & 74.89 & 22.92 & 101.73 & 1.46 & 2.03 & 5.59 & 2.79 \\
\hline $1997 / 3 / 20$ & 11.95 & 75.65 & 23.06 & 101.54 & 1.24 & 2.54 & 4.83 & 4.06 \\
\hline $1997 / 3 / 21$ & 9.61 & 81.85 & 22.21 & 101.24 & 1.85 & 0.00 & 0.00 & 0.51 \\
\hline $1997 / 3 / 22$ & 13.93 & 71.17 & 21.78 & 101.22 & 2.21 & 3.30 & 6.10 & 3.05 \\
\hline $1997 / 3 / 23$ & 10.06 & 81.15 & 21.45 & 101.36 & 1.41 & 1.78 & 3.81 & 2.54 \\
\hline $1997 / 3 / 24$ & 14.37 & 75.42 & 23.27 & 101.98 & 2.31 & 3.56 & 6.35 & 5.84 \\
\hline $1997 / 3 / 25$ & 12.38 & 75.79 & 24 & 102.53 & 3.63 & 3.30 & 5.59 & 1.52 \\
\hline $1997 / 3 / 26$ & 12.33 & 77.63 & 24.43 & 102.32 & 1.37 & 4.06 & 4.32 & 1.78 \\
\hline $1997 / 3 / 27$ & 10.19 & 82.45 & 23.11 & 102.13 & 1.4 & 2.03 & 3.81 & 4.06 \\
\hline $1997 / 3 / 28$ & 15.15 & 78.35 & 24.62 & 102.2 & 1.47 & 4.06 & 3.30 & 4.32 \\
\hline
\end{tabular}




\begin{tabular}{|c|c|c|c|c|c|c|c|c|}
\hline \multirow{3}{*}{ Day } & \multicolumn{5}{|c|}{ Weather Data } & \multicolumn{3}{|c|}{ Lysimeter ET } \\
\hline & NRAD & $\mathrm{RH}$ & TEMP & ATMP & wZ & Cattail & Sawgrass & Open Water \\
\hline & $M J m^{-2} d^{-1}$ & $\%$ & ${ }^{\circ} \mathrm{C}$ & kpa & $\mathrm{m} \mathrm{sec}^{-1}$ & $\mathrm{~mm}$ & $\mathrm{~mm}$ & $\mathrm{~mm}$ \\
\hline $1997 / 3 / 29$ & 13.12 & 80.65 & 23.33 & 102.13 & 1.63 & 4.32 & 4.26 & 4.83 \\
\hline $1997 / 3 / 30$ & 14.67 & 71.03 & 24.48 & 102.07 & 1.26 & 3.30 & 6.10 & 4.06 \\
\hline $1997 / 3 / 31$ & 13.04 & 73.9 & 22.17 & 101.86 & 2.55 & 3.81 & 5.08 & 5.33 \\
\hline $1997 / 4 / 1$ & 14.52 & 52.51 & 17.73 & 101.56 & 3.29 & 3.02 & 7.62 & 2.54 \\
\hline $1997 / 4 / 2$ & 13.05 & 63.45 & 19.7 & 101.93 & 2.46 & 4.32 & 6.60 & 4.06 \\
\hline $1997 / 4 / 3$ & 11.97 & 69.4 & 19.59 & 101.84 & 2.25 & 3.81 & 2.87 & 5.33 \\
\hline $1997 / 4 / 4$ & 16.2 & 64.39 & 20.71 & 101.87 & 1.93 & 4.83 & 6.86 & 4.32 \\
\hline $1997 / 4 / 5$ & 13.65 & 72.22 & 22.06 & 101.9 & 2.45 & 4.32 & 5.59 & 5.08 \\
\hline $1997 / 4 / 6$ & 15.36 & 69.13 & 23.74 & 101.95 & 2.27 & 4.57 & 6.35 & 6.35 \\
\hline $1997 / 4 / 7$ & 11.9 & 79.31 & 23.8 & 101.98 & 1.52 & 1.78 & 3.81 & 1.52 \\
\hline $1997 / 4 / 8$ & 14.93 & 75.99 & 22.21 & 101.73 & 2.39 & 2.29 & 3.81 & 0.00 \\
\hline $1997 / 4 / 9$ & 12.54 & 75.8 & 22.77 & 101.72 & 2.59 & 3.81 & 5.08 & 5.59 \\
\hline $1997 / 4 / 10$ & 13.51 & 71.6 & 22.55 & 102 & 2.96 & 3.56 & 6.10 & 5.33 \\
\hline $1997 / 4 / 11$ & 4.46 & 74.65 & 22.55 & 101.94 & 2.76 & 2.03 & 2.03 & 3.30 \\
\hline $1997 / 4 / 12$ & 11.9 & 78.67 & 24.39 & 101.6 & 2.26 & 1.27 & 1.78 & 0.00 \\
\hline $1997 / 4 / 13$ & 10.6 & 83.62 & 24.67 & 101.54 & 1.76 & 2.03 & 3.30 & 1.02 \\
\hline $1997 / 4 / 14$ & 1.83 & 90.46 & 21.05 & 101.57 & 3.26 & 1.27 & 0.51 & 0.00 \\
\hline $1997 / 4 / 15$ & 5.57 & 90.17 & 21.07 & 101.64 & 3.43 & 0.25 & 0.00 & 0.00 \\
\hline $1997 / 4 / 16$ & 2.9 & 94.88 & 19.73 & 101.63 & 2.54 & 0.00 & 0.00 & 0.00 \\
\hline $1997 / 4 / 17$ & 14.82 & 73.38 & 21.57 & 101.2 & 1.99 & 2.03 & 2.79 & 0.25 \\
\hline $1997 / 4 / 18$ & 16.73 & 50.48 & 17.15 & 100.69 & 2.52 & 4.57 & 7.11 & 5.33 \\
\hline $1997 / 4 / 19$ & 17.38 & 58.33 & 17.34 & 101.12 & 1.46 & 4.83 & 6.86 & 5.84 \\
\hline $1997 / 4 / 20$ & 18.14 & 65.13 & 19.77 & 101.21 & 1.4 & 4.83 & 6.86 & 4.83 \\
\hline $1997 / 4 / 21$ & 14.94 & 70.15 & 21.62 & 101.18 & 1.49 & 3.81 & 5.59 & 4.57 \\
\hline $1997 / 4 / 22$ & 15.58 & 70.52 & 25.4 & 101.22 & 2.21 & 5.08 & 3.81 & 3.81 \\
\hline $1997 / 4 / 23$ & 6.18 & 85.17 & 22.3 & 100.48 & 3.45 & 0.00 & 2.54 & 0.00 \\
\hline $1997 / 4 / 24$ & 18.38 & 68 & 20.55 & 100.79 & 1.56 & 4.10 & 5.38 & 2.03 \\
\hline $1997 / 4 / 25$ & 14.67 & 74.74 & 23.26 & 101.45 & 1.55 & 4.61 & 5.89 & 4.32 \\
\hline $1997 / 4 / 26$ & 2.27 & 89.96 & 23.45 & 101.65 & 1.95 & 0.51 & 1.02 & 2.54 \\
\hline $1997 / 4 / 27$ & 12.99 & 81.51 & 27.3 & 101.56 & 3.3 & 2.05 & 3.08 & 0.00 \\
\hline
\end{tabular}




\begin{tabular}{|c|c|c|c|c|c|c|c|c|}
\hline \multirow{3}{*}{ Day } & \multicolumn{5}{|c|}{ Weather Data } & \multicolumn{3}{|c|}{ Lysimeter ET } \\
\hline & NRAD & RH & TEMP & ATMP & WZ & Cattail & Sawgrass & Open Water \\
\hline & $M J m^{-2} d^{-1}$ & $\%$ & ${ }^{\circ} \mathrm{C}$ & $\mathrm{kpa}$ & $\mathrm{m} \mathrm{sec}^{-1}$ & $\mathrm{~mm}$ & $\mathrm{~mm}$ & $\mathrm{~mm}$ \\
\hline $1997 / 4 / 28$ & 2.97 & 88.74 & 24.46 & 101.12 & 3.42 & 1.90 & 1.27 & 3.30 \\
\hline $1997 / 4 / 29$ & 15.58 & 73.55 & 23.95 & 101.25 & 1.88 & 2.56 & 3.08 & 0.00 \\
\hline $1997 / 4 / 30$ & 17.43 & 75.24 & 22.68 & 101.21 & 1.16 & 4.36 & 5.64 & 4.57 \\
\hline $1997 / 5 / 1$ & 18.97 & 72.69 & 24.33 & 101.35 & 1.44 & 5.59 & 7.69 & 5.84 \\
\hline $1997 / 5 / 2$ & 15.71 & 80.79 & 25.29 & 101.68 & 1.73 & 4.83 & 5.64 & 3.30 \\
\hline $1997 / 5 / 3$ & 15.59 & 83.87 & 26.43 & 101.85 & 2.46 & 3.30 & 4.83 & 4.32 \\
\hline $1997 / 5 / 4$ & 12.98 & 79.1 & 23.44 & 101.79 & 2.59 & 4.06 & 4.61 & 2.03 \\
\hline $1997 / 5 / 5$ & 15.56 & 65.59 & 21.67 & 101.74 & 2.97 & 5.59 & 7.94 & 4.49 \\
\hline $1997 / 5 / 6$ & 18.31 & 68.3 & 22.39 & 101.68 & 1.85 & 4.14 & 4.26 & 2.03 \\
\hline $1997 / 5 / 7$ & 17.84 & 74.54 & 23.2 & 101.81 & 1.66 & 3.30 & 7.43 & 4.83 \\
\hline $1997 / 5 / 8$ & 17.36 & 74.17 & 23.91 & 101.87 & 1.64 & 4.83 & 6.41 & 4.57 \\
\hline $1997 / 5 / 9$ & 17.31 & 73.32 & 25.28 & 101.85 & 1.12 & 4.32 & 6.15 & 4.83 \\
\hline $1997 / 5 / 10$ & 17.01 & 78.68 & 24.23 & 101.62 & 1.95 & 5.08 & 3.59 & 6.35 \\
\hline $1997 / 5 / 11$ & 10.18 & 79.12 & 24.29 & 101.66 & 2.87 & 4.06 & 5.13 & 6.20 \\
\hline $1997 / 5 / 12$ & 2.48 & 94.96 & 23.21 & 101.12 & 1.88 & 0.00 & 0.00 & 0.00 \\
\hline $1997 / 5 / 13$ & 14.16 & 81.2 & 25.15 & 101.23 & 1.51 & 1.78 & 2.29 & 0.51 \\
\hline $1997 / 5 / 14$ & 18.23 & 73.16 & 24.25 & 101.52 & 1.36 & 4.32 & 6.92 & 3.05 \\
\hline $1997 / 5 / 15$ & 17.95 & 73.45 & 25.56 & 101.68 & 1.04 & 5.33 & 6.92 & 5.33 \\
\hline $1997 / 5 / 16$ & 4.68 & 84.7 & 23.52 & 101.63 & 1.17 & 1.52 & 2.05 & 2.54 \\
\hline $1997 / 5 / 17$ & 8.98 & 83.36 & 24.87 & 101.77 & 0.97 & 2.79 & 3.59 & 1.78 \\
\hline $1997 / 5 / 18$ & 9.39 & 87.51 & 25.18 & 101.84 & 1.61 & 2.54 & 1.27 & 2.03 \\
\hline $1997 / 5 / 19$ & 10.84 & 89.56 & 26.16 & 101.85 & 1.52 & 2.54 & 3.81 & 2.54 \\
\hline $1997 / 5 / 20$ & 14.85 & 87.24 & 27.25 & 101.85 & 1.68 & 2.54 & 2.02 & 4.83 \\
\hline $1997 / 5 / 21$ & 20.06 & 77.41 & 28.33 & 101.87 & 1.64 & 4.32 & 6.15 & 4.06 \\
\hline $1997 / 5 / 22$ & 17.62 & 85.57 & 27.46 & 101.85 & 2.39 & 2.54 & 6.09 & 3.30 \\
\hline $1997 / 5 / 23$ & 12.79 & 85.27 & 26.22 & 102.01 & 2.61 & 3.05 & 4.32 & 1.02 \\
\hline $1997 / 5 / 24$ & 15.63 & 76.1 & 26.16 & 102.03 & 2.65 & 3.81 & 5.64 & 1.02 \\
\hline $1997 / 5 / 25$ & 15.96 & 79.58 & 26.1 & 101.82 & 2.16 & 4.32 & 6.41 & 4.83 \\
\hline $1997 / 5 / 26$ & 15.43 & 78.87 & 27.06 & 101.67 & 1.85 & 4.83 & 4.65 & 4.32 \\
\hline $1997 / 5 / 27$ & 19.83 & 79.72 & 26.78 & 101.7 & 1.68 & 4.06 & 4.32 & 1.27 \\
\hline
\end{tabular}




\begin{tabular}{|c|c|c|c|c|c|c|c|c|}
\hline \multirow{3}{*}{ Day } & \multicolumn{5}{|c|}{ Weather Data } & \multicolumn{3}{|c|}{ Lysimeter ET } \\
\hline & NRAD & RH & TEMP & ATMP & wz & Cattail & Sawgrass & Open Water \\
\hline & $M J m^{-2} d^{-1}$ & $\%$ & ${ }^{\circ} \mathrm{C}$ & kpa & $\mathrm{m} \mathrm{sec}^{-1}$ & $\mathrm{~mm}$ & $\mathrm{~mm}$ & $\mathrm{~mm}$ \\
\hline $1997 / 5 / 28$ & 14.65 & 86.6 & 24.97 & 101.74 & 2.66 & 2.79 & 2.82 & 0.25 \\
\hline $1997 / 5 / 29$ & 13.63 & 79.45 & 25.42 & 101.76 & 3.11 & 3.05 & 5.59 & 2.54 \\
\hline $1997 / 5 / 30$ & 16.58 & 82.14 & 25.9 & 101.71 & 2.35 & 4.87 & 5.59 & 2.03 \\
\hline $1997 / 5 / 31$ & 14.32 & 84.23 & 26.18 & 101.4 & 1.29 & 4.83 & 4.85 & 2.03 \\
\hline $1997 / 6 / 1$ & 9.02 & 90.67 & 24.41 & 101.08 & 2.1 & 1.78 & 1.27 & 0.00 \\
\hline $1997 / 6 / 2$ & 17.51 & 86.23 & 25.86 & 100.89 & 1.53 & 2.54 & 2.80 & 2.03 \\
\hline $1997 / 6 / 3$ & 13.86 & 76.3 & 25.92 & 100.86 & 1.38 & 3.84 & 5.13 & 0.51 \\
\hline $1997 / 6 / 4$ & 16.98 & 73.93 & 26.16 & 100.7 & 1.59 & 5.64 & 7.43 & 5.59 \\
\hline $1997 / 6 / 5$ & 14.86 & 80.23 & 26.8 & 100.63 & 1.81 & 4.36 & 5.08 & 4.32 \\
\hline $1997 / 6 / 6$ & 17.86 & 80.85 & 25.98 & 100.53 & 2.2 & 3.05 & 6.41 & 5.84 \\
\hline $1997 / 6 / 7$ & 16.15 & 80.59 & 24.62 & 101.05 & 2.09 & 4.36 & 6.66 & 5.84 \\
\hline $1997 / 6 / 8$ & 16.69 & 83.12 & 25.43 & 101.34 & 2.69 & 4.36 & 6.92 & 5.08 \\
\hline $1997 / 6 / 9$ & 4.75 & 92.2 & 25.39 & 101.39 & 2.5 & 0.25 & 0.25 & 0.00 \\
\hline $1997 / 6 / 10$ & 11.77 & 91.85 & 25.89 & 101.32 & 2.82 & 0.76 & 0.51 & 0.51 \\
\hline $1997 / 6 / 11$ & 13.89 & 87.12 & 27.16 & 101.34 & 2.57 & 1.27 & 5.12 & 3.81 \\
\hline $1997 / 6 / 12$ & 13.59 & 87.32 & 26.55 & 101.21 & 1.9 & 1.52 & 2.03 & 1.52 \\
\hline $1997 / 6 / 13$ & 12.23 & 87.94 & 26.51 & 101.28 & 1.93 & 1.02 & 2.54 & 1.52 \\
\hline $1997 / 6 / 14$ & 10.77 & 89.11 & 25.82 & 101.48 & 2.27 & 3.05 & 3.81 & 1.02 \\
\hline $1997 / 6 / 15$ & 19.24 & 80.5 & 28.17 & 101.27 & 2.13 & 3.84 & 4.61 & 0.00 \\
\hline $1997 / 6 / 16$ & 17.68 & 80.75 & 28.46 & 101.22 & 1.49 & 3.59 & 7.43 & 4.32 \\
\hline $1997 / 6 / 17$ & 11.88 & 88.99 & 26.28 & 101.47 & 1.39 & 2.54 & 3.05 & 2.54 \\
\hline $1997 / 6 / 18$ & 16.9 & 84.66 & 28.04 & 101.82 & 1.82 & 2.81 & 4.09 & 0.76 \\
\hline $1997 / 6 / 19$ & 17.7 & 79.12 & 27.79 & 101.96 & 1.56 & 3.05 & 6.35 & 1.52 \\
\hline $1997 / 6 / 20$ & 16.73 & 79.58 & 26.99 & 101.86 & 1.4 & 3.84 & 4.61 & 0.00 \\
\hline $1997 / 6 / 21$ & 19.47 & 78.34 & 27.85 & 101.79 & 1.26 & 5.13 & 7.94 & 5.84 \\
\hline $1997 / 6 / 22$ & 14.85 & 83.13 & 27.68 & 101.84 & 1.05 & 3.08 & 3.80 & 4.06 \\
\hline $1997 / 6 / 23$ & 9.38 & 89.07 & 25.83 & 101.82 & 0.93 & 1.27 & 2.76 & 1.77 \\
\hline $1997 / 6 / 24$ & 15.76 & 84.97 & 27.89 & 101.86 & 1.94 & 3.08 & 3.59 & 1.27 \\
\hline $1997 / 6 / 25$ & 19.68 & 77.92 & 29.02 & 101.94 & 2.23 & 3.81 & 5.59 & 3.30 \\
\hline $1997 / 6 / 26$ & 8.98 & 87.41 & 27.21 & 101.95 & 1.31 & 1.02 & 3.56 & 1.78 \\
\hline
\end{tabular}




\begin{tabular}{|c|c|c|c|c|c|c|c|c|}
\hline \multirow{3}{*}{ Day } & \multicolumn{5}{|c|}{ Weather Data } & \multicolumn{3}{|c|}{ Lysimeter ET } \\
\hline & NRAD & RH & TEMP & ATMP & wZ & Cattail & Sawgrass & Open Water \\
\hline & $\mathrm{MJ} \mathrm{m}^{-2} \mathrm{~d}^{-1}$ & $\%$ & ${ }^{\circ} \mathrm{C}$ & kpa & $\mathrm{m} \mathrm{sec}^{-1}$ & $\mathrm{~mm}$ & $\mathrm{~mm}$ & $\mathrm{~mm}$ \\
\hline $1997 / 6 / 27$ & 16.67 & 78.51 & 27.91 & 101.86 & 1.22 & 2.05 & 5.33 & 4.06 \\
\hline $1997 / 6 / 28$ & 18.98 & 73.66 & 28.3 & 101.74 & 1.62 & 5.38 & 5.69 & 5.59 \\
\hline $1997 / 6 / 29$ & 19.51 & 73.66 & 28.89 & 101.66 & 1.34 & 5.38 & 8.13 & 5.71 \\
\hline $1997 / 6 / 30$ & 16.36 & 79.39 & 28 & 101.73 & 1.37 & 4.36 & 7.87 & 4.83 \\
\hline $1997 / 7 / 1$ & 16.26 & 80 & 27.88 & 101.52 & 1.53 & 4.87 & 6.10 & 3.81 \\
\hline $1997 / 7 / 2$ & 11.44 & 85.5 & 27.22 & 101.1 & 1.41 & 1.27 & 2.03 & 1.52 \\
\hline $1997 / 7 / 3$ & 18.43 & 74.6 & 29.93 & 101.04 & 1.43 & 3.85 & 6.10 & 4.06 \\
\hline $1997 / 7 / 4$ & 16.47 & 79.65 & 28.6 & 101.22 & 1.43 & 4.87 & 7.37 & 5.59 \\
\hline $1997 / 7 / 5$ & 11.23 & 85.32 & 25.68 & 101.52 & 1.43 & 2.54 & 1.78 & 2.54 \\
\hline $1997 / 7 / 6$ & 15.96 & 83.72 & 26.56 & 101.84 & 1.42 & 2.54 & 4.32 & 1.52 \\
\hline $1997 / 7 / 7$ & 16.9 & 80.54 & 29.15 & 102.19 & 1.42 & 2.56 & 4.32 & 4.57 \\
\hline $1997 / 7 / 8$ & 14.95 & 82.08 & 28.77 & 102.12 & 1.29 & 2.54 & 5.59 & 1.78 \\
\hline $1997 / 7 / 9$ & 13.88 & 85.4 & 26.68 & 101.78 & 1.07 & 1.78 & 5.59 & 2.54 \\
\hline $1997 / 7 / 10$ & 20.32 & 78.74 & 27.25 & 101.77 & 1.33 & 3.07 & 6.10 & 5.59 \\
\hline $1997 / 7 / 11$ & 14.29 & 86.4 & 25.79 & 101.78 & 1.45 & 2.54 & 5.84 & 2.54 \\
\hline $1997 / 7 / 12$ & 16.87 & 84.28 & 26.8 & 101.79 & 1.06 & 1.27 & 3.05 & 1.27 \\
\hline $1997 / 7 / 13$ & 17.46 & 82.24 & 27.61 & 101.56 & 1.42 & 3.85 & 7.37 & 5.08 \\
\hline $1997 / 7 / 14$ & 10.68 & 87.01 & 26.57 & 101.57 & 0.76 & & & \\
\hline $1997 / 7 / 15$ & 13.95 & 83.67 & 27.05 & 101.76 & 1.1 & & & \\
\hline $1997 / 7 / 16$ & 16.69 & 81.32 & 27.78 & 101.83 & 1.24 & & & \\
\hline $1997 / 7 / 17$ & 16.94 & 78.02 & 28.77 & 101.79 & 1.1 & & & \\
\hline $1997 / 7 / 18$ & 14.24 & 84.96 & 27.26 & 101.62 & 1.21 & & & \\
\hline $1997 / 7 / 19$ & 15.17 & 85.07 & 26.43 & 101.63 & 1 & & & \\
\hline $1997 / 7 / 20$ & 17.5 & 82.74 & 27.27 & 101.81 & 1 & & & \\
\hline $1997 / 7 / 21$ & 18.74 & 80.21 & 28.34 & 101.95 & 1.6 & & & \\
\hline $1997 / 7 / 22$ & 8.39 & 89.06 & 27.18 & 101.78 & 1.25 & & & \\
\hline $1997 / 7 / 23$ & 16.13 & 83.62 & 28.73 & 101.76 & 1.72 & & & \\
\hline $1997 / 7 / 24$ & 15.37 & 82.81 & 28.43 & 101.86 & 1.59 & & & \\
\hline $1997 \cap / 25$ & 14.35 & 83.01 & 28.1 & 101.84 & 1.14 & & & \\
\hline $1997 / 7 / 26$ & 18.13 & 80.11 & 27.91 & 101.82 & 1.39 & & & \\
\hline
\end{tabular}




\begin{tabular}{|c|c|c|c|c|c|c|c|c|}
\hline \multirow{3}{*}{ Day } & \multicolumn{5}{|c|}{ Weather Data } & \multicolumn{3}{|c|}{ Lysimeter ET } \\
\hline & NRAD & $\mathrm{RH}$ & TEMP & ATMP & WZ & Cattail & Sawgrass & Open Water \\
\hline & $\mathrm{MJ} \mathrm{m} \mathrm{m}^{-2} \mathrm{~d}^{-1}$ & $\%$ & ${ }^{\circ} \mathrm{C}$ & kpa & $m \sec ^{-1}$ & $\mathrm{~mm}$ & $\mathrm{~mm}$ & $\mathrm{~mm}$ \\
\hline $1997 / 7 / 27$ & 16.74 & 76.8 & 28.46 & 101.84 & 1.44 & & & \\
\hline $1997 / 7 / 28$ & 12.42 & 83.14 & 27.55 & 101.85 & 1.16 & & & \\
\hline $1997 / 7 / 29$ & 13.63 & 80.54 & 28.19 & 101.87 & 1.41 & & & \\
\hline $1997 / 7 / 30$ & 20.19 & 74.55 & 29.62 & 101.92 & 1.39 & & & \\
\hline $1997 \cap / 31$ & 18.7 & 79.83 & 28.74 & 101.95 & 1.47 & & & \\
\hline $1997 / 8 / 1$ & 11.1 & 88.11 & 26.45 & 101.84 & 1.23 & & & \\
\hline $1997 / 8 / 2$ & 10.66 & 88.04 & 26.95 & 101.82 & 1.33 & & & \\
\hline $1997 / 8 / 3$ & 13.48 & 85.68 & 27.16 & 101.84 & 1.18 & & & \\
\hline $1997 / 8 / 4$ & 14.9 & 83.93 & 27.82 & 101.82 & 1.32 & & & \\
\hline $1997 / 8 / 5$ & 12.35 & 85.43 & 27.84 & 101.76 & 1.92 & & & \\
\hline $1997 / 8 / 6$ & 9.29 & 90.33 & 27.01 & 101.8 & 1.22 & & & \\
\hline $1997 / 8 / 7$ & 9.41 & 91.36 & 26.13 & 101.8 & 1.08 & & & \\
\hline $1997 / 8 / 8$ & 16.8 & 83.81 & 28.05 & 101.89 & 0.87 & & & \\
\hline $1997 / 8 / 9$ & 13.8 & 85.33 & 27.93 & 101.89 & 1.29 & & & \\
\hline $1997 / 8 / 10$ & 9.75 & 89.42 & 26.81 & 101.92 & 1.29 & & & \\
\hline $1997 / 8 / 11$ & 12.42 & 84.44 & 28.57 & 101.98 & 1.14 & & & \\
\hline $1997 / 8 / 12$ & 11.72 & 86.12 & 28.88 & 101.97 & 1.13 & & & \\
\hline $1997 / 8 / 13$ & 18.94 & 77.33 & 30.37 & 101.83 & 0.93 & & & \\
\hline $1997 / 8 / 14$ & 15.07 & 81.35 & 29.35 & 101.69 & 1.07 & & & \\
\hline $1997 / 8 / 15$ & 11.9 & 86.67 & 28.33 & 101.66 & 0.88 & & & \\
\hline $1997 / 8 / 16$ & 10.57 & 86.36 & 27.71 & 101.71 & 1.11 & & & \\
\hline $1997 / 8 / 17$ & 9.94 & 86.72 & 28.57 & 101.74 & 1.12 & & & \\
\hline $1997 / 8 / 18$ & 17.23 & 79.38 & 30.39 & 101.73 & 1.2 & & & \\
\hline $1997 / 8 / 19$ & 12.08 & 85.97 & 29.01 & 101.64 & 1.16 & & & \\
\hline $1997 / 8 / 20$ & 15.44 & 82.33 & 29.36 & 101.61 & 1.16 & & & \\
\hline $1997 / 8 / 21$ & 11.24 & 85 & 28.88 & 101.54 & 1.26 & & & \\
\hline $1997 / 8 / 22$ & 14.76 & 82.66 & 29.16 & 101.53 & 2.07 & & & \\
\hline $1997 / 8 / 23$ & 13.77 & 84.47 & 28.47 & 101.53 & 1.53 & & & \\
\hline $1997 / 8 / 24$ & 15.44 & 80.16 & 29.22 & 101.55 & 1.25 & & & \\
\hline $1997 / 8 / 25$ & 11.8 & 84.22 & 28.23 & 101.53 & 1.26 & & & \\
\hline
\end{tabular}




\begin{tabular}{|c|c|c|c|c|c|c|c|c|}
\hline \multirow{3}{*}{ Day } & \multicolumn{5}{|c|}{ Weather Data } & \multicolumn{3}{|c|}{ Lysimeter ET } \\
\hline & NRAD & RH & TEMP & ATMP & wz & Cattail & Sawgrass & Open Water \\
\hline & $\mathrm{MJ} \mathrm{m} \mathrm{m}^{-2} \mathrm{~d}^{-1}$ & $\%$ & ${ }^{\circ} \mathrm{C}$ & $\mathrm{kpa}$ & $\mathrm{m} \mathrm{sec}^{-1}$ & $\mathrm{~mm}$ & $\mathrm{~mm}$ & $\mathrm{~mm}$ \\
\hline $1997 / 8 / 26$ & 15.55 & 82.41 & 28.15 & 101.51 & 2.01 & & & \\
\hline $1997 / 8 / 27$ & 17.35 & 77.47 & 27.89 & 101.37 & 1.93 & & & \\
\hline $1997 / 8 / 28$ & 17.12 & 70.12 & 28.09 & 101.53 & 1.18 & & & \\
\hline $1997 / 8 / 29$ & 16.06 & 68.35 & 29 & 101.59 & 1.05 & & & \\
\hline $1997 / 8 / 30$ & 14.21 & 73.78 & 29.51 & 101.57 & 1.13 & & & \\
\hline $1997 / 8 / 31$ & 13.72 & 77.96 & 28.75 & 101.57 & 2.02 & & & \\
\hline $1997 / 9 / 1$ & 10.63 & 90 & 27.57 & 101.42 & 2.02 & & & \\
\hline $1997 / 9 / 2$ & 14.51 & 83.74 & 28.82 & 101.57 & 1.43 & & & \\
\hline $1997 / 9 / 3$ & 11.15 & 86.16 & 29 & 101.39 & 1.16 & & & \\
\hline $1997 / 9 / 4$ & 7.84 & 90.93 & 28.09 & 101.17 & 1.24 & & & \\
\hline $1997 / 9 / 5$ & 11.35 & 78.2 & 27.7 & 101.52 & 3.63 & & & \\
\hline $1997 / 9 / 6$ & 10.66 & 76.61 & 27.99 & 101.72 & 2.72 & & & \\
\hline $1997 / 9 / 7$ & 8.97 & 78.85 & 27.34 & 101.59 & 2.04 & & & \\
\hline $1997 / 9 / 8$ & 14.29 & 76.73 & 27.68 & 101.35 & 2.05 & & & \\
\hline 1997/9/9 & 12.12 & 82.62 & 28.16 & 101.15 & 1.39 & & & \\
\hline $1997 / 9 / 10$ & 13.85 & 75.43 & 28.9 & 101.14 & 1.29 & & & \\
\hline $1997 / 9 / 11$ & 11.09 & 84.37 & 28.19 & 101.32 & 1.26 & & & \\
\hline $1997 / 9 / 12$ & 10 & 88.88 & 27.61 & 101.56 & 1.28 & & & \\
\hline $1997 / 9 / 13$ & 13.16 & 84.25 & 29.03 & 101.71 & 1.65 & & & \\
\hline $1997 / 9 / 14$ & 7.38 & 88.79 & 28.74 & 101.74 & 1.52 & & & \\
\hline $1997 / 9 / 15$ & 11.88 & 83.82 & 29.4 & 101.6 & 1.36 & & & \\
\hline $1997 / 9 / 16$ & 14.71 & 83.63 & 29.44 & 101.44 & 1.41 & & & \\
\hline $1997 / 9 / 17$ & 13.52 & 82.49 & 29.32 & 101.39 & 1.68 & & & \\
\hline $1997 / 9 / 18$ & 13.4 & 81.24 & 29.13 & 101.52 & 1.85 & & & \\
\hline $1997 / 9 / 19$ & 14.16 & 79.46 & 29.15 & 101.64 & 1.47 & & & \\
\hline $1997 / 9 / 20$ & 14.24 & 81.6 & 28.19 & 101.6 & 1.37 & & & \\
\hline $1997 / 9 / 21$ & 13.03 & 81.31 & 28.06 & 101.63 & 1.46 & & & \\
\hline $1997 / 9 / 22$ & 14.48 & 81.87 & 28.78 & 101.74 & 2.05 & & & \\
\hline $1997 / 9 / 23$ & 11.66 & 82.12 & 29.63 & 101.66 & 1.84 & & & \\
\hline $1997 / 9 / 24$ & 9.76 & 87.09 & 28.79 & 101.5 & 1.58 & & & \\
\hline
\end{tabular}




\begin{tabular}{|c|c|c|c|c|c|c|c|c|}
\hline \multirow{3}{*}{ Day } & \multicolumn{5}{|c|}{ Weather Data } & \multicolumn{3}{|c|}{ Lysimeter ET } \\
\hline & NRAD & $\mathrm{RH}$ & TEMP & ATMP & wz & Cattail & Sawgrass & Open Water \\
\hline & $M J m^{-2} d^{-1}$ & $\%$ & ${ }^{\circ} \mathrm{C}$ & $\mathrm{kpa}$ & $\mathrm{m} \mathrm{sec}^{-1}$ & $\mathrm{~mm}$ & $\mathrm{~mm}$ & $\mathrm{~mm}$ \\
\hline $1997 / 9 / 25$ & 11.13 & 85.38 & 29.62 & 101.16 & 2.2 & & & \\
\hline $1997 / 9 / 26$ & 6.73 & 91.16 & 28.4 & 101.07 & 2.52 & & & \\
\hline $1997 / 9 / 27$ & 2.56 & 93.8 & 27.65 & 100.95 & 2.31 & & & \\
\hline $1997 / 9 / 28$ & 7.07 & 88.41 & 28.36 & 101.01 & 2.32 & & & \\
\hline $1997 / 9 / 29$ & 10.65 & 79.61 & 28.74 & 101.28 & 1.38 & & & \\
\hline $1997 / 9 / 30$ & 12.49 & 79.12 & 28.4 & 101.47 & 1.06 & & & \\
\hline $1997 / 10 / 1$ & 14.75 & 74.76 & 27.98 & 101.38 & 1.35 & & & \\
\hline $1997 / 10 / 2$ & 10.57 & 78.25 & 26.91 & 101.26 & 1.09 & & & \\
\hline $1997 / 10 / 3$ & 13.87 & 79.57 & 26.78 & 101.29 & 1.57 & & & \\
\hline $1997 / 10 / 4$ & 9.58 & 82.3 & 27.29 & 101.45 & 1.86 & & & \\
\hline $1997 / 10 / 5$ & 8.65 & 94.54 & 24.52 & 101.69 & 0.91 & & & \\
\hline $1997 / 10 / 25$ & 8.65 & 87.44 & 26.49 & 101.49 & 1.44 & & & \\
\hline $1997 / 10 / 26$ & 11.03 & 82.47 & 27.61 & 101.49 & 2.17 & & & \\
\hline $1997 / 10 / 27$ & 6.04 & 91.02 & 25.66 & 101.32 & 1.82 & & & \\
\hline $1997 / 10 / 28$ & 13.73 & 81.1 & 18.32 & 101.72 & 2.51 & & & \\
\hline $1997 / 10 / 29$ & 10.37 & 82.72 & 21.22 & 101.88 & 1.73 & & & \\
\hline $1997 / 10 / 30$ & 8.71 & 81.93 & 24.21 & 101.83 & 1.47 & & & \\
\hline $1997 / 10 / 31$ & 1.94 & 92.41 & 26.61 & 101.47 & 1.2 & & & \\
\hline $1997 / 11 / 1$ & 6.31 & 80.6 & 27.07 & 101.03 & 2.55 & & & \\
\hline $1997 / 11 / 2$ & 2.58 & 84.04 & 24.21 & 101.01 & 2.78 & & & \\
\hline $1997 / 11 / 3$ & 7.19 & 69.73 & 20.16 & 101.7 & 1.1 & & & \\
\hline $1997 / 11 / 4$ & 7.65 & 75.64 & 19.28 & 102.03 & 1.58 & & & \\
\hline $1997 / 11 / 5$ & 6.43 & 80.13 & 21.34 & 102.18 & 2.69 & & & \\
\hline $1997 / 11 / 6$ & 9.84 & 83.8 & 23.18 & 101.71 & 1.9 & & & \\
\hline $1997 / 11 / 7$ & 7.48 & 78.21 & 20.62 & 101.18 & 2.18 & & & \\
\hline $1997 / 11 / 8$ & 10.03 & 75.67 & 16.07 & 101.11 & 2.12 & & & \\
\hline $1997 / 11 / 9$ & 10.8 & 78.33 & 16.33 & 101.25 & 1.63 & & & \\
\hline $1997 / 11 / 10$ & 10.11 & 80.51 & 18.17 & 101.49 & 1.01 & & & \\
\hline $1997 / 11 / 11$ & 8.93 & 80.82 & 20.93 & 101.76 & 0.94 & & & \\
\hline $1997 / 11 / 12$ & 8.45 & 79.69 & 23.32 & 101.68 & 2.01 & & & \\
\hline
\end{tabular}




\begin{tabular}{|c|c|c|c|c|c|c|c|c|}
\hline \multirow[b]{2}{*}{ Day } & \multicolumn{5}{|c|}{ Weather Data } & \multicolumn{3}{|c|}{ Lysimeter ET } \\
\hline & $\begin{array}{r}\text { NRAD } \\
\mathrm{MJ} \mathrm{m}^{-2} \mathrm{~d}^{-1} \\
\end{array}$ & $\begin{array}{r}\mathrm{RH} \\
\% \\
\end{array}$ & $\begin{array}{r}\text { TEMP } \\
{ }^{\circ} \mathrm{C} \\
\end{array}$ & $\begin{array}{r}\text { ATMP } \\
\mathrm{kpa} \\
\end{array}$ & $\begin{array}{r}\mathrm{WZ} \\
\mathrm{m} \mathrm{sec}^{-1}\end{array}$ & $\begin{array}{r}\text { Cattail } \\
\mathrm{mm} \\
\end{array}$ & $\begin{array}{r}\text { Sawgrass } \\
\mathrm{mm}\end{array}$ & $\begin{array}{r}\text { Open Water } \\
\mathrm{mm} \\
\end{array}$ \\
\hline $1997 / 11 / 13$ & 2 & 91.68 & 26.57 & 100.98 & 2.9 & & & \\
\hline $1997 / 11 / 14$ & 4.79 & 89.28 & 25.91 & 100.72 & 2.45 & & & \\
\hline $1997 / 11 / 15$ & 10.82 & 81.52 & 21.41 & 101.59 & 1.24 & & & \\
\hline $1997 / 11 / 16$ & 9.75 & 83.95 & 19.9 & 102.02 & 2.24 & & & \\
\hline $1997 / 11 / 17$ & 9.81 & 74.84 & 17.64 & 102.39 & 3.22 & & & \\
\hline $1997 / 11 / 18$ & 7.49 & 81.6 & 19.85 & 102.36 & 1.3 & & & \\
\hline $1997 / 11 / 19$ & 7.5 & 85.33 & 20.91 & 102.07 & 1.99 & & & \\
\hline $1997 / 11 / 20$ & 4.3 & 85.59 & 22.3 & 101.92 & 1.76 & & & \\
\hline $1997 / 11 / 21$ & 6.57 & 89.25 & 23.82 & 101.76 & 1.44 & & & \\
\hline $1997 / 11 / 22$ & 3.14 & 96.53 & 24.61 & 101.47 & 0.94 & & & \\
\hline $1997 / 11 / 23$ & 2.01 & 96.35 & 24.13 & 101.52 & 0.89 & & & \\
\hline $1997 / 11 / 24$ & 6.13 & 81.67 & 20.71 & 102.01 & 3.07 & & & \\
\hline $1997 / 11 / 25$ & 7.74 & 79.35 & 20.9 & 102.25 & 2.51 & & & \\
\hline $1997 / 11 / 26$ & 6.08 & 83.63 & 21.32 & 101.99 & 1.24 & & & \\
\hline $1997 / 11 / 27$ & 10.85 & 76.31 & 23.86 & 101.87 & 2.51 & & & \\
\hline $1997 / 11 / 28$ & 12.87 & 76.42 & 24.08 & 101.89 & 2.41 & & & \\
\hline $1997 / 11 / 29$ & 4.52 & 91.9 & 23.9 & 101.41 & 1.47 & & & \\
\hline $1997 / 11 / 30$ & 13.97 & 0 & 21.7 & 100.8 & 2.15 & & & \\
\hline $1997 / 12 / 1$ & 15.09 & 70.2 & 18.12 & 100.79 & 2.3 & & & \\
\hline $1997 / 12 / 2$ & 12.13 & 79.22 & 20.6 & 101.63 & 1.3 & & & \\
\hline $1997 / 12 / 3$ & 7.19 & 82.95 & 21.58 & 101.82 & 1.36 & & & \\
\hline $1997 / 12 / 4$ & 1 & 95.67 & 21.5 & 101.31 & 2.06 & & & \\
\hline $1997 / 12 / 5$ & 14.92 & 57.67 & 16.81 & 101.23 & 2.24 & & & \\
\hline $1997 / 12 / 6$ & 8.13 & 57.55 & 12.6 & 101.7 & 2.45 & & & \\
\hline $1997 / 12 / 7$ & 8.95 & 67.36 & 10.76 & 101.99 & 1.6 & & & \\
\hline $1997 / 12 / 8$ & 8.78 & 72.44 & 14.75 & 101.85 & 1.27 & & & \\
\hline $1997 / 12 / 9$ & 8.56 & 83.17 & 21.91 & 101.43 & 1.67 & & & \\
\hline $1997 / 12 / 10$ & 6.3 & 85.99 & 24.33 & 101.25 & 2.45 & & & \\
\hline $1997 / 12 / 11$ & 8.84 & 84.01 & 25.47 & 101.29 & 1.9 & & & \\
\hline $1997 / 12 / 12$ & 11.77 & 84.44 & 26.5 & 101.39 & 2.51 & & & \\
\hline
\end{tabular}




\begin{tabular}{rrrrrrrr}
\hline & \multicolumn{9}{c}{ Weather Data } & \multicolumn{3}{c}{ Lysimeter ET } \\
\cline { 2 - 8 } Day & $\begin{array}{r}\text { NRAD } \\
\mathrm{MJ} \mathrm{m}^{-2} \mathrm{~d}^{-1}\end{array}$ & $\begin{array}{r}\text { RH } \\
\%\end{array}$ & $\begin{array}{r}\text { TEMP } \\
{ }^{\circ} \mathrm{C}\end{array}$ & $\begin{array}{r}\text { ATMP } \\
\mathrm{kpa}\end{array}$ & $\begin{array}{r}\text { WZ } \\
\mathrm{m} \mathrm{sec}^{-1}\end{array}$ & $\begin{array}{r}\text { Cattail } \\
\mathrm{mm}\end{array}$ & $\begin{array}{r}\text { Sawgrass Open Water } \\
\mathrm{mm}\end{array}$ \\
\hline $1997 / 12 / 16$ & 24.38 & 65.14 & 17.45 & 101.33 & 3.38 & & \\
$1997 / 12 / 17$ & 17.64 & 55.31 & 17.27 & 101.6 & 2.25 & & \\
$1997 / 12 / 18$ & 9.64 & 67.4 & 15.06 & 101.92 & 1.23 & & \\
$1997 / 12 / 19$ & 10.6 & 74.46 & 17.02 & 102.35 & 1.34 & & \\
$1997 / 12 / 20$ & 8.22 & 80.28 & 18.22 & 102.25 & 1.55 & & \\
$1997 / 12 / 21$ & 4.25 & 88.89 & 20.4 & 101.79 & 1.02 & & \\
$1997 / 12 / 22$ & 12.2 & 73.13 & 24.97 & 101.87 & 2.32 & & \\
$1997 / 12 / 23$ & 5.23 & 89.55 & 22.81 & 101.78 & 1.27 & & \\
$1997 / 12 / 24$ & 6.79 & 84.96 & 24.56 & 101.38 & 2.5 & & \\
$1997 / 12 / 25$ & 6.54 & 84.73 & 25.27 & 101.4 & 2.13 & & \\
$1997 / 12 / 26$ & 5.9 & 91.88 & 22.95 & 101.52 & 1.48 & & \\
$1997 / 12 / 27$ & 1.96 & 94.53 & 23.95 & 100.8 & 4.14 & & \\
$1997 / 12 / 28$ & 15.75 & 69.47 & 13.99 & 101.27 & 2.42 & & \\
$1997 / 12 / 29$ & 6.36 & 67.87 & 15.11 & 100.85 & 4.67 & & \\
$1997 / 12 / 30$ & 7.32 & 74.33 & 12.05 & 101.47 & 2.1 & & \\
$1997 / 12 / 31$ & 5.44 & 70.1 & 14.43 & 102.29 & 2.1 & & \\
\hline
\end{tabular}

NRAD =net solar radiation

$\mathrm{RH}=$ =relative humidity

TEMP =temperature

ATMP =atmospheric pressure

$\mathrm{WZ} \quad=$ wind speed 
APPENDIX B

ALBUM OF FIELD WORK

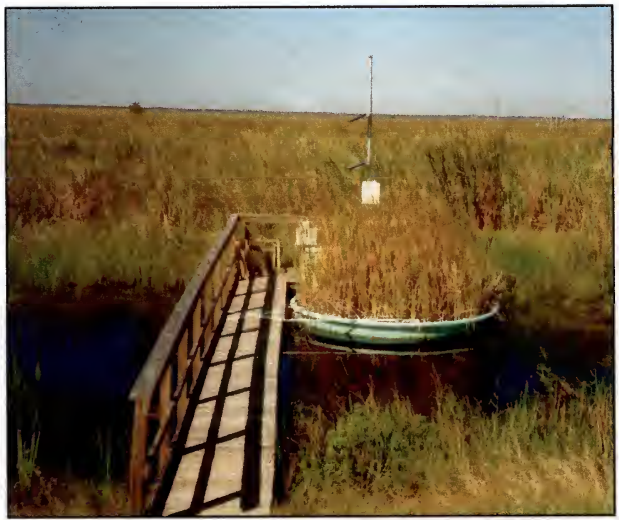

Figure B.1 Cattail lysimeter in the Fort Drum marsh. 


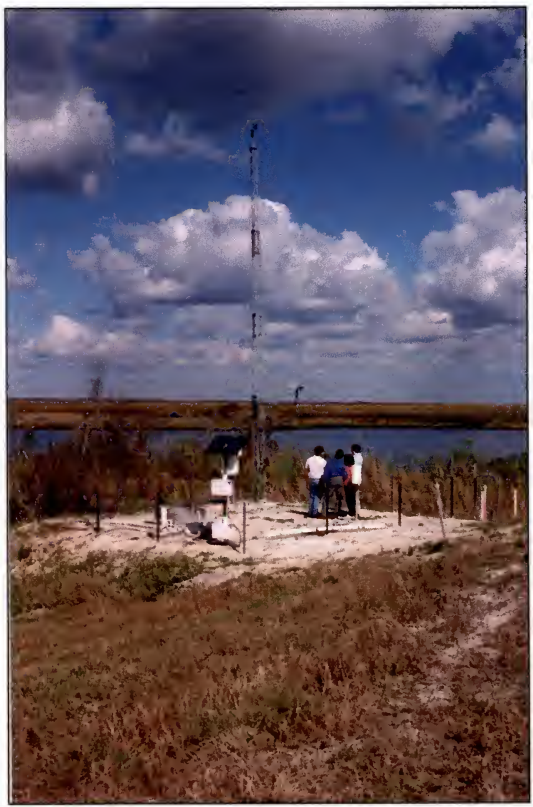

Figure B.2 Weather station in the Fort Drum marsh. 


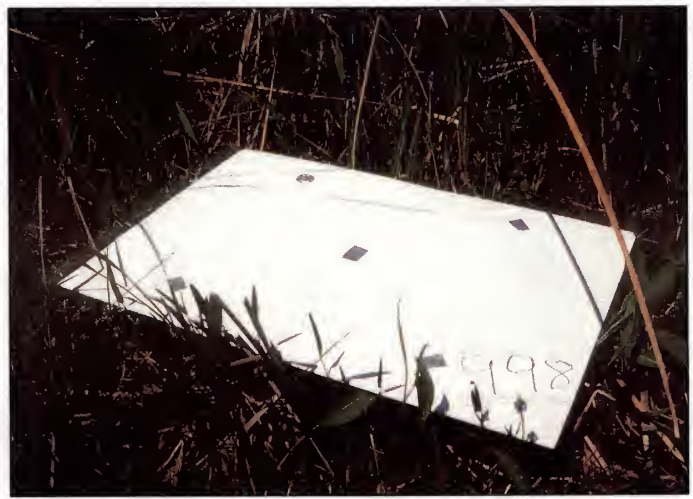

Figure B.3. Geolocation target sitting on the water and vegetation surface. 


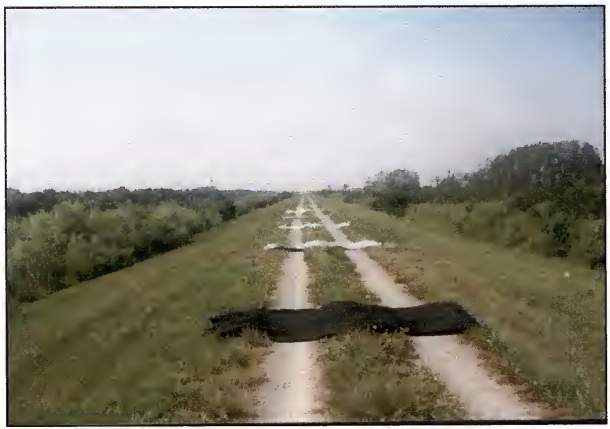

Figure B.4. Calibration panels set up along the dike. 


\section{LIST OF REFERENCES}

Abtew, W., S. Newman, K. Pietro, and T. Kosier. 1995. Canopy resistance studies of cattails. Trans. of ASAE 38:113-119.

Abtew, W. and J. Obeysekera. 1995. Lysimeter study of evapotranspiration of cattails and comparison of three estimation methods. Trans. of ASAE 38:121-129.

Allen, L. H., Jr., T. R. Sinclair, and J. M. Bennett. 1997. Evapotranspiration of vegetation of Florida: perpetuated misconceptions versus mechanistic processes. Soil Crop Sci. Soc. Florida Proc. 56:1-10.

Allen, R.G., W. O. Pruitt, and M. E. Jensen. 1991. Environmental requirements of lysimeters. In Lysimeters for Evapotranspiration and Environmental Measurements, R.G. Allen, T. A. Howell, W. O. Pruitt, I. A. Walter, M. E. Jensen (Ed.), 170-181. ASCE, New York.

Allen, R.G., J. H. Prueger and R. W. Hill. 1992. Evapotranspiraton from isolated stands of hydrophytes: Cattail and bulrush. Trans. of the ASAE 35(4):1191-1198.

Allen, R. G., R. W. Hill and V. Srikanth. 1994. Evapotranspiraton parameters for variably sized wetlands. ASAE. Paper No. 94-2132. St. Joseph, Mich.:ASAE.

Anderson, M. G. and S. B. Idso. 1987. Surface geometry and stomatal conductance effects on evaporation from aquatic macrophytes. Water Res. Res. 23:1037-1043.

Bernaowicz, S., and S. Leszcynski, and S. Tyczynska. 1976. The influence of transpiration by emergent plants on the water balance in lakes. Aquat. Bot. 2:275288.

Blaney, H. F., and W. D. Criddle. 1950. Determining water requirements in irrigated areas from climatological and irrigation data. USDA Soil Conserv. Serv. SCSTP-96. 44 pp.

Bruegge, C. J., A. E. Stiegman, D. R. Coulter, R. R. Hale, D. J. Diner, and A. W. Springsteen. 1995. Reflectance stability analysis of Spectralon diffuse calibration panels. SPIE Proceedings, International Society for Optical Engineering, 1493:132-142. 
Brunt, D. 1952. Physical and Dynamical Meteorology, $2^{\text {nd }}$ ed. University Press, Cambridge. 428pp.

Brutsaert, W. 1986. Catchment-scale evaporation and atmospheric boundary layer. Water Resources Research, 22(9):39-46.

Carter, G. A. 1998. Reflectance waveband and indices for remote estimation of photosynthesis and stomatal conductance in pine canopies. Remote Sens. Environ. 63:61-72.

Caselles, V., M. M. Aerigao, E. Hurtado, C. Coll, and A. Brasa. 1998. Mapping actual evapotranspiration by combining Landsat TM and NOAA-AVHRR images: application to the Barrax area, Albacete, Spain. Remote Sens. Environ. 63:1-10.

Carlson, T. N. and D. A. Ripley. 1997. On the relation between NDVI, fractional vegetation cover, and leaf area index. Remote Sens. Environ. 62:241-252.

Choudhury. B. J. 1997. Global pattern of potential evaporation calculated from the Penman-Monteith equation using satellite and assimilated data. Remote Sens. Environ. 61:64-81.

Curran, P. J. 1983. Estimation green LAI from multispectral aerial photography. Photo Eng. and Remote Sens., 49(12): 1709-1720.

de Boer, T. A. 1993. Botanical characteristics of vegetation and their influence on remote sensing. In Land Observation by Remote Sensing Theory and Applications, H. J. Buiten and J. G. P. W. Clevers (Ed.), 89-106. Gordon and Breach Science, Pennsylvania, U.S.

Dolan, T. J., A. J. Hermann, S. E. Bayley, and J. Zoltek, Jr. 1984. Evapotranspiration of a Florida, U.S.A., freshwater wetland. Journal of Hydrology, 74: 355-371.

Doorenbos, J., and W. O. Pruitt. 1977. Guidelines for Predicting Crop Water Requirements. FAO Irrig. And Drain. Paper No. $24,2^{\text {nd }}$ ed., FAO Rome, Italy, $156 \mathrm{pp}$.

Doren, R. F., K. Rutchey, and R. Welch. 1999. The Everglades: a perspective on the requirements and applications for vegetation map and database products. Photo. Eng. and Remote Sens., 65 (2): 155-161.

Engman, E. T. and Gurney. R. J. 1991. Remote Sensing in Hydrology. Chapman and Hall, New York.

ERDAS. 1995. ERDAS Field Guide, $3^{\text {rd }}$ ed. Atlanta, Georgia, pp

Fernald, E. A., and D. J. Patton. 1984. Water Resources Atlas of Florida. 
Gitelson, A. A., Y. J. Kaufman, and M. N. Merzlyak. 1996. Use of a green channel in remote sensing of global vegetation from EOS-MODIS. Remote Sens. Environ. 58: $289-298$.

Harrison, L. P. 1963. Fundamental concepts and definitions relating to humidity. In Humidity and Moisture, Vol. 3, A. Wexler (ed.), Reinhold Publishing Co., N.Y.

Heimburg, K. 1982. Evapotranspiration: An automatic measurement system and a remote-sensing method for regional estimates. Doctoral dissertation. Univ. of Florida.

Heimburg, K. 1984. Hydrology of north-central Florida cypress domes. In Cypress Swamps, K. C. Ewel and H. T. Odum (ed.), 72-82. University Presses of Florida, Florida.

Howell, T. A., A. D. Schneider, and M. E. Jensen. 1991. History of lysimeter design and use for evapotranspiration measurements. In Lysimeters for Evapotranspiration and Environmental Measurements, R.G. Allen, T. A. Howell, W. O. Pruitt, I. A. Walter, M. E. Jensen (Ed.), 1-9. ASCE, New York.

Jensen, M.E., R.D. Burman, and R.G. Allen, eds. 1990. Evapotranspiration and Irrigation Water Requirement. ASCE Manuals and Reports on Engineering Practice No. 70. ASCE, 332 pp.

Jensen, J. R. 2000. Remote Sensing of the Environment: An Earth Resource Perspective. Prentice-Hall Inc., Upper Saddle River, New Jersey, 544 pp.

Kadlec, R. H. and R. L. Knight. 1996. Treatment Wetlands. CRS press, Boca Ration, Florida, $893 \mathrm{pp}$.

Kock, M. S. and P. S. Rawlik. 1993. Transpiration and stomatal conductance of two wetland macrophytes (Cladium jamaicense and Typha domingensis) in the subtropical Everglades. American Journal of Botany, 80 (10): 1146-1154.

Landsat Project Science Office. 2001. Landsat-7 Science Data User's Handbook. http://ltpwww.gsfc.nasa.gov/IAS/handbook/handbook_toc.html on April 11, 2001.

Lee C., H. J. Theiss, J. S. Bethel, and E. M. Mikhail. 2000. Rigorous mathematical modeling of airborne pushbroom imaging systems. Photo Eng. and Remote Sens., 66 (4): 385-392.

Lillesand, T. M., and R. W. Kiefer. 1994. Remote Sensing and Image Interpretation, $3^{\text {rd }}$ ed. John Wiley and Sons, New York, New York, 750 pp. 
Liu, Q., and A. Huete. 1995. A feedback based modification of the NDVI to minimize canopy back ground and atmospheric noise. IEEE Trans. Geosci Remote Sens. 33: 457-465.

Madden, M., D. Jones, and L. Vilchek. 1999. Photointerpretation key for the everglades vegetation classification system. Photo. Eng. and Remote Sens., 65 (2): 171-177.

Mao, L. T. and D. V. Rao. 1997. Water Budget Analysis for the Fort Drum Marsh Conservation Area. Water Years 1993 to 1996. Technical Memorandum No. 23, Department of Water Resources, St. Johns River Water Management District, Palatka, Florida.

Mao, L. T. and M. Bergman. 1999. Methods of Measurement and Estimation of Evapotranspiration of Three Wetland Environments in the Upper St. Johns River Basin. 1996-1997 Status Report. Technical Memorandum No. 30, Department of Water Resources, St. Johns River Water Management District, Palatka, Florida.

Mitsch, W. J. and J. G. Gosselink. 1993. Wetlands, $2^{\text {nd }}$ ed. Van Nostrand Reinhold, New York, $722 \mathrm{pp}$.

Monteith, J. L. and M. H. Unsworth. 1990. Principle of Environmental Physics, $2^{\text {nd }}$ ed. Arnold, London, 291 pp.

Murray, F. W. 1967. On the computation of saturation vapor pressure, J. Appl. Meteor., 6: 203-204.

Nemani, R., and S. W. Running. 1989. Testing a theoretical climate-soil-leaf area hydrological equilibrium of forests using satellite data and ecosystem simulation. Agric. For. Meteorol. 44: 245-260.

Ponzio, K. 1995. Fort Drum Marsh Conservation Area - Assessment of Desired Ecological Communities and Recommended Management Activities. Dept of Water Resources, St. Johns River Water Management District, Palatka, Florida.

Priestley, C. H. B., and R. J. Taylor. 1972. On the assessment of surface heat flux and evaporation using large scale parameters. Monthly Weather Review, 100: 81-92.

Otis, C. H. 1914. The transpiration of emerged water plants: its measurement and its relationships. Bot. Gaz. 58: 457-494.

Rao, D. V., S. A. Jenab, and D. Clapp. 1995. Rainfall Analysis for Northeast Florida: Summary of Monthly and annual Rainfall Data through 1995. Special Publication SJ97-SP22. St. Johns River Water Management District, Palatka, Florida. 
Raymond, L. H. and S. J. Owen-Joyce. 1985. Estimates of consumptive use and evapotranspiraton in Palo Verde Valley, California, 1981 and 1983. In Remote Sensing Applications for Consumptive Use, A. I. Johnson and A. Rango (Ed.). AWRA monograph series No. 6, Tucson, Arizona.

Saxton K. E. and J. L. McGuinness, 1982. Evapotranspiration. In Hydrologic Modeling of Small Watersheds, C. T. Hann, H. P. Johnson, and D. L. Brakensiek (Ed.), 229273. ASAE monograph series No.5, St. Joseph, Michigan.

Shih, S. F. 1981. Evapotranspiration as related to climate factors in South Florida. Florida Scientist 44:109-118

Smith M. 1992. Expert consultation on revision of FAO methodologies for crop water requirements. Food and Agric. Org. of the United Nation, Rome, Italy, $60 \mathrm{pp}$.

Stehman, S. V. 1999. Alternative measures for comparing thematic map accuracy. In Spatial Accuracy Assessment, K. Lowell \& A. Jaton (Ed.), 45-51. Ann Arbor Press, Celsea, Michigan.

Stephens, J. C., and E. H. Steward. 1963. A comparison of procedures for computing evaporation and evapotranspiration. Publ. No. 62, Trans. Intern. Union of Geodesy and Geophysics, Berkeley, Calif.,123-133.

Swain, P. H. and S. M. Davis. 1978. Remote sensing : the Quantitative Approach, McGraw-Hill, New York, New York, 396 pp.

Tan, C. H., 1998. Regional Scale Evaptranspiration Estimation Using Vegetation Index and Surface Temperature from NOAA Satellite AVHRR Data. Doctoral Dissertation, Univesity of Florida.

Thornthwaite, C. W., and B. Holzman, 1939. The determination of evaporation from land and water surfaces. Monthly Weather Review, 67: 4-11.

Welch, R., 1996. GPS, image processing and GIS techniques for coastal wetland mapping applications. International Archives of Photogrammetry and Remote Sensing, 31 (4): 931-933.

Wright, J. L., and M. E. Jensen, 1972. Peak water requirements of crops in Southern Idaho. J. Irrig. And Drain. Div. 96(1):193-201. 


\section{BIOGRAPHICAL SKETCH}

Chung-hsin Juan was born in Taipei, Taiwan in 1968. He attended Chien-Kuo high school in Taipei, Taiwan. He earned a Bachelor of Science degree in agricultural engineering at the National Taiwan University in 1990. Because of his excellent academic performance, he was admitted to continue his graduate study in the Agricultural Engineering Department, National Taiwan University without any regular entrance exam and earned a Master degree in 1992. Later on, he served in the military as a second lieutenant, commanding officer in one of the closest front points to China.

He began his Ph.D. studies in August 1995 with a major in agricultural engineering and a minor in remote sensing, in the Agricultural and Biological Engineering Department at the University of Florida, with a graduate certificate program of ecological engineering in the Center for Wetlands at the University of Florida. His research interests include agricultural and natural resources, water resources and hydrology, remote sensing applications, geographic information systems, wetland ecology and hydrology, ecological engineering, system ecology, and ecological economics. 
I certify that I have read this study and that in my opinion it conforms to acceptable standards of scholarly presentation and is fully adequate, in scope and quality, as a dissertation for the degree of Doctor of Philosophy.

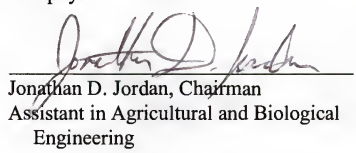

I certify that I have read this study and that in my opinion it conforms to acceptable standards of scholarly presentation and is fully adequate, in scope and quality, as a dissertation for the degree of Doctor of Philosophy.

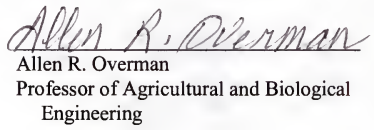

I certify that I have read this study and that in my opinion it conforms to acceptable standards of scholarly presentation and is fully adequate, in scope and quality, as a dissertation for the degree of Doctor of Philosophy.

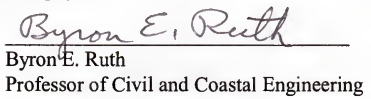

I certify that I have read this study and that in my opinion it conforms to acceptable standards of scholarly presentation and is fully adequate, in scope and quality, as a dissertation for the degree of Doctor of Philosophy.

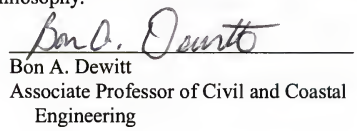


I certify that I have read this study and that in my opinion it conforms to acceptable standards of scholarly presentation and is fully adequate in scope and quality, as a dissertation for the degree of Doctor of Philosophy

Mark T. Brown

Assistant Professor of Environmental

Engineering Sciences

This dissertation was submitted to the Graduate Faculty of the College of Engineering and to the Graduate School and was accepted as partial fulfillment of the requirements for the degree of Doctor of Philosophy.

May 2001

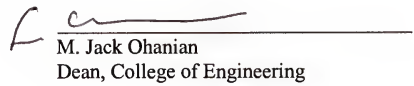

Winfred M. Phillips

Dean, Graduate School 